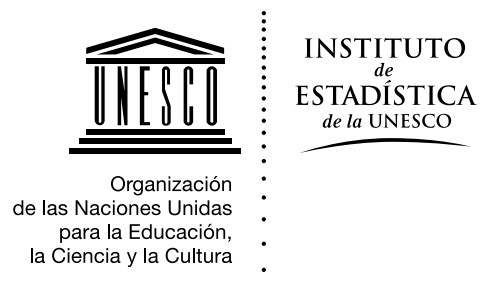

Clasificación Internacional Normalizada de la Educación

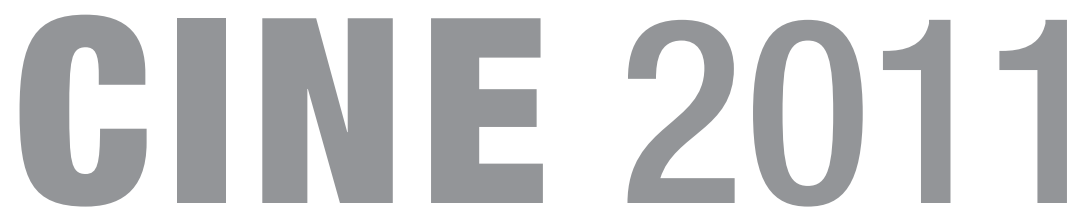





\section{Clasificación Internacional Normalizada de la Educación CINE 2011}

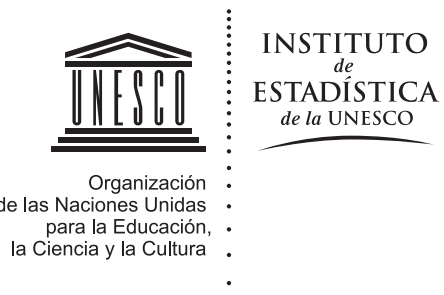




\section{UNESCO}

La Constitución de la Organización de las Naciones Unidas para la Educación, la Ciencia y la Cultura (UNESCO) fue aprobada por 20 países en la Conferencia de Londres, en noviembre de 1945, y entró en vigor el 4 de noviembre de 1946. La Organización cuenta actualmente con 195 Estados Miembros y 8 Miembros Asociados.

El principal objetivo de la UNESCO es contribuir a la paz y la seguridad en el mundo promoviendo, mediante la educación, la ciencia, la cultura y la comunicación, la colaboración entre las naciones, a fin de asegurar el respeto universal de la justicia, el estado de derecho, los derechos humanos y las libertades fundamentales que la Carta de las Naciones Unidas reconoce a todos los pueblos del mundo sin distinción de raza, sexo, idioma o religión.

Para cumplir este mandato, la UNESCO desempeña cinco funciones principales: 1) estudios prospectivos sobre la educación, la ciencia, la cultura y la comunicación para el mundo del mañana; 2) el fomento, la transferencia y el intercambio del conocimiento mediante actividades de investigación, formación y educativas; 3) acciones normativas, para la preparación y aprobación de instrumentos internos y recomendaciones estatutarias; 4) conocimientos especializados que se transmiten a los Estados Miembros mediante cooperación técnica para que elaboren sus políticas y proyectos de desarrollo; y 5) el intercambio de información especializada.

La Sede de la UNESCO se encuentra en París, Francia.

\section{Instituto de Estadística de la UNESCO}

El Instituto de Estadística de la UNESCO (UIS) es la oficina de estadística de la UNESCO y es el depositario de la ONU en materia de estadísticas mundiales en los campos de la educación, la ciencia y la tecnología la cultura y la comunicación.

EI UIS fue fundado en 1999. Se creó con el fin de mejorar el programa de estadística de la UNESCO, así como para desarrollar y suministrar estadísticas exactas, oportunas y políticamente relevantes, requeridas en un contexto actual cada vez más complejo y rápidamente cambiante.

La Sede del UIS se encuentra en Montreal, Canadá.

Publicado en 2013 por:

Instituto de Estadística de la UNESCO

C.P. 6128, Succursale Centre-Ville

Montréal, Québec H3C 3J7

Canada

Tel: (1 514) 343-6880

Correo electrónico: uis.publications@unesco.org

http://www.uis.unesco.org

ISBN 978-92-9189-129-0

Ref: UIS/2012/INS/10/REV.2

Diseño gráfico: JCNicholls / www.jcnicholls.com

OUNESCO-UIS 2013 


\section{PRÓLOGO}

Debido a las variaciones que los sistemas educativos nacionales suelen presentar en términos de estructura y contenido curricular, evaluar y comparar el desempeño de los países a lo largo del tiempo o monitorear sus avances en la consecución de metas nacionales e internacionales pueden transformarse en tareas complejas. Por consiguiente, garantizar la comparabilidad de los datos es un requisito indispensable para entender e interpretar correctamente la información, los procesos y los resultados de los sistemas educativos desde una perspectiva global. Esto se puede lograr mediante la aplicación de la Clasificación Internacional Normalizada de la Educación (CINE), el marco de referencia estándar utilizado para categorizar y reportar estadísticas educativas internacionalmente comparables.

La CINE 2011 fue aprobada por la 36ª Conferencia General de la UNESCO en noviembre de 2011. Esta clasificación, desarrollada para servir como instrumento de recopilación y presentación de estadísticas nacionales e internacionales, fue originalmente elaborada por la UNESCO en la década de los setenta y fue objeto de una primera revisión en 1997. Cada cierto tiempo, este marco de referencia es actualizado con la finalidad de recoger los nuevos avances de los sistemas educativos del mundo.

La CINE 2011 incluye en esta última versión definiciones más precisas de los niveles de educación a la vez que clarifica cómo pueden ser estas aplicadas a la CINE. Nuevas categorías se han agregado a la clasificación de niveles de educación para cubrir la expansión registrada por la educación de la primera infancia y la reestructuración de la educación terciaria. Entre algunas de las nuevas características de la versión 2011, se pueden mencionar las siguientes:

i) la introducción de certificaciones otorgadas por los programas de educación como una unidad estadística relacionada;

ii) un esquema de codificación de tres dígitos diseñado para identificar los distintos niveles de los programas de educación y el logro educativo;

iii) una sección sobre la administración y gobierno de la CINE; y

iv) un glosario ampliado.

Estas mejoras fueron introducidas por un panel de asesoramiento técnico integrado por expertos internacionales especializados en educación y estadísticas comparativas, con la colaboración de organizaciones y socios internacionales, tales como Eurostat y la Organización para la Cooperación y el Desarrollo Económicos (OCDE). El extenso proceso de revisión consistió en una serie de reuniones de expertos regionales y en una consulta formal a nivel mundial coordinada por el Instituto de Estadística de la UNESCO (UIS). Todos los Estados Miembros de la UNESCO fueron invitados a participar en estas actividades.

Los programas de recopilación de datos elaborados por el UIS y la UNESCO-OCDE-Eurostat (UOE) serán adaptados en concordancia con estos nuevos estándares. A partir de 2014, los Estados Miembros aplicarán la CINE 2011 al momento de reportar estadísticas educativas.

La CINE 2011 contribuirá a la producción de estadísticas internacionales aún más confiables y caracterizadas por un mayor grado de comparabilidad. De esta manera, la CINE 2011 refleja la evolución permanente que experimentan los sistemas educativos del mundo.

Diciembre de 2012

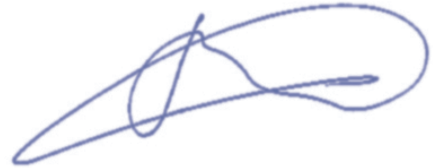

Hendrik van der Pol

Director

Instituto de Estadística de la UNESCO 



\section{ÍNDICE}

Sección 1. ¿Qué es la CINE?

Sección 2. Unidad de clasificación...................................................................................................

Sección 3. Programas que abarcan más de un nivel CINE, programas secuenciales y modulares ....11

Sección 4. Alcance de la educación en la CINE.............................................................................13

Sección 5. Variables de clasificación cruzada..............................................................................

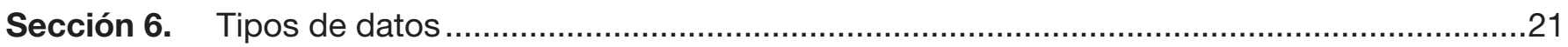

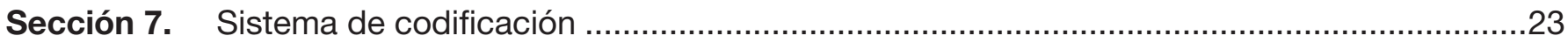

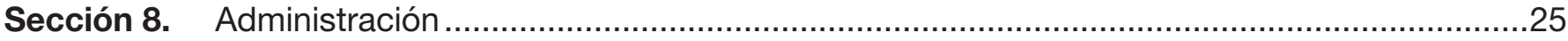

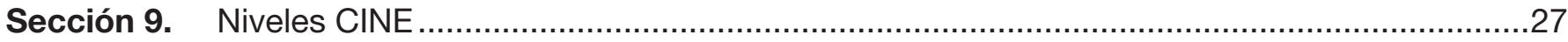

Nivel CINE 0 - Educación de la primera infancia ………..................................................28

Nivel CINE 1 - Educación primaria ................................................................................32

Nivel CINE 2 - Educación secundaria baja ………………………………………....35

Nivel CINE 3 - Educación secundaria alta ................................................................40

Nivel CINE 4 - Educación postsecundaria no terciaria ...................................................45

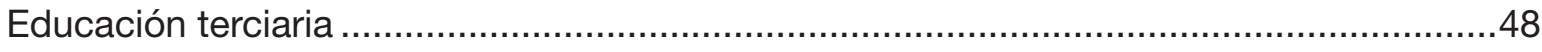

Nivel CINE 5 - Educación terciaria de ciclo corto ………………………………….....50

Nivel CINE 6 - Grado en educación terciaria o nivel equivalente.........................................53

Nivel CINE 7 - Nivel de maestría, especialización o equivalente …………….....................57

Nivel CINE 8 - Nivel de doctorado o equivalente............................................................61

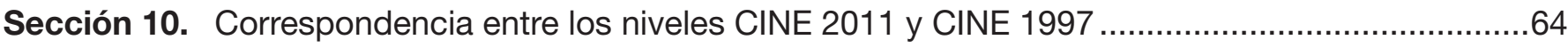

Anexo I. Trayectorias educativas potenciales en la CINE 2011 …..................................................70

Anexo II. Codificación de los programas educativos .................................................................

Anexo III. Codificación de logro educativo ………….................................................................

Anexo IV. Grupos amplios y campos de educación .....................................................................76

Anexo V. Educación no formal de acuerdo a la CINE: Otros temas de interés ..................................79

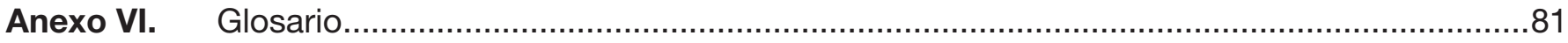




\section{SECCIÓN 1 ¿QUÉ ES LA CINE?}

1. La Clasificación Internacional Normalizada de la Educación (CINE) forma parte de la familia internacional de Clasificaciones Económicas y Sociales de las Naciones Unidas, las cuales son empleadas a nivel mundial en la elaboración de estadísticas con el objetivo de acopiar y analizar datos comparables a nivel internacional de manera consistente. Dentro de estas, la CINE representa una clasificación de referencia que permite ordenar los programas educativos y sus respectivas certificaciones por niveles de educación y campos de estudio. Su elaboración es el resultado de un acuerdo internacional adoptado formalmente por la Conferencia General de los Estados Miembros de la UNESCO.

2. La CINE se ha concebido como un marco que facilita la clasificación de actividades educativas, tal como son definidas en los programas y las certificaciones otorgadas por estos, en categorías consensuadas a nivel internacional. En consecuencia, las definiciones y conceptos básicos de la CINE se han formulado de modo que sean universalmente válidos y aplicables al espectro total de sistemas educativos.

3. La CINE clasifica los programas educativos de acuerdo a sus contenidos en función de dos variables de clasificación cruzadas: niveles de educación (véase la Sección 9) y campos de educación (véase el Anexo IV). La CINE 2011 presenta una revisión de la clasificación de los niveles de educación propuesta en la versión anterior (CINE 1997). Adicionalmente, incluye una clasificación relacionada de los niveles de logro educativo basada en certificaciones educativas reconocidas.

4. La información recabada de acuerdo a los criterios de la CINE se puede utilizar en la compilación de estadísticas sobre diversos aspectos de la educación de interés para los formuladores de políticas y demás usuarios de estadísticas internacionales de educación. Estos aspectos incluyen la matrícula y asistencia escolar, la inversión en educación en términos de recursos humanos o financieros y el nivel educativo de la población.

5. La aplicación de la CINE facilita la transformación de estadísticas nacionales detalladas sobre participantes, proveedores y patrocinadores de la educación - compiladas sobre la base de conceptos y definiciones nacionales - en categorías agregadas que pueden ser comparadas e interpretadas a nivel internacional.

6. La recopilación de datos sobre estadísticas de educación reunidas y compiladas de acuerdo a la CINE puede basarse en diferentes fuentes de datos, tales como registros administrativos, encuestas de hogares e individuos y estadísticas de agregados macroeconómicos. Las pautas sobre cómo implementar la CINE 2011 en fuentes de estadísticas serán incluidas en un manual operativo y en otros materiales de capacitación (véase la Sección 8).

7. La CINE 2011 se sustenta en tres componentes esenciales: i) definiciones y conceptos consensuados a nivel internacional; ii) los sistemas de clasificación; y iii) mapas de programas y certificaciones educativas de los países elaborados de acuerdo a los criterios de la CINE (mapas CINE).

8. Los "mapas CINE" representan una herramienta esencial que permite organizar la información relativa a los sistemas nacionales de educación, a los programas que los integran y a las certificaciones otorgados por estos últimos a fin de garantizar la comparabilidad de las estadísticas asociadas con los distintos niveles de la CINE y su posterior interpretación a nivel internacional. 
9. Los mapas CINE, al vincular los criterios de clasificación con las propiedades de los programas educativos y sus certificaciones, garantizan la transparencia del proceso que permite clasificar y codificar, en categorías comparables, a los programas nacionales y a sus respectivas certificaciones, posibilitando de esta forma la utilización de estas en estadísticas internacionales. 


\section{SECCIÓN 2 UNIDAD DE CLASIFICACIÓN}

10. Las unidades básicas de clasificación de la CINE son el programa educativo nacional (y subnacional) y las certificaciones reconocidas relacionadas.

11. En términos de la CINE, un programa educativo se define como el conjunto o secuencia coherente de actividades educativas diseñadas y organizadas para lograr un objetivo predeterminado de aprendizaje o para llevar a cabo un conjunto especifico de tareas educativas a lo largo de un periodo sostenido de tiempo. Su objetivo comprende el mejoramiento de conocimientos, destrezas y competencias dentro de un contexto personal, cívico, social o laboral. Normalmente, los objetivos de aprendizaje tienen como propósito preparar a la persona para seguir estudios avanzados o para una ocupación u oficio o tipos de ocupaciones u oficios, aunque también puede estar orientado al desarrollo personal o representar una actividad de tiempo libre. Una característica común a todos los programas educativos es que, una vez logrados los objetivos de aprendizaje, su conclusión exitosa es reconocida a través de una certificación.

A continuación se especifica el sentido en que han de entenderse los términos clave de esta formulación:

12. ACTIVIDADES EDUCATIVAS: toda actividad intencionada que implique alguna modalidad de comunicación destinada a producir aprendizaje.

13. COMUNICACIÓN: relación entre dos o más personas, o entre personas y un medio inanimado, que supone la transmisión de información (mensajes, ideas, conocimientos, estrategias, etc.). La comunicación puede ser verbal o no verbal, directa (presencial) o indirecta (a distancia), y hacer uso de una gran variedad de canales y medios de difusión.

14. APRENDIZAJE: la adquisición o modificación de conocimientos, informaciones, actitudes, valores, destrezas, competencias y la promoción de cambios en el nivel de comprensión y comportamiento por parte de una persona a través de la experiencia, la práctica, el estudio o la instrucción.

15. ORGANIZADA: prevista en un patrón o secuencia que contempla objetivos explícitos o implícitos. Lo anterior supone la existencia de un agente proveedor (una o varias personas, o un organismo) que proporciona tanto el entorno de aprendizaje como el método de instrucción a través de los cuales se organiza la comunicación. La instrucción se caracteriza por la presencia de una persona (profesor o facilitador) responsable de orientar y comunicar el proceso de adquisición de conocimientos y competencias, con el propósito de producir aprendizaje. El medio de instrucción también puede ser indirecto, por ejemplo: un programa informático, de radio o televisión; una película o cinta magnetofónica; Internet u otras tecnologías de la información.

16. SOSTENIBLE: la experiencia de aprendizaje comprende o incluye los elementos de duración y continuidad.

17. Si bien un programa educativo puede ser rigurosamente definido y normado dentro del contexto nacional, la definición de programa educativo de la CINE recoge las múltiples posibilidades existentes en los distintos países con el propósito de asegurar la comparación internacional.

18. Asimismo, dentro de un programa, las actividades educativas pueden estar estructuradas en torno a subcomponentes conocidos en los países bajo distintos nombres, tales como "cursos", "módulos", "unidades" o "asignaturas". Para los efectos de la CINE, el concepto de "curso" equivale al de "módulo", "unidad" o "asignatura". Por su parte, un programa educativo puede 
estar organizado en base a componentes no habitualmente considerados "cursos", por ejemplo, actividades lúdicas, prácticas o pasantías laborales, proyectos de investigación y preparación de disertaciones.

19. La clasificación de programas educativos es la base sobre la cual se elaboran informes estadísticos respecto de distintos aspectos de los sistemas educativos, por ejemplo, matrícula, ingresos, docentes y otro personal y recursos financieros. Las estadísticas sobre programas educativos pueden proporcionar información sobre las relaciones entre los elementos de entrada (estudiantes que ingresan), el proceso (participación) y la producción o elementos de salida (certificaciones) del sistema.

20. En el contexto de la CINE, el término "certificación" representa una confirmación oficial de la conclusión de un programa educativo o de una etapa de este. Generalmente, esta confirmación se oficializa mediante un documento. Las certificaciones se obtienen mediante: i) la conclusión exitosa de un programa educativo; ii) la conclusión exitosa de una etapa de un programa educativo (certificaciones intermedias); o iii) la validación de conocimientos, destrezas y competencias adquiridas independiente de la participación de la persona en un programa educativo. Habitualmente, un programa se considera concluido cuando el estudiante ha logrado objetivos predeterminados de aprendizaje. En el contexto de la CINE, los créditos obtenidos por la conclusión de cursos específicos (módulos o asignaturas) no se consideran certificaciones. En estos casos, un número suficiente de créditos o asignaturas equivalente, en términos de duración y/o cobertura del plan de estudios, a un programa completo representaría una certificación.

21. En la versión CINE 2011, las certificaciones otorgadas por un programa educativo se consideran como unidades de clasificación suplementarias. En este contexto, el término "certificación" es sinónimo con "credencial". Sin embargo, otros términos tales como "certificado", "grado", "título" o "diploma” también se utilizan en forma intercambiable. La clasificación de certificaciones reconocidas por las autoridades nacionales de educación es la base para la elaboración de estadísticas sobre logro educativo.

22. Dentro del esquema de la CINE, primero se clasifican los programas educativos y en un segundo término las certificaciones. Los mapas CINE representan herramientas que muestran los vínculos entre programas educativos y sus respectivas certificaciones. Normalmente, un programa educativo conduce a una sola certificación. Sin embargo, en ciertos casos varios programas pueden otorgar la misma certificación en tanto que un solo programa puede dar lugar a diferentes certificaciones.

23. Durante la última década, el reconocimiento de los conocimientos (previos) adquiridos a través de modalidades no formales o informales de aprendizaje se ha hecho más común en un gran número de países. La CINE 2011 permite clasificar las certificaciones obtenidas a través de la adquisición demostrable de destrezas, conocimientos y competencias en la medida que sean comparables a la conclusión exitosa de programas de educación formal y sean reconocidas a través de certificaciones formales.

24. La CINE no ha sido concebida con el objetivo de medir las competencias de las personas, ya que no existe una relación directa entre los programas o certificaciones y el logro educativo real. En el mejor de los casos, los programas educativos en los que una persona ha participado o finalizado representan solo una aproximación de los conocimientos, destrezas y competencias adquiridas al momento de su conclusión exitosa. 
25. Los marcos nacionales y regionales de certificación representan herramientas útiles al momento de establecer distinciones entre los conocimientos, destrezas y competencias asociados con programas y las certificaciones otorgadas por estos. En numerosos países se utilizan estos marcos para describir los niveles nacionales de destrezas y competencias de la población en relación con el logro educativo. Se recomienda a los países transparentar los vínculos entre la CINE y sus marcos nacionales o regionales de certificación en caso de que estos últimos existan. 


\section{SECCIÓN 3 PROGRAMAS QUE ABARCAN MÁS DE UN NIVEL CINE, PROGRAMAS SECUENCIALES Y MODULARES}

26. Al momento de clasificar los programas nacionales de educación por niveles CINE, es posible que los puntos de transición entre estos programas y los puntos de ingreso al mercado laboral no siempre coincidan con los puntos de transición entre los niveles CINE. Se pueden identificar tres casos: i) programas que abarcan dos o más niveles CINE; ii) dos o más programas secuenciales que sumados constituyen un nivel CINE, y iii) programas impartidos bajo la modalidad de módulos o cursos sin una secuencia claramente definida.

27. Un programa educativo con una duración que excede el criterio establecido para un nivel CINE (véanse los párrafos 70 y 71) es considerado como un programa que abarca más de un nivel CINE. Por consiguiente, a lo largo de un programa, será necesario identificar el o los puntos de transición de un nivel CINE al siguiente de acuerdo al criterio. Por ejemplo, si un programa nacional de educación primaria se prolonga por ocho años o más, los últimos grados deben ser clasificados como correspondientes al nivel CINE 2 (por ejemplo, los seis primeros grados como del nivel CINE 1 y los dos últimos grados como del nivel CINE 2).

28. En la clasificación de un programa que abarca más de un nivel CINE, se deben utilizar los puntos de transición del programa - etapas o certificaciones intermedias - con el objeto de asignar los grados pertinentes del programa a los correspondientes niveles CINE. De no existir tal punto de transición, la duración acumulada típica del nivel CINE (véase el párrafo 71) dará la pauta sobre cómo identificar las líneas divisorias entre los niveles CINE. Véase la Sección 9 para más detalles de los niveles CINE.

29. Generalmente, los programas que abarcan más de un nivel CINE no otorgan una certificación tras la conclusión del nivel CINE inferior. En estos casos, para definir la conclusión de nivel es recomendable utilizar otros criterios como, por ejemplo, el hecho de haber cursado el último grado del nivel inferior o de tener acceso a grados de un nivel CINE más avanzado.

30. Durante la elaboración de informes, los programas que abarcan más de un nivel CINE requieren una consideración especial. El número de matriculados se debe reportar por nivel, usualmente utilizando estadísticas por año y grado para hacer la correcta diferenciación entre niveles. Es probable que la estimación de recursos humanos y financieros también deba realizarse por nivel o por grupo de niveles (por ejemplo, educación terciaria). Al momento de reportar sobre los nuevos ingresos o los graduados de un nivel CINE, es indispensable considerar todos los niveles que el programa abarca en forma separada.

31. Con el objeto de cumplir con los criterios de duración establecidos para los niveles CINE (véanse los párrafos 70 y 71), podría ser necesario clasificar dos o más programas secuenciales en el mismo nivel en el caso de que su duración combinada cumpla con el criterio de duración mínima, pero la duración de cada programa no cumpla con el criterio referido. En estos casos, la progresión del primer al segundo o subsiguiente programa en el sistema nacional no se verá reflejada en el reporte de graduados del nivel CINE dado, pero las certificaciones intermedias reconocidas podrán ser reportadas en las subcategorías: i) "conclusión parcial del nivel" en los niveles CINE 2 y 3, o ii) "nivel no concluido" en otros niveles (véase el párrafo 60). Esta situación podría darse en un sistema de educación donde los niveles CINE 1 al 3 estén formados por una secuencia de cuatro programas en lugar de solo dos o tres. 
32. Durante la elaboración de informes, dos o más programas secuenciales de un mismo nivel CINE requieren una consideración especial. Los datos de matrícula deben combinarse para todos los programas de ese nivel. Asimismo, los datos sobre ingresos de estudiantes deben considerar solo a aquellas personas que ingresan a un programa de un nivel por primera vez, en tanto que los datos sobre graduados deben incluir solamente a los participantes que han finalizado el último programa de la secuencia del nivel. En términos de logro educativo, solo la conclusión del último programa de la secuencia se contabilizará como conclusión del nivel, es decir, la conclusión de programas precedentes dentro del nivel CINE se reportará en las subcategorías "conclusión parcial del nivel" o "nivel no concluido" (véase el párrafo 60).

33. Los programas modulares permiten que el estudiante organice el contenido de su educación en forma flexible mediante la combinación de diferentes cursos o módulos. Una combinación de módulos se considerará equivalente a un programa educativo si cumple con la definición de la CINE sobre programas educativos (véase el párrafo 11).

34. Todos quienes participan en los módulos que forman parte de un programa educativo se contabilizan como estudiantes matriculados en el programa, aunque solo cursen algunos de los módulos que, tomados individualmente, pueden tener una duración inferior a la del nivel correspondiente. Un programa modular se considera concluido cuando el número y los tipos de módulos que este comprende se han cursado en forma exitosa. 


\section{SECCIÓN 4 ALCANCE DE LA EDUCACIÓN EN LA CINE}

35. La CINE 2011 cubre los programas educativos formales y no formales disponibles a una persona en cualquiera etapa de su vida. Las certificaciones reconocidas por las autoridades nacionales competentes se utilizan para medir el logro educativo independientemente de cómo se hayan obtenido, es decir, a través de la conclusión de un programa educativo formal o no formal o de una actividad de aprendizaje informal. La CINE no cubre programas de aprendizaje informal, imprevisto o aleatorio ni certificaciones no reconocidas. La educación formal y no formal comprende una gama de programas y tipos de educación diseñadas en un contexto nacional, tales como la primera educación, la educación regular, programas de segunda oportunidad, programas de alfabetización, educación de adultos, formación permanente, educación abierta y a distancia, aprendizaje de oficios, educación técnica o vocacional, capacitación o educación para necesidades especiales.

36. La educación formal es la educación institucionalizada e intencionada, organizada por entidades públicas y organismos privados acreditados que, en su conjunto, constituye el sistema educativo formal del país. Por consiguiente, los programas de educación formal deben ser reconocidos como tales por las autoridades nacionales pertinentes o instancias equivalentes, por ejemplo, cualquier otra institución que colabore con las autoridades nacionales o subnacionales de educación. La educación formal comprende principalmente la educación previa al ingreso al mercado de trabajo (véase el párrafo 37). Con frecuencia, la educación vocacional, la educación para necesidades especiales y algunos programas de educación de adultos se consideran parte del sistema nacional de educación formal. Por definición, las certificaciones otorgadas por la educación formal son reconocidas y, por lo tanto, se encuentran dentro del ámbito de la CINE. La educación institucionalizada supone la existencia de una organización que proporciona actividades educativas estructuradas - por ejemplo, las basadas en una relación o interacción entre estudiantes y docentes - que son diseñadas expresamente con fines de formación y aprendizaje.

37. Usualmente, la educación formal tiene lugar en centros educativos cuya función primordial es impartir educación de tiempo completo a estudiantes dentro de un sistema concebido como una continua trayectoria de escolarización. La educación formal está relacionada a la etapa educativa previa al ingreso al mercado de trabajo y se ha descrito como la educación (formal) que normalmente recibiría, hasta antes de su primera entrada al mercado laboral, una persona que asiste a la escuela a tiempo completo.

38. La educación formal también incluye y atiende la educación de todos los grupos de edad, con contenidos programáticos y certificaciones equivalentes a los impartidos u otorgados en la educación previa al ingreso al mercado de trabajo. Por su parte, aquellos programas impartidos parcialmente en el lugar de trabajo también pueden ser considerados como parte de la educación formal si conducen a una certificación reconocida por las autoridades competentes (o las instancias equivalentes). Con frecuencia, estos programas se desarrollan en colaboración con instituciones educativas y empleadores. Un ejemplo de lo anterior es el aprendizaje de oficios.

39. La educación no formal, al igual que la educación formal (pero contrariamente al aprendizaje informal, imprevisto o aleatorio), es la educación institucionalizada, intencionada y organizada por un proveedor de educación. La característica que define la educación no formal es que representa una alternativa o complemento a la educación formal de las personas dentro del proceso de aprendizaje a lo largo de la vida. Con frecuencia se plantea como una forma de garantizar el derecho a la educación para todos. Atiende a todos los grupos de edad si bien su 
estructura no implica necesariamente una trayectoria continua. La educación no formal puede ser de corta duración y/o baja intensidad y habitualmente se imparte bajo la forma de cursos, seminarios o talleres. En general, la educación no formal conduce a certificaciones que no son reconocidas por las autoridades nacionales o subnacionales competentes como equivalentes a la educación formal. En ocasiones no otorga certificación alguna. Sin embargo, es posible obtener certificaciones formales mediante la participación exclusiva en programas específicos de educación no formal. Esta situación suele darse cuando el programa no formal perfecciona las competencias adquiridas en otro contexto.

40. Según el contexto nacional, la educación no formal puede cubrir programas que contribuyen a la alfabetización de jóvenes y adultos y a la educación de niños no escolarizados, así como programas de enseñanza de habilidades básicas para la vida, de destrezas laborales o los relacionados al desarrollo social y cultural. Asimismo, puede incluir iniciativas de capacitación en el lugar de trabajo destinadas a reforzar o adaptar certificaciones y destrezas ya existentes, capacitar para el empleo a personas no económicamente activas y, en ciertos casos, representar trayectorias alternativas a la educación formal. Por último, la educación no formal puede incluir actividades de aprendizaje con fines de desarrollo personal y, por lo tanto, no está exclusivamente vinculada con aspectos laborales.

41. Normalmente, la conclusión de un programa educativo no formal, incluyendo o no la obtención de una certificación educativa no formal, no da acceso a un nivel más avanzado si no está adecuadamente validada en el sistema formal de educación y debidamente reconocida por las autoridades nacionales o subnacionales competentes (o entidades equivalentes).

42. Para propósitos estadísticos, la CINE 2011 establece una clara distinción entre la educación formal y no formal. Al momento de clasificar los programas educativos no formales, la CINE 2011 recomienda utilizar el criterio de equivalencia de contenido y/o las certificaciones otorgadas por estos. El Anexo V ofrece más información sobre la clasificación de programas no formales. En la actualidad, las actividades de recopilación de datos internacionales en materia de educación (elaboración de mapas, censos y encuestas) se centran principalmente en la educación formal.

43. En términos de medir la participación en educación, el aprendizaje informal no se incluye en el ámbito de la CINE, si bien las certificaciones obtenidas a través de este sí se toman en cuenta al momento de determinar los niveles de logro educativo. El aprendizaje informal se ha definido como una modalidad de aprendizaje intencionada o deliberada, aunque no institucionalizada. En consecuencia, este aprendizaje es menos estructurado y organizado que aquellos correspondientes a la educación formal y no formal. Puede incluir actividades de aprendizaje realizadas en el hogar, centro de trabajo, centro comunitario o como parte del quehacer diario. Además, estas pueden ser autodirigidas o dirigidas por la familia o la comunidad. Al igual que en el caso de la educación formal y no formal, es posible establecer una distinción entre el aprendizaje informal y el aprendizaje imprevisto o aleatorio.

44. La CINE también excluye el aprendizaje imprevisto o aleatorio, es decir, las diversas formas de aprendizaje que no se encuentran organizadas o que comprenden actividades de comunicación que no han sido diseñadas con el fin de producir un aprendizaje. El aprendizaje imprevisto o aleatorio puede ocurrir como consecuencia del diario quehacer, o de eventos o comunicaciones que no han sido deliberadamente creados como actividades educativas o de aprendizaje. Entre los ejemplos de aprendizaje aleatorio se pueden mencionar las actividades que tienen lugar durante una reunión o las asociadas con una transmisión de radio o televisión que no constituye un programa educativo. 


\section{SECCIÓN 5 VARIABLES DE CLASIFICACIÓN CRUZADA}

45. Las principales variables de clasificación cruzada de la CINE son los niveles y campos de educación (en el caso de estos últimos, véase el Anexo IV). En cada nivel de la CINE, los programas y certificaciones se subdividen por dimensiones complementarias. Estas incluyen:

- la orientación de los programas;

- la conclusión del nivel CINE;

- el acceso a un nivel CINE más avanzado; y

- la posición en la estructura nacional de títulos y certificaciones.

Sin embargo, no todas las dimensiones complementarias aplican a todos los niveles. Por su parte, el nivel CINE 0 también se subdivide según el tipo de programa impartido y la edad del grupo objetivo. Las categorías y subcategorías de las dimensiones complementarias proporcionan mayores detalles para facilitar el acopio y reporte de datos internacionalmente comparables.

46. Otras características y atributos de los programas y las certificaciones, más allá de los descritos en la CINE, pueden incluir al proveedor del servicio, el entorno educativo, el contexto institucional, la modalidad de provisión de la educación, el tipo de participante o la modalidad de participación. Pese a no figurar en la CINE como dimensiones complementarias, estas características pueden cumplir una función importante en términos de distinguir la naturaleza de los programas y definir el alcance de las actividades de acopio de datos.

\section{Niveles}

47. El concepto de "nivel" de educación está representado por un set que agrupa programas educativos en relación a grados de experiencias de aprendizaje y a los conocimientos, habilidades y competencias que un programa educativo se propone impartir. Adicionalmente, un nivel CINE está asociado con el grado de complejidad y especialización del contenido de un programa, que puede ir desde básico hasta avanzado.

48. Por lo tanto, el concepto de "nivel" de educación es esencialmente una construcción basada en el supuesto de que los programas educativos se pueden agrupar en una serie ordenada de categorías. Estas representan grandes pasos de la progresión educativa en términos de la complejidad del contenido educativo, es decir, cuanto más avanzado sea el programa, más elevado será el nivel de educación.

49. La clasificación de programas educativos en niveles de progresión permite recoger la variedad de opciones disponibles en los sistemas educativos. La mayoría de estos ofrecen trayectorias alternativas entre los niveles 0/1 y 8 (véase el Gráfico 2 en el Anexo I). Dado que los sistemas educativos ofrecen múltiples ramificaciones, secuencias alternativas de programas y opciones de segunda oportunidad, las personas pueden organizar su trayectoria educativa de maneras muy diversas. Sin embargo, es improbable que la trayectoria de una persona cubra todos los niveles posibles.

50. La clasificación de los programas por nivel se debe basar en el contenido educativo. Sin embargo, los programas y planes de estudio son muy diversos, polifacéticos y complejos para permitir 
evaluar y comparar en forma directa y consistente el contenido de los programas entre los diversos sistemas educativos. Debido a la falta de mediciones directas que permitan clasificar el contenido educativo, la CINE ha incorporado criterios de aproximación que facilitan asignar un programa educativo determinado al nivel apropiado de educación. Estos criterios de aproximación pueden ser específicos a cada nivel CINE y se describen en las respectivas secciones. Al final de esta sección se resumen los criterios generales de duración y duración acumulada por nivel.

51. Dichos criterios de aproximación constan de criterios principales y subsidiarios. Los criterios principales destacan las características esenciales de los programas educativos en cada nivel CINE. Los criterios subsidiarios, por su parte, se relacionan con las características compartidas por muchos de estos programas en un nivel CINE determinado, aunque no necesariamente por todos (véase la Sección 9).

52. Al momento de clasificar un programa, es preciso tener presente que el criterio primario es la complejidad y especialización del contenido educativo y cómo este contenido se ve reflejado en los criterios de aproximación. No se debe sustituir el contenido educativo por el contexto institucional como criterio de clasificación. Por ejemplo, los programas de nivel CINE 4 podrían impartirse en instituciones o centros educativos que típicamente ofrecen programas de nivel CINE 5 o 6.

\section{Orientación}

53. En los niveles CINE 2 al 5 se hace una distinción respecto de la orientación del programa, existiendo la posibilidad de utilizarla en los niveles CINE 6 al 8. Existen dos categorías de orientación: educación general y vocacional. En los niveles de educación terciaria se utilizan los términos "académico" y "profesional" en lugar de general y vocacional, respectivamente. En la actualidad, la CINE 2011 no define con mayor precisión los términos académico y profesional para los niveles más avanzados, pero ofrece la posibilidad de distinguir entre las orientaciones académicas y profesionales sobre la base, por ejemplo, de los campos de educación. Mientras no se desarrollen definiciones de educación académica y profesional, en el nivel 5 se utilizarán las definiciones de educación general y vocacional.

54. La educación vocacional se define como una serie de programas destinados principalmente a que los participantes adquieran las destrezas, los conocimientos prácticos y la comprensión necesaria para ejercer una ocupación u oficio determinado o un tipo de ocupaciones u oficios. Dichos programas pueden tener un componente laboral (por ejemplo, aprendizaje de oficios, programas de sistemas de educación dual). La conclusión exitosa de estos programas otorga certificaciones pertinentes al mercado laboral reconocidas por la autoridad nacional competente o por dicho mercado.

55. La educación general se define como programas educativos destinados a desarrollar conocimientos, destrezas y competencias de carácter general y habilidades de lectura, escritura y utilización de números (numeracy en inglés) del participante, a menudo con el fin de prepararlo para continuar su educación, ya sea en el mismo nivel CINE o en uno más avanzado, o con el fin de sentar las bases para el aprendizaje a lo largo de la vida. Habitualmente, estos programas están basados en escuelas o en centros educativos postsecundarios no terciarios. La educación general incluye programas educativos que preparan al participante para ingresar a educación vocacional, aunque no así para desempeñar una ocupación u oficio determinado o tipos de ocupaciones $u$ oficios, ni conducen directamente a una certificación pertinente al mercado laboral. 


\section{Conclusión y acceso a niveles más avanzados de educación}

56. Los requisitos para la conclusión exitosa de un programa educativo - por ejemplo, el logro de los objetivos de aprendizaje - generalmente se señalan en la descripción del programa y suelen incluir:

- requisitos de asistencia (matrícula y asistencia regular hasta el último año del programa); y/o

- adquisición demostrable de las destrezas, competencias y conocimientos esperados.

57. La adquisición de dichas destrezas, competencias y conocimientos que forman parte de los objetivos de aprendizaje de un programa educativo normalmente se validan mediante:

- la aprobación de un examen final, o de un examen basado en los planes de estudio, o bien la aprobación de una serie de exámenes;

- la acumulación de un numero predeterminado de créditos; o

- una evaluación formal de las destrezas, competencias y conocimientos adquiridos.

En el ámbito de la educación formal, un resultado satisfactorio normalmente implica el otorgamiento de una certificación reconocida por las autoridades nacionales competentes.

58. Los programas educativos de los niveles CINE 1 y 2 (y, en ocasiones, de los niveles CINE 3 o 4) no siempre otorgan una certificación tras su conclusión. En estos casos, para determinar la conclusión exitosa de un nivel se debe utilizar un criterio distinto al de certificación, por ejemplo, el hecho de haber cursado la totalidad del último año de un programa o de tener acceso a un nivel de educación más avanzado.

59. En los niveles CINE 1 a 3, la conclusión de un programa siempre se considerara equivalente a la conclusión del nivel cuando el programa está destinado a otorgar acceso directo a un nivel CINE más avanzado que, en el caso del nivel CINE 3, correspondería a los niveles CINE 5, 6 o 7. Se considera que una certificación otorga acceso a un nivel CINE más avanzado incluso si dicho acceso estuviese limitado a solo algunos de los programas ofrecidos en este nivel. La conclusión de programas clasificados en los niveles CINE 4 al 8 se considera equivalente a la conclusión de nivel. Sin embargo, con referencia al logro educativo, las certificaciones obtenidas antes de completar el programa (por ejemplo, tras la conclusión exitosa de una etapa de un programa que otorgue un certificación intermedia reconocida) se clasifican en un nivel CINE inferior. Cuando una certificación no proporciona acceso directo a un nivel CINE más avanzado, la conclusión exitosa de programas puede considerarse como conclusión del nivel (sin acceso) o como nivel inconcluso. En los niveles CINE 2 y 3, las certificaciones que no dan acceso directo a un nivel CINE más avanzado pueden ser consideradas como conclusión del nivel (sin acceso), conclusión parcial del nivel o nivel inconcluso.

60. En los niveles CINE 2 y 3 existen cuatro subcategorías que establecen una distinción entre los programas educativos y sus respectivas certificaciones:

i) nivel inconcluso (por consiguiente, sin acceso directo a un nivel más avanzado - en el caso del nivel CINE 3 a los niveles CINE 5, 6 o 7);

ii) conclusión parcial del nivel; sin acceso directo a un nivel CINE más avanzado;

iii) conclusión del nivel; sin acceso directo a un nivel CINE más avanzado; y

iv) conclusión del nivel; con acceso directo a un nivel CINE más avanzado (en el caso del nivel CINE 3 corresponde a programas de primer título de educación terciaria de nivel CINE 5, 6 o 7. 
61. La conclusión exitosa de un programa de nivel CINE 2 o 3 que no da acceso a programas de un nivel CINE más avanzado (que en el caso del nivel CINE 3 correspondería a los niveles CINE 5, 6 o 7) se considerará equivalente a la conclusión, o conclusión parcial, del nivel si este cumple los siguientes criterios: i) duración mínima de dos años de estudio en un nivel determinado; y ii) duración acumulada mínima, a partir del comienzo del nivel CINE 1, de ocho años en el caso de programas de nivel CINE 2 y once años en el caso de programas de nivel CINE 3. La conclusión exitosa de programas más cortos en cualquiera de estos dos niveles solo se considera equivalente a la conclusión de dicho programa. Para propósitos del logro educativo, cualquier certificación reconocida obtenida a través de la conclusión exitosa de programas cortos es clasificada en un nivel CINE menos avanzado que aquel correspondiente al programa.

62. Los programas que:

a) no cumplen los criterios de contenido, duración mínima y duración acumulada se clasifican en la categoría 1 (nivel inconcluso).

b) cumplen los criterios de contenido, duración mínima y duración acumulada, forman parte de una secuencia de programas dentro del mismo nivel CINE (pero no son los últimos programas de la secuencia) y no dan acceso directo a un nivel más avanzado se clasifican en la categoría 2 (conclusión parcial del nivel).

c) cumplen los criterios de contenido, duración mínima, duración acumulada y son los últimos programas de la secuencia se clasifican en la categoría 3 (conclusión del nivel sin acceso directo). Normalmente, estos programas otorgan certificaciones pertinentes al mercado laboral.

d) pertenecen al nivel CINE 3 y solo dan acceso a programas de nivel CINE 4 también se clasifican en la categoría 3 (conclusión del nivel sin acceso directo).

e) dan acceso directo a la educación terciaria en los niveles CINE 5, 6 o 7 se clasifican en la categoría 4 (conclusión de nivel con acceso directo).

63. En un nivel CINE determinado, un programa para un grupo específico de participantes (adultos o personas con necesidades especiales) puede tener una duración inferior o superior a un programa similar de educación regular. Sin embargo, la conclusión de un programa se considerará conclusión del nivel solo si la certificación otorgada implica la adquisición de un nivel de conocimientos, destrezas y competencias equivalentes a las de un programa de educación regular del mismo nivel.

64. El solo hecho de participar en un programa sin concluirlo exitosamente no equivale a la conclusión, o conclusión parcial, del nivel y, salvo en el caso de los niveles CINE 0 y 1, no se tendrá en cuenta al momento de determinar los niveles de logro educativo. Por consiguiente, el nivel de logro educativo de personas que no hayan concluido un programa determinado será el nivel más alto que habían alcanzado antes de a ingresar al programa.

65. Mientras que el criterio de conclusión de nivel se asocia con la conclusión exitosa de un programa y, por consiguiente, es directamente aplicable a personas, los programas educativos se clasifican sobre la base de la certificación más alta por la que preparan, incluso si algunos de los participantes no logran obtenerla. 


\section{Posición en la estructura nacional de títulos y certificaciones}

66. La distinción entre programas de nivel CINE 6 y 7 se basa en su posición en la estructura nacional de títulos y certificaciones. Por lo tanto, con el fin de contabilizar en forma rigurosa los nuevos ingresos y graduados de la educación terciaria (o de los niveles que la constituyen), se hace imprescindible tomar en cuenta la secuencia de programas y certificaciones nacionales. La posición de un programa se asigna en base a la secuencia de títulos y certificaciones de los sistemas nacionales de educación terciaria.

67. Los programas de nivel CINE 6 reciben la clasificación de programas de "primer título" si la conclusión anterior de un programa de este nivel no representa un requisito de ingreso. Todos los demás programas de este nivel se clasifican como de "segundo o siguiente título".

68. Los programas de nivel CINE 7 reciben la clasificación de primer título siempre que la conclusión anterior de un programa de nivel CINE 6 no represente un requisito de ingreso. Por su parte, otros programas de nivel CINE 7 pueden requerir la previa conclusión de un programa de nivel CINE 6 o de otro programa de nivel CINE 7. En la CINE, estos programas se clasifican en forma separada con el objeto de poder identificar en forma más clara a las personas que ingresan al nivel CINE 7 por primera vez y a las que se gradúan de este nivel.

\section{Criterios de duración y duración acumulada}

69. Dada su importancia en la clasificación de programas por niveles y en la identificación de conclusión del nivel, a continuación se describen los criterios de duración en más detalle. Los demás criterios se describen en la Sección 9.

70. Los siguientes rangos de duración de niveles CINE se utilizan como criterios para clasificar los programas de educación formal:

- Nivel CINE 0: no se establecen criterios de duración; sin embargo, solo se incluyen en este nivel los programas que se impartan en periodos de actividades educativas equivalentes a dos horas diarias y cien días al año;

- Nivel CINE 1: la duración puede variar entre 4 y 7 años, siendo 6 años la más común;

- Nivel CINE 2: la duración puede variar entre 2 y 5 años, siendo 3 años la más común;

- Nivel CINE 3: la duración puede variar entre 2 y 5 años, siendo 3 años la más común;

- Nivel CINE 4: la duración puede variar entre 6 meses y 2 o 3 años;

- Nivel CINE 5: la duración puede variar entre 2 y 3 años; y

- Nivel CINE 8: la duración mínima es de 3 años.

La duración típica de los niveles CINE 6 y 7 se describe más fácilmente haciendo referencia a la duración de los programas en cada nivel respectivamente debido a que, en distintos países, la duración del nivel CINE depende de la secuencia de programas ofrecidos en estos niveles.

- Nivel CINE 6: la duración de los programas del nivel de "Grado en educación terciaria o nivel equivalente" puede variar entre 3 y 4 o más años a partir del nivel CINE 3 o entre 1 a 2 años a partir de otro programa del nivel CINE 6; y 
- Nivel CINE 7: la duración de los programas nivel de "Maestría, especialización o equivalente" puede variar entre 1 y 4 años a partir del nivel CINE 6 o puede extenderse entre 5 y 7 años a partir del nivel CINE 3.

71. La CINE utiliza los siguientes rangos de duración acumulada como criterio para clasificar los programas de educación formal por nivel:

- Niveles CINE 1+2: la duración acumulada típica es de 9 años, aunque puede fluctuar entre 8 y 11 años; y

- Niveles CINE 1+2+3: la duración acumulada típica es de 12 años, aunque puede fluctuar entre 11 y 13 años. El ingreso a la educación terciaria usualmente requiere como mínimo 11 años de educación impartida en los niveles CINE 1 al 3.

72. Cuando se aplica el criterio de duración a programas modulares o de tiempo parcial, la duración teórica del programa debe ser calculada en tiempo completo equivalente.

73. Si bien el principal objetivo de la CINE es promover el acopio y utilización de datos comparables de educación, se reconoce que al nivel de los países se pueden dar circunstancias especiales que requieren cierta flexibilidad al momento de definir la duración por nivel. Por lo tanto, en los párrafos 70 y 71 se presentan rangos de duración. Idealmente, para la clasificación de programas se utiliza la duración más frecuente o común.

74. La duración por nivel y la duración acumulada, según se describen en los párrafos 70 y 71 , pueden servir de pauta. Sin embargo, es posible usar los puntos institucionales de transición como criterios para asignar un programa a un nivel CINE determinado. La selección de puntos nacionales de transición con objeto de que coincidan con las categorías internacionales se determinará principalmente de acuerdo al contenido de los respectivos programas educativos y no sobre la base de su duración (acumulada). 
75. La CINE se aplica principalmente a estadísticas sobre participantes, ingresos, graduados y logro educativo. En este sentido, La CINE no representa un manual de recolección de datos ni define en detalle la cobertura de la recolección de datos o las unidades estadísticas. Sin embargo, con relación a los distintos tipos de estadísticas, durante la implementación de la CINE se deben tener en consideración los siguientes principios.

\section{Matrícula, asistencia e ingresos}

76. Con objeto de medir con precisión las matrículas, asistencia e ingresos, los estudiantes deben asignarse a un nivel, categoría o subcategoría CINE. Se debe evitar utilizar el contexto institucional como base para compilar estadísticas. Los estudiantes de distintos niveles y categorías CINE en el mismo centro o institución educativa deben ser reportados en forma separada, haciendo estimaciones de ser necesario. Los estudiantes que cursan programas que abarcan más de un nivel CINE deben ser reportados usando estadísticas por grados o etapas.

77. La asignación de estudiantes a niveles y categorías CINE se basa en las características del programa y no en las características individuales de los participantes. Por ejemplo, la categoría educación preprimaria está orientada a niños de 3 o más años, pero los niños menores de 3 años matriculados en este programa también deben ser reportados en esta categoría. En igual forma, las estadísticas que utilizan categorías de acceso a un nivel más avanzado deben estar basadas en el diseño del programa y no en la trayectoria del estudiante.

78. Se debe establecer una diferencia entre los estudiantes que ingresan a un nivel CINE por primera vez y los que inician un programa educativo sin ingresar a un nuevo nivel (es decir, los que habían ingresado a este nivel con anterioridad). Al momento de reportar a los primeros, se deben excluir aquellos estudiantes que ingresan a un programa educativo que esté precedido por otro programa del mismo nivel. En el caso de programas que abarcan dos niveles CINE, los estudiantes que ingresan al primer grado del nivel CINE más avanzado deben considerarse nuevos ingresos a un nivel CINE, a pesar de que desde la perspectiva nacional esto solo representa una continuación de los estudios dentro del mismo programa.

\section{Graduados}

79. Respecto de los graduados de un nivel CINE, solo se incluye a las personas que comenzaron y finalizaron exitosamente un programa educativo clasificado como "conclusión del nivel". En principio, y con el fin de mantener el vínculo entre ingresos, matrícula y graduados, solo deberá contabilizarse a los estudiantes que hayan concluido la totalidad del nivel o el conjunto de niveles en que se encontraban matriculados (por ejemplo, la primera graduación de educación terciaria). Los estudiantes que hayan recibido la misma certificación o certificaciones equivalentes por haber concluido solo una etapa de un nivel CINE no deben ser contabilizados como graduados.

80. Los graduados deben contabilizarse una sola vez en cualquier nivel CINE y en el nivel del programa más avanzado exitosamente concluido. Lo anterior es particularmente relevante en el caso de la educación secundaria alta y la educación terciaria, donde puede existir una secuencia de programas dentro de un mismo nivel CINE. Una medición rigurosa de los graduados permitiría realizar un seguimiento de un estudiante a lo largo del nivel (o conjunto de niveles) desde su ingreso y hasta su conclusión. Esto no suele darse en la práctica, y para calcular el número de graduados con frecuencia se debe recurrir a métodos estimativos tales como encuestas de seguimiento de cohortes basadas en muestras. 


\section{Logro educativo}

81. El logro educativo de un individuo se define como el nivel CINE más avanzado que el individuo ha concluido. Para fines operativos, el logro educativo se mide con respecto al programa educativo más avanzado concluido exitosamente, el cual suele ser validado por una certificación reconocida. Las certificaciones intermedias se clasifican en un nivel inferior al que corresponde al programa.

82. Un "programa educativo se considera como concluido exitosamente" cuando el estudiante ha cursado y terminado un programa de educación formal y se le concede una certificación reconocida (véanse también los párrafos 56 a 58).

83. Las autoridades educativas nacionales competentes pueden reconocer las certificaciones otorgadas por programas no formales de educación, o validar las destrezas obtenidas a través del aprendizaje informal, como equivalentes a certificaciones de la educación formal. Dichas certificaciones también están consideradas en la definición CINE de logro educativo. Las certificaciones de educación no formal o la validación de destrezas no reconocidas por la educación formal no se encuentran dentro del ámbito de la CINE (véase el párrafo 35).

84. La definición de logro educativo que proporciona la CINE debe distinguirse de otros conceptos relacionados a los logros educativos de un individuo. Los logros de un individuo pueden incluir niveles educativos cursados, pero no concluidos exitosamente, o los conocimientos, destrezas y competencias reales de un individuo (es decir, niveles de alfabetismo y utilización de números - numeracy) susceptibles de ser determinados mediante pruebas estandarizadas o años de escolarización.

85. La conclusión exitosa de un programa no se aplica a las personas que cursan solo parte de un programa educativo o no cumplen los requisitos de conclusión (por ejemplo, no aprueban los exámenes finales). Estas deben ser clasificadas de acuerdo al nivel CINE más avanzado concluido exitosamente (es decir, el nivel alcanzado antes de ingresar al programa no concluido).

86. En términos de la clasificación del logro educativo, el nivel 0 adquiere un significado distinto al utilizado en la clasificación de programas educativos: significa no haber concluido exitosamente el nivel CINE 1. Esto incluye a personas que nunca han cursado un programa educativo, que participaron alguna vez en educación de la primera infancia o que cursaron educación primaria sin haber concluido exitosamente el nivel CINE 1. Para este nivel de logro educativo se han desarrollado varias subcategorías (véase el Cuadro 4).

87. El logro educativo puede ser clasificado de acuerdo al nivel CINE concluido (o parcialmente concluido), la orientación del programa y el acceso a niveles CINE más avanzados. Si una persona ha finalizado el mismo nivel en más de una ocasión (por ejemplo, cursando dos programas distintos ofrecidos como opciones paralelas), solo se deberían reportar las características de la última certificación obtenida.

88. Las estadísticas sobre logro educativo cubren personas de todos los grupos de edad, algunas o muchas de las cuales pueden haber finalizado programas educativos en el pasado u obtenido certificaciones que son distintas de las que actualmente se otorgan. Con el fin de permitir la comparabilidad de los indicadores tanto a lo largo del tiempo como entre cohortes educativos, el logro educativo debe clasificarse en base a las características de los programas y las certificaciones vigentes al momento de la conclusión exitosa. 


\section{SECCIÓN 7 SISTEMA DE CODIFICACIÓN}

89. La clasificación de programas educativos propuesta en la CINE utiliza dos sistemas paralelos de codificación, uno para programas (Programas-CINE o CINE-P) y otro para logro educativo (Logro-CINE o CINE-A). Cada sistema cuenta con nueve niveles, en tanto que dentro de cada nivel se utilizan dimensiones complementarias con el objeto de destacar categorías o subcategorías adicionales, si fuera pertinente. Se ha adoptado un sistema de codificación de tres dígitos para clasificar tanto los programas como el logro educativo.

\section{Cuadro 1. Codificación de los niveles CINE (primer dígito)}

\begin{tabular}{|c|l|c|l|}
\hline \multicolumn{2}{|c|}{ Programas-CINE (CINE-P) } & \multicolumn{2}{l|}{ Logro-CINE (CINE-A) } \\
\hline 0 & Educación de la primera infancia & 0 & Menos que primaria \\
\hline 1 & Educación primaria & 1 & Educación primaria \\
\hline 2 & Educación secundaria baja & 2 & Educación secundaria baja \\
\hline 3 & Educación secundaria alta & 3 & Educación secundaria alta \\
\hline 4 & Educación postsecundaria no terciaria & 4 & Educación postsecundaria no terciaria \\
\hline 5 & Educación terciaria de ciclo corto & 5 & Educación terciaria de ciclo corto \\
\hline 6 & Grado en educación terciaria o nivel equivalente & 6 & Grado en educación terciaria o nivel equivalente \\
\hline 7 & Nivel de maestría, especialización o equivalente & 7 & Nivel de maestría, especialización o equivalente \\
\hline 8 & Nivel de doctorado o equivalente & 8 & Nivel de doctorado o equivalente \\
\hline 9 & No clasificado en otra parte & 9 & No clasificado en otra parte \\
\hline
\end{tabular}

\section{Cuadro 2. Codificación CINE de categorías (segundo dígito) ${ }^{1}$}

\begin{tabular}{|c|c|c|c|}
\hline \multicolumn{2}{|r|}{ Programas-CINE (CINE-P) } & \multicolumn{2}{|r|}{ Logro-CINE (CINE-A) } \\
\hline 0 & No se define con mayor detalle & 0 & No se define con mayor detalle \\
\hline 1 & Desarrollo educacional de la primera infancia & 1 & Nunca cursó un programa educativo \\
\hline 2 & Educación preprimaria & 2 & Educación de la primera infancia en forma parcial \\
\hline 3 & No se utiliza & 3 & Educación primaria en forma parcial (sin conclusión del nivel CINE 1) \\
\hline 4 & General/académica & 4 & General/académica \\
\hline 5 & Vocacional/profesional & 5 & Vocacional/profesional \\
\hline 6 & Orientación no especificada² & 6 & Orientación no especificada ${ }^{3}$ \\
\hline 7 & No se utiliza & 7 & No se utiliza \\
\hline 8 & No se utiliza & 8 & No se utiliza \\
\hline 9 & No clasificado en otra parte & 9 & No clasificado en otra parte \\
\hline \multicolumn{4}{|c|}{$\begin{array}{l}\text { 1. Programas: tipo de programa (nivel CINE-P 0), orientación (niveles CINE-P 2-8), no se define con mayor detalle (nivel CINE-P 1). } \\
\text { Logro: participación (nivel CINE-A 0), orientación (niveles CINE-A 2-5), no se define con mayor detalle (niveles CINE-A } 1 \text { y 6-8). } \\
\text { 2. Utilizada en niveles CINE-P } 6 \text { al } 8 . \\
\text { 3. Utilizada en niveles CINE-A } 5 \text { al } 8 .\end{array}$} \\
\hline
\end{tabular}




\section{Cuadro 3. Codificación CINE de subcategorías (tercer dígito) ${ }^{1}$}

\begin{tabular}{|c|c|c|c|}
\hline \multicolumn{2}{|r|}{ CINE - Programas (CINE-P) } & \multicolumn{2}{|r|}{ CINE - Logro (CINE-A) } \\
\hline 0 & No se define con mayor detalle & 0 & No se define con mayor detalle ${ }^{2}$ \\
\hline 1 & $\begin{array}{l}\text { La conclusión exitosa se considera insuficiente para la conclusión, } \\
\text { o conclusión parcial, del nivel; sin acceso directo a programas de } \\
\text { niveles más avanzados }\end{array}$ & 1 & No se utiliza \\
\hline 2 & $\begin{array}{l}\text { La conclusión exitosa se considera suficiente para la conclusión } \\
\text { parcial del nivel; sin acceso directo a programas de niveles más } \\
\text { avanzados }\end{array}$ & 2 & $\begin{array}{l}\text { Conclusión parcial del nivel; sin acceso } \\
\text { directo a programas en niveles CINE más } \\
\text { avanzados }\end{array}$ \\
\hline 3 & $\begin{array}{l}\text { La conclusión exitosa se considera suficiente para la conclusión } \\
\text { del nivel; sin acceso directo a programas de nivel más avanzados }{ }^{3}\end{array}$ & 3 & $\begin{array}{l}\text { Conclusión del nivel; sin acceso directo a } \\
\text { programas en niveles CINE más avanzados }{ }^{3}\end{array}$ \\
\hline 4 & $\begin{array}{l}\text { La conclusión exitosa se considera suficiente para la conclusión } \\
\text { del nivel; con acceso directo a programas de nivel más } \\
\text { avanzados }^{3,4}\end{array}$ & 4 & $\begin{array}{l}\text { Conclusión del nivel; con acceso directo } \\
\text { a programas en niveles CINE más } \\
\text { avanzados }^{3,5}\end{array}$ \\
\hline 5 & $\begin{array}{l}\text { Programas de primer título del grado en educación terciaria o nivel } \\
\text { equivalente ( } 3 \text { a } 4 \text { años) }\end{array}$ & 5 & No se utiliza \\
\hline 6 & $\begin{array}{l}\text { Programas largos de primer título del grado en educación terciaria } \\
\text { o maestría/especialización o nivel equivalente }\end{array}$ & 6 & No se utiliza \\
\hline 7 & $\begin{array}{l}\text { Programas de segundo o siguiente título - tras cursar un } \\
\text { programa del grado en educación terciaria o nivel equivalente }\end{array}$ & 7 & No se utiliza \\
\hline 8 & $\begin{array}{l}\text { Programas de segundo o siguiente título - tras cursar un programa } \\
\text { de nivel de maestría/especialización o equivalente }\end{array}$ & 8 & No se utiliza \\
\hline 9 & No clasificado en otra parte & 9 & No clasificado en otra parte \\
\hline \multicolumn{4}{|c|}{$\begin{array}{l}\text { 1. Programas: conclusión/acceso (niveles CINE-P } 2 \text { al } 5 \text { y 8), posición en la estructura nacional de títulos y certificaciones (niveles CINE-P 6-7), no } \\
\text { se define con mayor detalle (niveles CINE-P 0-1). } \\
\text { Logro: conclusión/acceso (niveles CINE -A } 2 \text { a 4), no se define con mayor detalle (niveles CINE-A 0-1 y 5-8). }\end{array}$} \\
\hline \multicolumn{4}{|c|}{$\begin{array}{l}\text { 2. En niveles CINE-A } 1 \text { y } 5 \text { al } 7 \text {, incluye la conclusión exitosa de un programa o etapa de un programa de nivel CINE más avanzado considerado } \\
\text { insuficiente para la conclusión o conclusión parcial del nivel. }\end{array}$} \\
\hline \multicolumn{4}{|c|}{ 3. En el caso del nivel CINE 3, "niveles CINE más avanzados" refiere al nivel CINE-P 5, 607.} \\
\hline \multicolumn{4}{|c|}{$\begin{array}{l}\text { 4. En el caso de los niveles CINE } 5 \text { y 8, todos los programas se clasifican como de tipo 4, independientemente del hecho que den o no acceso a un } \\
\text { nivel CINE más avanzado. }\end{array}$} \\
\hline \multicolumn{4}{|c|}{$\begin{array}{l}\text { 5. En niveles CINE-A } 2 \text { al 4, incluye la conclusión exitosa de un programa o etapa de un programa de nivel CINE más avanzado considerado } \\
\text { insuficiente para la conclusión, o conclusión parcial, del nivel. }\end{array}$} \\
\hline
\end{tabular}

90. No todas las combinaciones de categorías y subcategorías son posibles ni de uso difundido en los sistemas educativos. Los códigos de tres dígitos presentados en este documento solo reflejan las categorías actualmente en uso. En los Anexos II y III se presenta un listado completo de estos códigos. En el caso que los usuarios de la clasificación CINE identificaran nuevas combinaciones de categorías y subcategorías, la lista puede ampliarse utilizando los códigos reservados para dimensiones adicionales. 


\section{SECCIÓN 8 ADMINISTRACIÓN}

91. El Instituto de Estadística de la UNESCO (UIS) es el custodio de la CINE y es, de esta manera, responsable del desarrollo, mantenimiento, actualización y revisión de esta clasificación de referencia. El Instituto también provee orientación sobre el uso efectivo y consistente de la CINE en materia de recopilación y análisis de datos. EI UIS se ha impuesto la tarea de mantener vínculos con otros custodios de clasificaciones relevantes para garantizar la consistencia entre marcos normativos estandarizados asociados.

92. Entre las responsabilidades adicionales asumidas por el UIS se incluyen:

- describir la utilización de la estructura y de los detalles de la clasificación en la elaboración y presentación de estadísticas;

- promover el uso de la CINE en la generación de estadísticas comparables a nivel internacional;

- proporcionar capacitación, apoyo técnico y materiales de orientación a los países para garantizar la efectiva implementación y utilización de esta clasificación en todo el mundo;

- establecer mecanismos de monitoreo para garantizar una debida retroalimentación por parte de los usuarios de la CINE respecto de posibles problemas en su uso (véase párrafo 96); y

- crear, en colaboración con otros socios en materia de acopio de estadísticas, un Comité CINE encargado de revisar la clasificación y asesorar respecto a su implementación (véase el párrafo 97).

93. EI UIS planea elaborar un manual operativo para facilitar la clasificación y homologación de los sistemas educativos nacionales de acuerdo a la CINE (inicialmente, los programas y las certificaciones otorgadas por la educación formal). El manual proporcionará directrices y notas explicativas que facilitarán la interpretación de esta clasificación (incluyendo ejemplos de países). Asimismo, se pondrá a disposición de los usuarios que lo soliciten material adicional de orientación y capacitación.

94. Las actividades de capacitación para la implementación de la CINE deberán organizarse a través de talleres regionales y de asistencia y cooperación técnica, de acuerdo a las necesidades y a las capacidades existentes de los países. Paralelamente, el UIS colaborará estrechamente con sus socios en materia de acopio de estadísticas en el desarrollo de materiales de capacitación y sus contenidos. La conversión de los mapas elaborados a partir de la CINE 1997 para lograr la conformidad con la CINE 2011, así como las pautas de clasificación de programas nuevos o modificados, merecen especial atención.

95. EI UIS proyecta elaborar y mantener en su sitio web una base de datos de los mapas homologados de acuerdo a la CINE - de los sistemas educativos nacionales (programas y certificaciones otorgadas por la educación formal). El material será actualizado de acuerdo a los cambios experimentados por los sistemas educativos a lo largo del tiempo.

96. Para asegurar el cumplimiento de la CINE 2011, será necesario establecer mecanismos de control de calidad en su implementación. El Instituto planea trabajar en estrecha colaboración con los países y sus socios en materia de acopio de estadísticas de educación (incluyendo Eurostat y la OCDE) con objeto de asegurar la consistencia de los mapas con los estándares de la CINE y la actualización de estos cuando sea necesario. Respecto de los mapas de programas y certificaciones educativas nacionales, se advierte la necesidad de crear un mecanismo de "revisión por pares" con la participación de Estados Miembros y otras agencias pertinentes. 
97. A su vez, se proyecta la conformación de un Comité CINE con el fin de asesorar al UIS en materia de clasificación de programas y certificaciones nacionales, de examinar la versión CINE actual y de identificar áreas potenciales de desarrollo. No obstante, las revisiones de la CINE no se encontrarían dentro de las responsabilidades de este comité. Dicho comité estaría integrado, en calidad de miembros permanentes, por la UNESCO (en su condición de organismo de las Naciones Unidas que ejerce el liderazgo en el ámbito de la educación), por custodios de otras clasificaciones asociadas relevantes en este ámbito y por socios clave en materia de acopio de estadísticas de educación, tales como la OCDE y Eurostat. La composición del Comité debería conservar un equilibrio técnico y geográfico, razón por la cual estaría temporalmente integrado por un grupo selecto de expertos en educación, estadísticas y clasificaciones de diferentes regiones del mundo con amplios conocimientos sobre la CINE, así como representantes de la comunidad de usuarios e investigadores. 


\section{SECCIÓN 9 NIVELES CINE}

98. En las siguientes subsecciones se definen los nueve niveles CINE. Cada subsección ha sido estructurada como se describe a continuación:

A. Las características principales describen los objetivos de los programas en los diferentes niveles CINE, la organización de la instrucción (las características del proceso de enseñanza y aprendizaje y los métodos típicos de evaluación, en caso de que sean aplicables), así como los requisitos de ingreso. En el caso de algunos niveles CINE, se mencionan los nombres nacionales de programas educativos ampliamente conocidos como posibles ejemplos de la correspondencia entre dichos programas y los niveles CINE.

B. Los criterios de clasificación ofrecen una definición más formal sobre cómo clasificar los programas educativos en sus respectivos niveles CINE a través del uso de criterios principales y subsidiarios. Para mayor información sobre el concepto general de "nivel" en la CINE véase la Sección 5.

C. La sección de programas que abarcan más de un nivel CINE ofrece directrices adicionales sobre la clasificación de programas educativos que se extienden a través de más de un nivel CINE. Para mayor información sobre el concepto básico de programas educativos que abarcan varios niveles CINE, véase la Sección 3.

D. Las dimensiones complementarias definen las características que permiten distinguir entre los distintos tipos de programas de un nivel CINE de acuerdo a la orientación del programa, a la conclusión de nivel y acceso a niveles CINE más avanzados y a la duración del programa o posición en la estructura nacional de títulos y certificaciones. Para mayor información general sobre estas dimensiones complementarias en la CINE, véase la Sección 5.

E. Otros programas incluidos en el nivel CINE hacen referencia a programas educativos menos convencionales o de educación no formal (por ejemplo, educación para necesidades especiales, educación de adultos o de segunda oportunidad) que, si bien pueden no satisfacer todos los criterios de clasificación (por ejemplo, la edad típica de ingreso), son equivalentes a otros programas de ese nivel CINE en términos de complejidad del contenido. Por consiguiente, estos programas también se clasifican en los niveles CINE correspondientes.

F. La clasificación de programas educativos proporciona los códigos de niveles, categorías y subcategorías CINE-P que se asignan a dichos programas.

G. La clasificación de logro educativo proporciona los códigos de niveles, categorías y subcategorías CINE-A que se asignan a las certificaciones educativas y medidas similares de conclusión exitosa de los programas educativos. Asimismo, señala en qué casos es necesario clasificar una certificación educativa en un nivel CINE-A diferente al nivel CINE-P que le correspondería al programa que suele otorgar dicha certificación.

99. En la Sección 10 se presentan, inmediatamente después de la descripción de niveles, cuadros de correspondencia (véanse Cuadros 20 y 21) que muestran la vinculación entre la CINE 2011 y la CINE 1997. 


\section{NIVEL CINE 0 EDUCACIÓN DE LA PRIMERA INFANCIA}

\section{A. Características principales}

100. Los programas de nivel CINE 0, o educación de la primera infancia, se caracterizan por privilegiar un enfoque holístico orientado a dar apoyo temprano al desarrollo cognitivo, físico, social y emocional del niño y familiarizar a los niños de corta edad con la instrucción organizada fuera del entorno familiar. El nivel CINE 0 solo incluye programas de la primera infancia que incorporan un componente educativo intencionado. Estos programas están generalmente encaminados a desarrollar las destrezas socioafectivas y académicas que permitirán al niño participar activamente en la vida social e ingresar a la educación primaria.

101. En este nivel, los programas no se caracterizan por ser altamente estructurados, estando más bien diseñados para proporcionar un conjunto de actividades educativas organizadas con algún propósito dentro de un entorno seguro. A través de ellas y bajo la supervisión de un integrante del personal docente, el niño aprende en interacción con otros niños, realizando habitualmente actividades lúdicas y de naturaleza creativa.

102. Los programas del nivel CINE 0 están dirigidos a niños menores que la edad oficial de ingreso al nivel CINE 1. En este nivel, existen dos categorías de programas: desarrollo educacional de la primera infancia y educación preprimaria. En la primera categoría, el contenido está destinado a niños de entre 0 y 2 años, en tanto que en la segunda se orienta a niños desde los tres años de edad hasta el inicio de la educación primaria.

103. Los programas clasificados en el nivel CINE 0 pueden recibir distintas denominaciones, por ejemplo: educación y desarrollo de la primera infancia, kindergarten, jardines infantiles, educación preprimaria, preescolar o inicial. Respecto de programas llamados crèche o guarderías, es importante asegurar que estos cumplan los criterios de clasificación establecidos en la CINE 0 especificados a continuación. Para propósitos de comparación a nivel internacional, se usa el término "educación de la primera infancia" para denominar al nivel CINE 0.

\section{B. Criterios de clasificación}

104. Para definir la educación de la primera infancia, los siguientes criterios son pertinentes:

\section{Criterios principales}

a) Propiedades educativas del programa (véanse los párrafos 105 y 106);

b) Contexto institucional (véase el párrafo 107);

c) Edad objetiva típica de los niños contemplada en el diseño del programa (véanse los párrafos 102 y 108); y

d) Duración o intensidad del programa (véase el párrafo 110).

\section{Criterios subsidiarios}

a) Certificaciones del personal (véase el párrafo 111);

b) Existencia de un marco regulatorio (véase el párrafo 112); y

c) Normalmente, no forma parte de la educación obligatoria (véase el párrafo 113). 
105. Las propiedades educativas del desarrollo educacional de la primera infancia comprenden un entorno de aprendizaje que es visualmente estimulante y verbalmente variado. Estos programas además promueven la autoexpresión con énfasis en la adquisición de lenguaje y su uso para lograr una comunicación significativa. Los niños tienen la oportunidad de participar en actividades lúdicas que les permiten desarrollar sus destrezas motoras y de coordinación a través de la interacción con el personal docente y bajo su supervisión. La CINE no cubre los programas destinados solamente al cuidado del niño (supervisión, nutrición y salud).

106. Las propiedades educativas de la educación preprimaria comprenden la interacción con pares y educadores, a través de la cual los niños aprenden a mejorar la utilización del lenguaje y sus habilidades sociales y comienzan a desarrollar sus destrezas de lógica y raciocinio y a articular sus procesos de reflexión. En este nivel se les expone por primera vez a conceptos alfabéticos y matemáticos. Asimismo, se promueve la exploración del mundo que los rodea y del entorno inmediato. Las actividades diseñadas para mejorar la motricidad gruesa (ejercicios, juegos, etc.) y otras actividades lúdicas supervisadas se pueden utilizar como oportunidades para promover el desarrollo de la interacción social, destrezas, autonomía y preparación para la escuela.

107. Los programas del nivel CINE 0 suelen ser impartidos en instituciones educativas o entornos institucionalizados (escuelas, centros comunitarios, hogares) preparados para acoger grupos de niños. Se excluyen de este nivel iniciativas estrictamente familiares que si bien pueden ser intencionadas no tienen la estructura de un "programa", es decir, actividades de educación informal del niño a cargo de padres, otros parientes o amigos no son consideradas en la CINE 0.

108. Dentro del nivel CINE 0, los programas de desarrollo educacional de la primera infancia están orientados a niños entre las edades de 0 a 2 años, en tanto que los programas de educación preprimaria se orientan a niños de entre los 3 años hasta la edad de ingreso al nivel CINE 1. La edad máxima de ingreso a educación preprimaria dependerá en cada caso de la edad teórica de ingreso al nivel CINE 1, es decir, a la educación primaria (véase el párrafo 117).

109. Los programas integrados de educación de la primera infancia que abarcan las dos subcategorías del nivel CINE 0 (es decir, programas educativos para niños entre las edades de 0 años y la edad de ingreso al nivel CINE 1) requieren especial atención al momento de su clasificación. Los programas divididos en años, etapas o ciclos, que respondan a los criterios de contenido descritos en el párrafo 105 se deberán clasificar como programas de desarrollo educacional de la primera infancia y los que respondan a los criterios de contenido descritos en el párrafo 106 como educación preprimaria. En el caso de programas sin subdivisiones, la clasificación en una de las dos categorías deberá basarse en la edad de los participantes.

110. Con el objeto de mejorar la comparabilidad internacional, la CINE recomienda la siguiente intensidad y duración mínima: los programas deberán impartirse en periodos de actividades educativas equivalentes a dos horas diarias y cien días al año. Solo los programas que cumplan estos criterios podrán ser clasificados en la CINE.

111. Cuando corresponda, el requisito de certificaciones pedagógicas del personal docente en los países donde exista tal requisito puede ser un buen criterio de aproximación para clasificar un programa educativo. De hecho, este criterio se puede aplicar con el fin de distinguir entre la educación de la primera infancia y la guardería o atención infantil para la cual no existen exigencias de personal con formación pedagógica.

112. Cuando corresponda, la existencia de un marco referencial o regulatorio elaborado o reconocido por la autoridad nacional competente (por ejemplo, el Ministerio de Educación u otro ministerio o 
entidad equivalente) podría constituir un buen criterio de aproximación para clasificar un programa educativo. Dicho marco debería incluir directrices, estándares o instrucciones que detallen las oportunidades de aprendizaje disponibles a los niños de corta edad.

113. En los sistemas educativos que han adoptado la educación obligatoria, los programas educativos no obligatorios diseñados para comenzar antes del inicio de la educación obligatoria y que cumplen los criterios anteriormente reseñados se clasifican en el nivel CINE 0. Asimismo, en ciertos países la primera etapa o ciclo de educación obligatoria puede clasificarse en el nivel CINE 0 si cumple los criterios de este nivel. Debido a esto, el inicio de la educación obligatoria no es criterio suficiente para distinguir entre los programas de nivel CINE 0 y CINE 1, a pesar de que este podría ser el caso en algunos sistemas educativos.

\section{Programas que abarcan más de un nivel CINE}

114. Los programas educativos que abarcan los niveles CINE 0 y 1 requieren especial atención al momento de su clasificación. En los sistemas educativos donde parte de la educación de la primera infancia está incluida en la educación primaria, se deberán clasificar en el nivel CINE 0 solo los grados, etapas o ciclos que reflejen los criterios descritos en el párrafo 104. Los grados, etapas o ciclos que respondan a los criterios presentados en el párrafo 124 se deben clasificar en el nivel CINE 1.

115. Si la aplicación de criterios de clasificación no proporcionara una clara línea divisoria entre los niveles CINE 0 y 1 , se recomienda lo siguiente:

i) en el caso de programas organizados en etapas que abarcan los niveles CINE 0 y 1 , se debe utilizar el final de la etapa más cercana a los seis años de edad como punto de transición entre estos niveles; $y$

ii) respecto de programas no organizados en etapas que abarcan los niveles CINE 0 y 1 , los grados que imparten educación a niños menores de seis años se deben clasificar en el nivel CINE 0 y todos los demás en el nivel CINE 1.

\section{Dimensiones complementarias}

116. Existe una dimensión que establece la distinción entre los programas educativos de nivel CINE 0:

- Grupo de edad objetivo (véase el párrafo 102).

\section{E. Otros programas incluidos en el nivel CINE 0}

117. El nivel CINE 0 también incluye programas para niños con necesidades especiales conforme a los criterios descritos en el párrafo 104, independientemente de la edad.

\section{F. Clasificación de programas educativos de nivel CINE 0}

118. En el nivel CINE 0, a los programas de desarrollo educacional de la primera infancia se les asigna el código 010 y a los programas de educación preprimaria el código 020 (véase el párrafo 102). No hay subcategorías que requieran ser distinguidas mediante el uso de un tercer digito. 


\section{G. Clasificación de logro educativo en los niveles CINE 0 y 1}

119. En términos de clasificar el logro educativo, se reserva el nivel 0 (menos que primaria) para las personas que:

- nunca han cursado un programa educativo;

- cursaron educación de la primera infancia (nivel CINE 0); o

- cursaron parte de la educación primaria pero no han concluido exitosamente el nivel CINE 1 (habiendo o no cursado el nivel CINE 0).

El Cuadro 4 proporciona códigos para clasificar el logro educativo asociado con la educación preprimaria y primaria. 


\section{NIVEL CINE 1 EDUCACIÓN PRIMARIA}

\section{A. Características principales}

120. Los programas del nivel CINE 1, o educación primaria, están principalmente destinados a proporcionar a los estudiantes destrezas básicas en lectura, escritura y matemáticas (es decir, alfabetismo y utilización de números - numeracy) y sentar una sólida base para el aprendizaje y la comprensión de las áreas esenciales del conocimiento y el desarrollo personal y social como preparación a la educación secundaria baja. Estos programas privilegian el aprendizaje a un nivel de complejidad básico con muy poca o ninguna especialización.

121. En el nivel CINE 1 (especialmente en los primeros años), las actividades educativas suelen estar organizadas por unidades, proyectos o amplias áreas de aprendizaje, donde se aplica usualmente un enfoque integrado de instrucción en lugar de asignaturas específicas. Normalmente, un profesor principal responsable de un grupo de alumnos organiza el proceso de aprendizaje, si bien una clase puede tener más de un profesor, particularmente en el caso de ciertas asignaturas o unidades.

122. Usualmente, en este nivel el único requisito de ingreso es la edad. En general, la edad habitual o legal de ingreso no es inferior a los 5 años de edad ni superior a los 7 años de edad. Este nivel suele tener una duración de seis años, aunque esta puede fluctuar entre cuatro y siete años. A su vez, la edad de salida de la educación primaria está situada típicamente en el rango de 10 a 12 años (véanse los párrafos 132 al 134). Una vez concluidos los programas de educación primaria, el niño continúa su educación en el nivel CINE 2 (educación secundaria baja).

123. Los programas clasificados en el nivel CINE 1 pueden recibir distintas denominaciones, por ejemplo: educación primaria, educación elemental o educación básica (etapa 1 o grados inferiores, si el sistema educativo cuenta con un programa que abarca los niveles CINE 1 y 2). Para propósitos de comparación a nivel internacional, se usa el término "educación primaria" para denominar al nivel CINE 1.

\section{B. Criterios de clasificación}

124. Para definir la educación primaria, los siguientes criterios son pertinentes:

\section{Criterios principales}

a) Instrucción sistemática en conocimientos, destrezas y competencias básicas (véase el párrafo 125);

b) Duración y edad típica de ingreso (véase el párrafo 122); e

c) Instrucción usualmente impartida por un docente principal por clase (véase el párrafo 126).

\section{Criterios subsidiarios}

a) Forma parte de la educación obligatoria (véase el párrafo 127).

125. La línea divisoria entre los niveles CINE 0 y 1 coincide con el punto de transición del sistema educativo donde empieza la instrucción en lectura, escritura y matemáticas en forma sistemática. Si bien es cierto que algunos programas de nivel CINE 0 ofrecen una introducción a la lectura, escritura y matemáticas, estos no proporcionan destrezas básicas lo suficientemente sólidas en estas áreas y, por consiguiente, no logran cumplir en plenitud los criterios que permiten su clasificación como de nivel CINE 1. Normalmente, la transición de educación preprimaria a 
educación primaria coincide con el ingreso a programas o a instituciones nacionales de educación elemental, primaria o básica.

126. Habitualmente, un profesor principal es responsable de un grupo de niños y facilita el proceso de aprendizaje, el cual suele estar organizado en torno a unidades, proyectos, o amplias áreas de aprendizaje como parte de un enfoque integrado (particularmente durante los primeros años de educación primaria). Sin embargo, una clase puede tener más de un profesor, particularmente en el caso de las asignaturas más especializadas. Generalmente, en este nivel se encuentran docentes con una formación que les permite dar orientación pedagógica en asignaturas básicas. Por el contrario, en los programas del nivel CINE 2, puede haber más de un profesor a cargo de la instrucción de diferentes áreas temáticas, y con frecuencia estos han recibido formación especializada en asignaturas determinadas.

127. A menudo, el inicio de la educación primaria coincide con el inicio de la educación obligatoria, excepto en sistemas educativos donde parte o la totalidad de la educación preprimaria es actualmente obligatoria. Por lo tanto, en los países donde la educación obligatoria es materia de legislación, esta comienza en el nivel CINE 1 o antes.

\section{Programas que abarcan más de un nivel CINE}

128. Los programas educativos que abarcan los niveles CINE 0 y 1 o 1 y 2 requieren especial atención al momento de clasificarlos. En los sistemas educativos donde la educación primaria forma parte de un programa educativo de ocho o más años de duración, se deben clasificar en el nivel CINE 1 solo las etapas, grados o ciclos que reflejen los criterios descritos en el párrafo 124. Cualquier grado, etapa o ciclo que responda a los criterios presentados en el párrafo 104 se debe clasificar en el nivel CINE 0, en tanto que los que respondan a los criterios presentados en el párrafo 143 se deben clasificar en el nivel CINE 2.

129. Si la utilización de criterios de clasificación no proporcionara una clara línea divisoria entre los niveles CINE 0 y 1, se recomienda utilizar los criterios adicionales descritos en el párrafo 114 para determinar el final del nivel CINE 0 y el comienzo del nivel CINE 1.

130. Si la utilización de criterios de clasificación no proporcionara una clara línea divisoria entre los niveles CINE 1 y 2 , se recomienda lo siguiente:

i) en el caso de programas organizados en etapas que abarcan los niveles CINE 1 y 2 , se debe utilizar el final de la etapa más cercana a los seis años de escolarización a partir del inicio del nivel CINE 1 como punto de transición entre estos niveles CINE; y

ii) respecto de programas no organizados en etapas que abarcan los niveles CINE 1 y 2 , solo los primeros 6 años se deben clasificar en el nivel CINE 1 y todos los demás en el nivel CINE 2 (véase el párrafo 149).

\section{Dimensiones complementarias}

131. Ninguna.

\section{E. Otros programas incluidos en el nivel CINE 1}

132. El nivel CINE 1 incluye programas para personas con necesidades especiales siempre que el programa proporcione enseñanza básica en lectura, escritura y matemáticas en forma sistemática, independientemente de la edad del participante. 
133. Este nivel también incluye programas de segunda oportunidad de educación primaria o de reintegración. Normalmente, estos programas están destinados a personas que:

i) abandonaron la escuela antes de finalizar la educación primaria (estos programas facilitan el reingreso al sistema educativo con el fin de completar este nivel), o

ii) finalizaron la educación primaria pero han optado por cursar un programa educativo o desempeñar un oficio para el cual no se encuentran lo suficientemente preparados. Los participantes suelen ser mayores que en el grupo del edad objetivo del nivel CINE 1 (aunque no necesariamente adultos).

134. Adicionalmente, se incluyen en este nivel los programas formales y no formales de alfabetización con un contenido similar en complejidad al de programas clasificados como de educación primaria y destinados a adultos y adolescentes de mayor edad que el estudiante típico de nivel CINE 1.

\section{F. Clasificación de programas educativos de nivel CINE 1}

135. A la totalidad de los programas de nivel CINE 1 se les asigna el código 100. No hay categorías o subcategorías que requieran ser diferenciadas mediante el uso de un segundo o tercer dígito.

\section{G. Clasificación de logro educativo en los niveles CINE 0 y 1}

136. Al momento de codificar el logro educativo, se debe dar especial consideración a la clasificación de personas que, a pesar de haber asistido a clases de educación primaria, no lograron finalizarla.

137. En términos de logro educativo, las certificaciones otorgadas por programas del nivel CINE 2 consideradas insuficientes para la conclusión, o conclusión parcial, de este nivel se clasifican en el nivel CINE 1 (por ejemplo, programas de nivel CINE 2 con una duración inferior a dos años o una duración acumulada inferior a ocho años a contar desde el inicio del nivel CINE 1).

138. En el Cuadro 4 se describen los códigos de clasificación de logro educativo asignados a los programas de nivel CINE 0 y 1 y a certificaciones otorgadas por programas de educación secundaria baja considerados insuficientes para conclusión, o conclusión parcial, del nivel CINE 2.

\section{Cuadro 4. Códigos de clasificación de logro educativo - Niveles CINE 0 y 1 (CINE-A)}

\begin{tabular}{|c|l|c|l|l|l|}
\hline \multicolumn{2}{|c|}{} & \multicolumn{3}{c|}{ Categoría } & \multicolumn{2}{c|}{ Subcategoría } \\
\hline \multirow{2}{*}{0} & $\begin{array}{l}\text { Menos que } \\
\text { educación primaria }\end{array}$ & 01 & $\begin{array}{l}\text { Nunca cursó un programa } \\
\text { educativo }\end{array}$ & 010 & Nunca cursó un programa educativo \\
\cline { 3 - 6 } & 02 & $\begin{array}{l}\text { Educación de la primera infancia } \\
\text { en forma parcial }\end{array}$ & 020 & Educación de la primera infancia en forma parcial \\
\cline { 3 - 6 } & 03 & $\begin{array}{l}\text { Educación primaria en forma } \\
\text { parcial (sin conclusión de nivel) }\end{array}$ & 030 & $\begin{array}{l}\text { Educación primaria en forma parcial (sin } \\
\text { conclusión de nivel) }\end{array}$ \\
\hline 1 & Educación primaria & 10 & Educación Primaria & 100 & $\begin{array}{l}\text { Incluye la conclusión exitosa de un programa de } \\
\text { secundaria baja considerado insuficiente para la } \\
\text { conclusión, o conclusión parcial, del nivel. }\end{array}$ \\
\hline
\end{tabular}




\section{NIVEL CINE 2 EDUCACIÓN SECUNDARIA BAJA}

\section{A. Características principales}

139. Los programas del nivel CINE 2, o educación secundaria baja, suelen estar destinados a reforzar los resultados de aprendizaje del nivel CINE 1. En general, el objetivo que se persigue es sentar las bases para el desarrollo humano y el aprendizaje a lo largo de la vida sobre las cuales los sistemas educativos puedan expandir oportunidades de educación adicionales. Es probable que algunos sistemas educativos ya ofrezcan programas vocacionales en el nivel CINE 2 orientados a proporcionar a las personas destrezas relevantes para el acceso al mercado laboral.

140. En este nivel, los programas suelen aplicar un modelo más orientado por asignaturas con el fin de introducir conceptos teóricos sobre una amplia gama de temas. El personal docente se caracteriza por haber recibido formación pedagógica en asignaturas específicas en tanto que - con mayor frecuencia que en el nivel CINE 1 - una clase puede tener varios profesores especializados en las asignaturas que enseñan.

141. El nivel CINE 2 se inicia tras cuatro a siete años de educación en el nivel CINE 1, siendo seis años la duración más común del nivel CINE 1. La edad típica de ingreso al nivel CINE 2 puede variar entre los 10 y 13 años, si bien la edad más común es de 12 años.

142. Los programas clasificados en el nivel CINE 2 pueden recibir distintas denominaciones, por ejemplo: escuela secundaria (primer ciclo/grados inferiores, de contar con un programa que abarque los niveles CINE 2 y 3), escuela media, junior secondary school, middle school o junior high school. Si un programa abarca los niveles CINE 1 y 2, se suelen utilizar los términos educación elemental o educación básica (segunda etapa/grados superiores). Para propósitos de comparación a nivel internacional, se usa el término "secundaria baja" para denominar al nivel CINE 2.

\section{B. Criterios de clasificación}

143. Para definir la educación secundaria baja, los siguientes criterios son pertinentes:

\section{Criterios principales}
a) Transición a una instrucción más orientada por asignaturas (véase el párrafo 144);
b) Requisitos de ingreso (véase el párrafo 145); y
c) Duración acumulada a partir del inicio del nivel CINE 1 (véase el párrafo 146).

\section{Criterios subsidiarios}
a) Edad típica de ingreso (véase el párrafo 141);
b) Instrucción a cargo de docentes de asignaturas y las certificaciones del docente (véase el párrafo 147); y
c) Relación con la educación obligatoria (véase el párrafo 148).

144. La línea divisoria entre los niveles CINE 1 y 2 coincide con el punto de transición en los sistemas educativos donde se privilegia la instrucción orientada por asignaturas. 
145. El ingreso a este nivel requiere la conclusión del nivel CINE 1 o la habilidad de manejar los contenidos del nivel CINE 2 a través de una combinación de estudios previos así como de experiencias prácticas y laborales. En determinados países, el ingreso a algunos o a todos los programas de nivel CINE 2 puede requerir la conclusión exitosa del nivel CINE 1 o un nivel específico de logros.

146. El nivel CINE 2 finaliza tras 8 a 11 años de educación a partir del inicio del nivel CINE 1 siendo 9 años la duración acumulada más observada. La edad de los alumnos al finalizar el nivel CINE 2 suele fluctuar entre los 14 y 16 años, siendo 15 años la edad más común.

147. Respecto del tipo de certificación que se exige a los docentes, pueden existir diferencias entre los niveles CINE 1 y 2 . En este último nivel, los profesores suelen estar cualificados en una o más asignaturas, así como en pedagogía. Adicionalmente, la organización de la instrucción puede ser diferente a la que es habitual en el nivel CINE 1, ya que normalmente se cuenta con varios profesores para una clase que enseñan en uno o en varios campos de especialización.

148. En muchos sistemas educativos que han adoptado la educación obligatoria, el fin de la educación secundaria baja coincide con el fin de la educación (general) obligatoria.

\section{Programas que abarcan más de un nivel CINE}

149. Los programas educativos que abarcan los niveles CINE 1 y 2 o niveles 2 y 3 requieren especial atención al momento de clasificarlos. Se deben clasificar en el nivel CINE 2 solo los grados, etapas o ciclos que reflejen los criterios descritos en el párrafo 143. Los grados, etapas o ciclos que respondan a los criterios presentados en el párrafo 124 se deben clasificar en el nivel CINE 1, en tanto que los que respondan a los criterios presentados en el párrafo 166 se deben clasificar en el nivel CINE 3.

150. Si la utilización de criterios de clasificación no proporcionara una clara línea divisoria entre los niveles CINE 1 y 2, se recomienda utilizar los criterios descritos en el párrafo 130 para determinar el final del nivel CINE 1 y el comienzo del nivel CINE 2.

151. Si la utilización de criterios de clasificación no proporcionara una clara línea divisoria entre los niveles CINE 2 y 3 , se recomienda lo siguiente:

i) en el caso de programas organizados en etapas que abarcan los niveles CINE 2 y 3 , se debe utilizar el final de la etapa más cercana a los nueve años de escolarización tras el inicio del nivel CINE 1 como punto de transición entre estos niveles; o

ii) respecto de programas que no están organizados en etapas, solo los grados comprendidos entre el final del nivel CINE 1 y el final de los nueve años de escolarización a partir del inicio del nivel CINE 1 deben clasificarse en el nivel CINE 2; los grados restantes se clasificarán en el nivel CINE 3 (véase el párrafo 171).

\section{Dimensiones complementarias}

152. Dos dimensiones permiten diferenciar los programa educativos del nivel CINE 2:

- Orientación de los programas (véase el párrafo 153);

- Conclusión del nivel y acceso a un nivel CINE más avanzado (véase el párrafo 154). 


\section{Orientación del programa}

153. En los párrafos 55 y 54 se definen dos categorías de orientación:

- General; y

- Vocacional.

\section{Conclusión del nivel y acceso a un nivel CINE más avanzado}

154. Respecto del nivel CINE 2, se han definido los siguientes cuatro niveles de conclusión y subcategorías de acceso.

i) Nivel CINE 2 inconcluso (por consiguiente, sin acceso directo a un nivel superior): programas terminales cortos (o secuencia de programas) de una duración inferior a dos años en el nivel CINE 2 o que finalizan después de menos de ocho años de educación acumulada a partir del comienzo del nivel CINE 1. Estos programas no dan acceso al nivel CINE 3. La conclusión exitosa de dichos programas no equivale a la conclusión del nivel CINE 2.

ii) Conclusión parcial del nivel CINE 2 sin acceso directo a un nivel CINE más avanzado: programas que representan al menos dos años en el nivel CINE 2, con una duración acumulada de al menos 8 años a partir del comienzo del nivel CINE 1 y que forman parte de una secuencia de programas en el nivel CINE 2, pero que no son el último programa de esta secuencia. Estos programas no dan acceso directo al nivel CINE 3. La conclusión exitosa de dichos programas se considera equivalente solamente a la conclusión parcial del nivel (ya que únicamente el programa final de la secuencia podría dar acceso al nivel CINE 3).

iii) Conclusión del nivel CINE 2 sin acceso directo a un nivel CINE más avanzado: programas de una duración mínima de dos años en el nivel CINE 2 y que finalizan después de al menos ocho años de duración acumulada a partir del comienzo del nivel CINE 1, pero no dan acceso al nivel CINE 3. Pese a ser considerados terminales, su conclusión exitosa equivale a la conclusión del nivel CINE 2.

iv) Conclusión del nivel CINE 2 con acceso directo a programas de un nivel CINE más avanzado: cualquier programa que otorgue acceso directo al nivel CINE 3 independientemente de la duración que pueda tener en este nivel o su duración acumulada desde el inicio del nivel CINE 1.

\section{E. Otros programas incluidos en el nivel CINE 2}

155. El nivel CINE 2 incluye programas de educación para personas con necesidades especiales destinados a reforzar los procesos básicos de enseñanza y aprendizaje iniciados en el nivel CINE 1 o a impartir destrezas pertinentes al empleo.

156. Adicionalmente, este nivel comprende programas de educación secundaria baja, de segunda oportunidad o de reintegración. Estos programas están generalmente destinados a personas que:

i) abandonaron la escuela después de finalizar la educación primaria, pero antes de finalizar educación secundaria baja (estos programas facilitan el reingreso al sistema educativo con el fin de completar un programa de este nivel), o

ii) finalizaron la educación secundaria baja, pero han optado por cursar un programa educativo o desempeñar un oficio para el cual no se encuentran lo suficientemente preparados.

Los participantes suelen ser mayores que el grupo de edad objetivo del nivel CINE 2. 
157. También se incluyen en este nivel los programas de educación de adultos con contenido educativo similar en complejidad al de programas previamente clasificados en el nivel CINE 2.

\section{F. Clasificación de los programas educativos de nivel CINE 2}

158. Las dos dimensiones complementarias que permiten la clasificación y elaboración de informes son: la orientación del programa (categorías) y la conclusión del nivel y el acceso a un nivel CINE más avanzado (subcategorías). En el Cuadro 5 se presentan los códigos para educación secundaria baja.

\section{Cuadro 5. Códigos de clasificación de programas educativos - Nivel CINE 2 (CINE-P)}

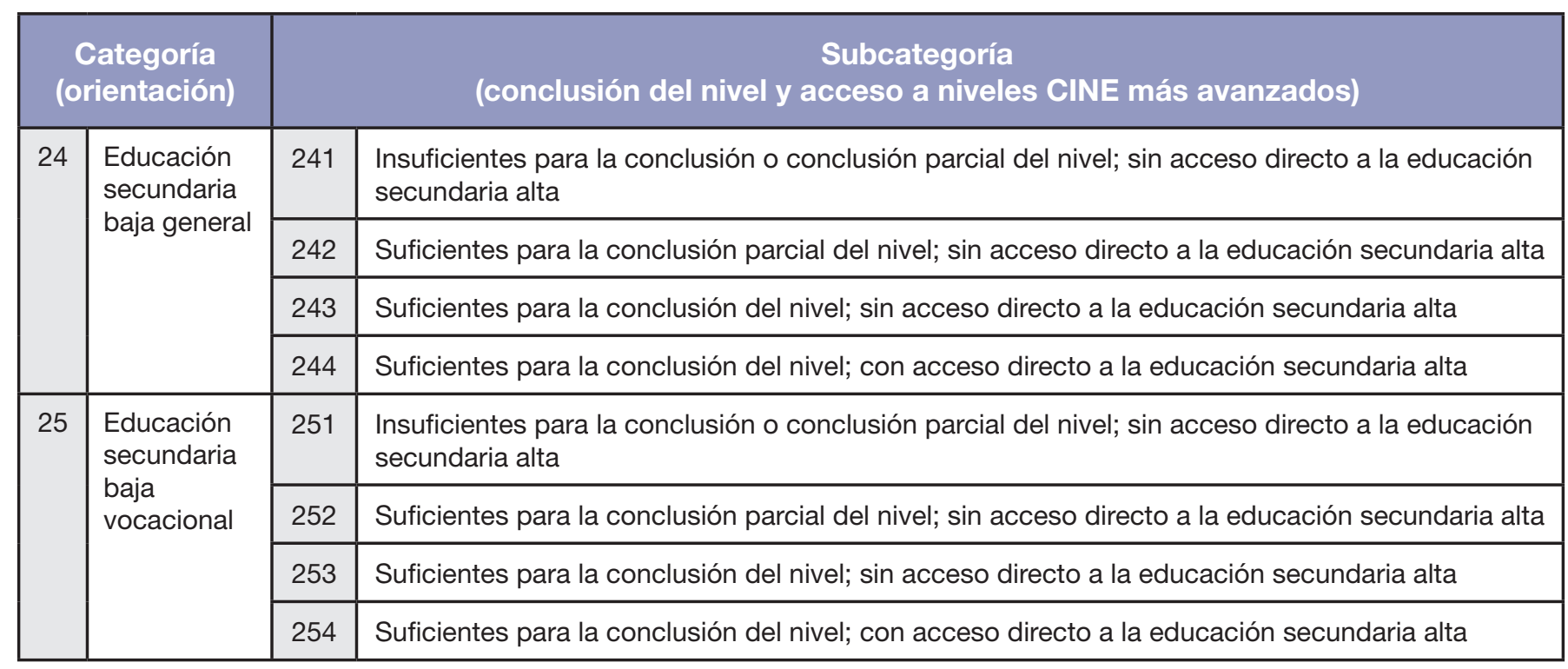

\section{G. Clasificación de logro educativo en el nivel CINE 2}

159. En términos de logro educativo, las certificaciones otorgadas por programas de nivel CINE 2 consideradas insuficientes para la conclusión o conclusión parcial de este nivel se clasifican en el nivel CINE 1 (véase el Cuadro 4).

160. En forma similar, las certificaciones otorgadas por programas de nivel CINE 3 consideradas insuficientes para la conclusión o conclusión parcial de este nivel se clasifican en el nivel CINE 2.

161. En el Cuadro 6 se presentan los códigos de clasificación asociados con el logro educativo en la educación secundaria baja y con las certificaciones de la educación secundaria alta considerados insuficientes para la conclusión o conclusión parcial de este nivel. 


\section{Cuadro 6. Códigos de clasificación de logro educativo - Nivel CINE 2 (CINE-A)}

\begin{tabular}{|c|l|c|l|}
\hline \multicolumn{2}{|c|}{$\begin{array}{c}\text { Categoría } \\
\text { (orientación) }\end{array}$} & \multicolumn{2}{c|}{$\begin{array}{c}\text { Subcategoría } \\
\text { (conclusión del nivel y acceso a niveles CINE más avanzados) }\end{array}$} \\
\hline \multirow{2}{*}{10} & Educación primaria & 100 & $\begin{array}{l}\text { Conclusión exitosa reconocida de un programa de educación secundaria baja } \\
\text { considerado insuficiente para la conclusión o conclusión parcial del nivel }\end{array}$ \\
\hline \multirow{2}{*}{24} & $\begin{array}{l}\text { Educación secundaria } \\
\text { baja general }\end{array}$ & 242 & Conclusión parcial de nivel; sin acceso directo a educación secundaria alta \\
\cline { 3 - 4 } & & 243 & Conclusión de nivel; sin acceso directo a educación secundaria alta \\
\cline { 3 - 4 } & $\begin{array}{l}\text { Educación secundaria } \\
\text { baja vocacional }\end{array}$ & 244 & Conclusión de nivel; con acceso directo a educación secundaria alta ${ }^{1}$ \\
\cline { 3 - 4 } & & 253 & Conclusión parcial de nivel; sin acceso directo a educación secundaria alta \\
\cline { 3 - 5 } & & 254 & Conclusión de nivel; con acceso directo a educación secundaria alta ${ }^{1}$ \\
\hline
\end{tabular}

1. Incluye la conclusión exitosa de un programa o de una etapa de un programa de educación secundaria alta considerado insuficiente para la conclusión, o conclusión parcial, del nivel. 


\section{NIVEL CINE 3 EDUCACIÓN SECUNDARIA ALTA}

\section{A. Características principales}

162. Los programas del nivel CINE 3, o educación secundaria alta, suelen tener como principal objetivo consolidar la educación secundaria como preparación a la educación terciaria, o bien proporcionar destrezas pertinentes al empleo o ambos.

163. Los programas de este nivel se caracterizan por impartir a los estudiantes un tipo de instrucción más diversificada, especializada y avanzada que los programas del nivel CINE 2. Asimismo, presentan un mayor grado de diferenciación y ofrecen un espectro más amplio de opciones y ramificaciones dentro del mismo nivel. Con frecuencia, los docentes han recibido una sólida formación en las asignaturas o campos de especialización que enseñan, particularmente en los grados superiores.

164. El nivel CINE 3 comienza después de 8 a 11 años de educación a partir del inicio del nivel CINE 1. La edad típica de ingreso de estos estudiantes fluctúa entre los 14 y 16 años. Los programas comprendidos en este nivel suelen tener una duración de doce o trece años a partir del inicio del nivel CINE 1 (es decir, cuando el estudiante tiene aproximadamente 17 o 18 años de edad), siendo 12 años la duración acumulada más común. Sin embargo, el egreso de la educación secundaria alta suele fluctuar entre 11 y 13 años a partir del inicio del nivel CINE 1.

165. Los programas clasificados en el nivel CINE 3 pueden recibir distintas denominaciones, por ejemplo: escuela secundaria (segunda etapa/grados superiores), senior secondary school o (senior) high school. Para propósitos de comparación a nivel internacional, se usa el término "secundaria alta" para denominar al nivel CINE 3.

\section{B. Criterios de clasificación}

166. Para definir la educación secundaria alta, los siguientes criterios son pertinentes:

\section{Criterios principales}

a) Segunda etapa o etapa final de la educación secundaria general y vocacional (véase el párrafo 167);

b) Requisitos de ingreso (véase el párrafo 168); y

c) Duración acumulada a partir del inicio del nivel CINE 1 (véase el párrafo 164).

\section{Criterio subsidiarios}

a) Programas más diferenciados, ofreciendo un espectro más amplio de opciones y ramificaciones (véase el párrafo 169); y

b) Certificaciones de los docentes (véase el párrafo 170).

167. Los programas correspondientes a la segunda etapa o la etapa final de la educación secundaria pueden ser programas generales o vocacionales del nivel CINE 3. Algunos de estos programas dan acceso directo al nivel CINE 4 y/o al nivel 5, 6 o 7. Al momento de identificar los puntos de transición entre los niveles CINE, es preciso comprobar si existe correspondencia entre las trayectorias generales y vocacionales. 
168. El ingreso a este nivel requiere la conclusión de la educación secundaria baja (nivel CINE 2) o la habilidad de manejar los contenidos del nivel CINE 3 a través de una combinación de estudios previos, así como de experiencias prácticas y laborales. El ingreso a algunos o a todos los programas de nivel CINE 3 puede requerir una certificación de nivel CINE 2 o bien un nivel específico de logros.

169. La transición del nivel CINE 2 al nivel CINE 3 coincide con el punto de transición en el sistema educativo en el cual los programas ofrecidos a los alumnos son más variados, especializados y avanzados y con una instrucción más profunda en asignaturas o campos específicos. Normalmente, estos programas presentan un mayor grado de diferenciación y ofrecen a los participantes un espectro más amplio de opciones y ramificaciones.

170. Las certificaciones que se exigen a los docentes en este nivel pueden ser distintas a las requeridas en el nivel CINE 2. Además de su formación pedagógica, los docentes suelen tener una mayor especialización en las materias que enseñan.

\section{Programas que abarcan más de un nivel CINE}

171. Los programas educativos que abarcan los niveles CINE 2 y 3 o los niveles 3 y 5 requieren especial atención al momento de clasificarlos. Se deben clasificar en el nivel CINE 3 solo los grados, etapas o ciclos que reflejen los criterios descritos en el párrafo 166. Los grados, etapas o ciclos que respondan a los criterios presentados en el párrafo 143 se deben clasificar en el nivel CINE 2, en tanto que los que respondan a los criterios presentados en el párrafo 211, se deben clasificar en el nivel CINE 5.

172. Si la utilización de criterios de clasificación no proporcionara una clara línea divisoria entre los niveles CINE 2 y 3, se recomienda utilizar los criterios descritos en el párrafo 151 para determinar el final del nivel CINE 2 y el comienzo del nivel CINE 3.

173. Si la duración teórica de un programa vocacional de nivel CINE 3 excede en dos o más años la duración teórica de un programa general de nivel CINE 3 del mismo sistema educativo, se debe considerar que dicho programa abarca educación secundaria alta (nivel CINE 3) y la educación postsecundaria no terciaria (nivel CINE 4) o la educación terciaria de ciclo corto (nivel CINE 5). Los grados, etapas o ciclos con una duración superior a la de los programas generales de nivel CINE 3 se deben clasificar en los niveles CINE 4 o 5 de acuerdo a la complejidad de sus contenidos.

\section{Dimensiones complementarias}

174. Dos dimensiones permiten diferenciar los programas educativos del nivel CINE 3:

- Orientación del programa (véase el párrafo 175); y

- Conclusión del nivel y acceso a niveles CINE más avanzados (véase el párrafo 176).

\section{Orientación del programa}

175. En los párrafos 55 y 54 se definen dos categorías de orientación:

- General; y

- Vocacional. 


\section{Conclusión del nivel y acceso a niveles CINE más avanzados}

176. Respecto del nivel CINE 3, se han definido cuatro niveles de conclusión y subcategorías de acceso:

i) Nivel CINE 3 inconcluso (por consiguiente, sin acceso directo a programas de primer título de educación terciaria de nivel CINE 5, 6 o 7): programas terminales cortos (o secuencia de programas) de una duración inferior a dos años en este nivel o que finalizan después de menos de once años de duración acumulada a partir del comienzo del nivel CINE 1. Estos programas no dan acceso directo a los niveles CINE 5, 6 o 7. La conclusión exitosa de dichos programas no equivale a la conclusión del nivel CINE 3. Cabe destacar que estos programas tampoco dan acceso directo al nivel CINE 4.

ii) Conclusión parcial del nivel CINE 3 sin acceso directo a programas de primer título de educación terciaria de nivel CINE 5, 6 o 7: programas que representan al menos dos años en el nivel CINE 3, con una duración acumulada de al menos 11 años a partir del nivel CINE 1 y que forman parte de una secuencia de programas de nivel CINE 3, pero que no son el último programa de la secuencia. Estos programas no dan acceso directo a los niveles CINE 5, 6 o 7. La conclusión exitosa de dichos programas solo se considera equivalente a la conclusión parcial del nivel (dado que solamente el programa final de la secuencia podría dar acceso a los niveles CINE 5, 6 o 7 de educación terciaria). Cabe señalar que estos programas tampoco dan acceso directo al nivel CINE 4.

iii) Conclusión del nivel CINE 3 sin acceso directo a programas de primer título de educación terciaria de nivel CINE 5, 6 o 7: programas de una duración mínima de dos años en el nivel CINE 3 y que finalizan después de al menos once años de educación acumulada a partir del comienzo del nivel CINE 1. Estos programas pueden ser terminales o dar acceso directo al nivel CINE 4. La conclusión exitosa de estos programas se considera equivalente a la conclusión del nivel CINE 3.

iv) Conclusión del nivel CINE 3 con acceso directo a programas de primer título de educación terciaria de nivel CINE 5, 6 o 7: cualquier programa que de acceso directo a dichos programas en el nivel CINE 5, 6 o 7, independientemente de su duración en el nivel CINE 3 o de su duración acumulada a partir del comienzo del nivel CINE 1. Estos programas también pueden dar acceso directo al nivel CINE 4.

\section{E. Otros programas incluidos en el nivel CINE 3}

177. Adicionalmente, el nivel CINE 3 incluye programas de educación para personas con necesidades especiales que son, en términos de complejidad del contenido, equivalentes a programas previamente clasificados en el nivel CINE 3.

178. Este nivel puede incluir algunos programas vocacionales de segundo ciclo en aquellos casos donde los puntos de transición al final del segundo ciclo corresponden a los puntos de transición entre los niveles de otras trayectorias (mayormente de orientación general) ofrecidas en el sistema.

179. Asimismo, este nivel incluye programas de educación secundaria alta de segunda oportunidad o de reintegración. Normalmente, estos programas están destinados a personas que:

i) abandonaron la escuela antes de finalizar la educación secundaria alta (estos programas facilitan el reingreso al sistema educativo con el fin de completar este nivel), o 
ii) han completado la educación secundaria alta pero han optado por cursar un programa o desempeñar un oficio para el cual no se encuentran lo suficientemente preparados.

Los participantes suelen ser mayores que el grupo de edad objetivo de la CINE 3.

180. También se incluyen en este nivel los programas de educación de adultos de un contenido similar en complejidad al de programas educativos clasificados en el nivel CINE 3.

\section{F. Clasificación de programas educativos de nivel CINE 3}

181. Las dos dimensiones complementarias que permiten la clasificación y elaboración de informes son: la orientación del programa (categorías) y la conclusión del nivel y el acceso a un nivel CINE más avanzado (subcategorías). Evidentemente no todas las combinaciones de orientación, conclusión y acceso son posibles ni de uso difundido en los sistemas educativos. El Cuadro 7 presenta los códigos correspondientes a educación secundaria.

\section{Cuadro 7. Códigos de clasificación de los programas educativos de nivel CINE 3 (CINE-P)}

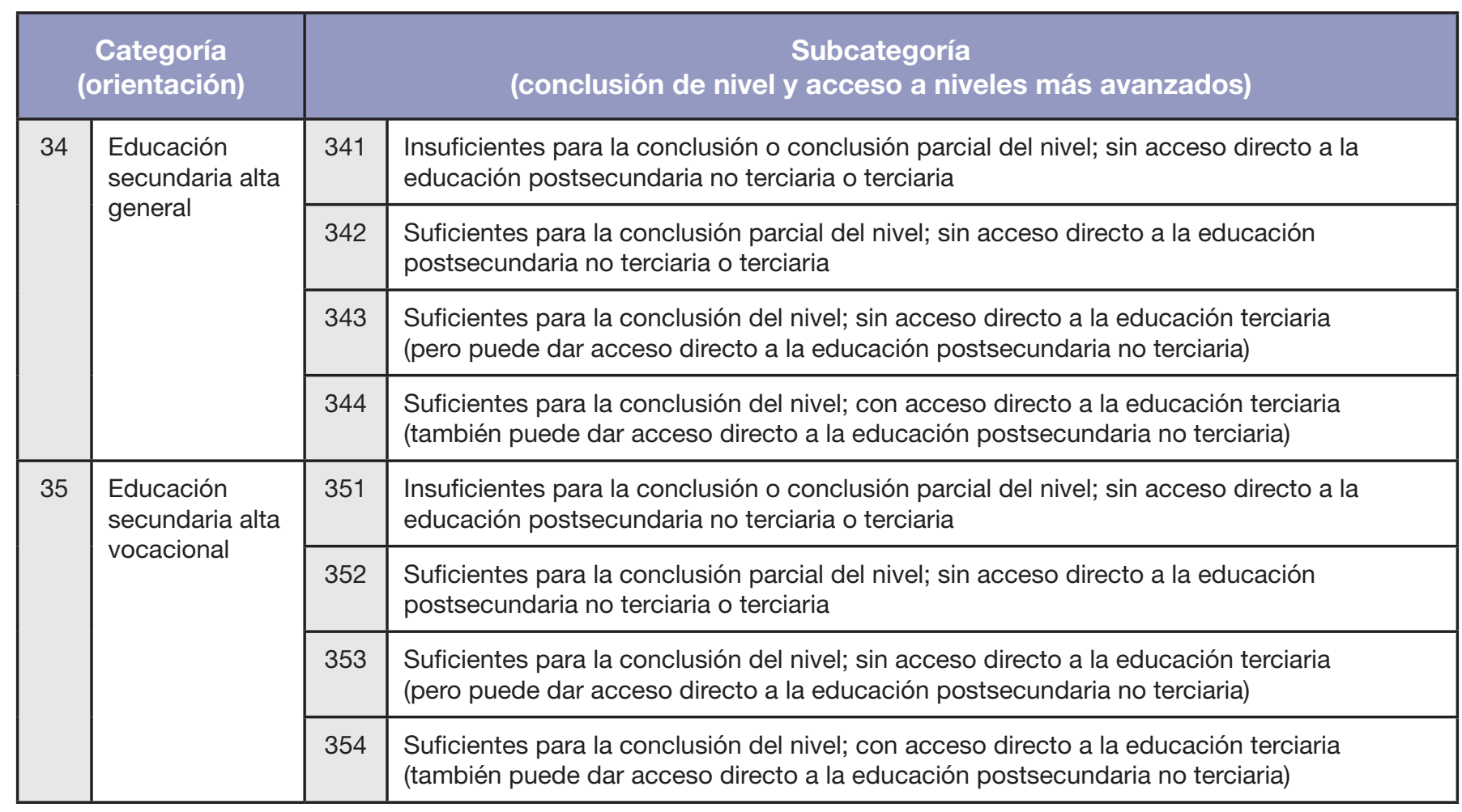

\section{G. Clasificación de logro educativo en el nivel CINE 3}

182. En términos de logro educativo, las certificaciones otorgadas por programas de nivel CINE 3 consideradas insuficientes para la conclusión de este nivel se clasifican en el nivel CINE 2.

183. En forma similar, las certificaciones otorgadas por programas de nivel CINE 4 consideradas insuficientes para la conclusión de este nivel se deben clasificar en el nivel CINE 3.

184. En el Cuadro 8 se presentan los códigos de clasificación de logro educativo asociados con programas y certificaciones de educación secundaria alta. 


\section{Cuadro 8. Códigos de clasificación de logro educativo en el nivel CINE 3 (CINE-A)}

\begin{tabular}{|c|c|c|c|}
\hline \multicolumn{2}{|r|}{$\begin{array}{l}\text { Categoría } \\
\text { (orientación) }\end{array}$} & \multicolumn{2}{|r|}{$\begin{array}{l}\text { Subcategoría } \\
\text { (conclusión de nivel y acceso a niveles más avanzados) }\end{array}$} \\
\hline 24 & $\begin{array}{l}\text { Educación secundaria } \\
\text { baja general }\end{array}$ & 244 & $\begin{array}{l}\text { Conclusión exitosa reconocida de un programa de educación secundaria alta } \\
\text { (general) considerado insuficiente para la conclusión o conclusión parcial del nivel }\end{array}$ \\
\hline 25 & $\begin{array}{l}\text { Educación secundaria } \\
\text { baja vocacional }\end{array}$ & 254 & $\begin{array}{l}\text { Conclusión exitosa reconocida de un programa de educación secundaria alta } \\
\text { (vocacional) considerado insuficiente para conclusión o conclusión parcial del nivel }\end{array}$ \\
\hline \multirow[t]{3}{*}{34} & \multirow[t]{3}{*}{$\begin{array}{l}\text { Educación secundaria } \\
\text { alta general }\end{array}$} & 342 & $\begin{array}{l}\text { Conclusión parcial del nivel, sin acceso directo a la educación postsecundaria no } \\
\text { terciaria o terciaria }\end{array}$ \\
\hline & & 343 & $\begin{array}{l}\text { Conclusión del nivel, sin acceso directo a la educación terciaria } \\
\text { (pero puede dar acceso directo a la educación postsecundaria no terciaria) }\end{array}$ \\
\hline & & 344 & $\begin{array}{l}\text { Conclusión del nivel, con acceso directo a la educación terciaria }{ }^{1} \\
\text { (también puede dar acceso directo a la educación postsecundaria no terciaria) }\end{array}$ \\
\hline \multirow[t]{3}{*}{35} & \multirow[t]{3}{*}{$\begin{array}{l}\text { Educación secundaria } \\
\text { alta vocacional }\end{array}$} & 352 & $\begin{array}{l}\text { Conclusión parcial del nivel, sin acceso directo a la educación postsecundaria no } \\
\text { terciaria o terciaria }\end{array}$ \\
\hline & & 353 & $\begin{array}{l}\text { Conclusión del nivel, sin acceso directo a la educación terciaria } \\
\text { (pero puede dar acceso directo a la educación postsecundaria no terciaria) }\end{array}$ \\
\hline & & 354 & $\begin{array}{l}\text { Conclusión del nivel con acceso directo a la educación terciaria }{ }^{1} \\
\text { (también puede dar acceso directo a la educación postsecundaria no terciaria) }\end{array}$ \\
\hline
\end{tabular}




\section{NIVEL CINE 4 EDUCACIÓN POSTSECUNDARIA NO TERCIARIA}

\section{A. Características principales}

185. La educación postsecundaria no terciaria refuerza los conocimientos adquiridos en educación secundaria, prepara para el mercado laboral y para la educación terciaria. Las destrezas, competencias y conocimientos impartidos en este nivel se encuentran debajo del nivel de complejidad que caracteriza a la educación terciaria. Los programas de nivel CINE 4, o educación postsecundaria no terciaria están generalmente diseñados para proporcionar a las personas que han concluido el nivel CINE 3 las certificaciones no terciarias requeridas para avanzar a la educación terciaria, o bien para insertarse en el mercado laboral en el caso que sus certificaciones de nivel CINE 3 no otorgaran acceso a este nivel. Por ejemplo, los graduados de programas generales de nivel CINE 3 pueden optar por una certificación vocacional no terciaria. Por su parte, los graduados de programas vocacionales de nivel CINE 3 pueden optar por mejorar su nivel de certificación o perfeccionar su especialización. El contenido de los programas de nivel CINE 4 no es lo suficientemente complejo para ser considerado como educación terciaria; sin embargo, claramente forma parte de la educación postsecundaria.

186. El ingreso a programas de nivel CINE 4 requiere la conclusión de un programa de nivel CINE 3. Sin embargo, estos requisitos de ingreso pueden ser menores que los exigidos para ingresar a programas terciarios de los niveles CINE 5, 6 o 7.

187. Generalmente, los programas de este nivel están destinados a proporcionar acceso directo al mercado laboral. Algunos sistemas educativos ofrecen programas generales de este nivel que normalmente están dirigidos a estudiantes que han concluido el nivel CINE 3, pero que desean mejorar sus posibilidades de ingreso a la educación terciaria.

188. Los programas clasificados en el nivel CINE 4 pueden recibir distintas denominaciones, por ejemplo: diploma técnico, préparation aux carriéres administratives y primary professional education. Para propósitos de comparación a nivel internacional, se usa el término "postsecundaria no terciaria" para denominar al nivel CINE 4.

\section{B. Criterios de clasificación}

189. Para definir la educación postsecundaria no terciaria, los siguientes criterios son pertinentes:

\section{Criterios principales}

a) Orientación (véase el párrafo 190);

b) Complejidad del contenido superior a la del nivel CINE 3 e inferior a la del nivel de educación terciaria (véase el párrafo 191); y

c) Requisitos de ingresos (véase el párrafo 186).

\section{Criterios subsidiarios}

Ninguno.

190. Los programas de nivel CINE 4 no forman parte de la educación terciaria, siendo más bien programas vocacionales y terminales que preparan para el mercado laboral. Algunos sistemas educativos ofrecen programas generales de este nivel. Los programas destinados a actualizar los 
contenidos de programas de nivel CINE 3 - por ejemplo, con el fin de preparar a los estudiantes para rendir exámenes de ingreso a la educación terciaria - se deben incluir en el nivel CINE 3.

191. Con frecuencia, los programas de nivel CINE 4, se caracterizan por ampliar - en lugar de profundizar - conocimientos, destrezas y competencias de las personas que han finalizado un programa de nivel CINE 3. Si bien estos programas no suelen ser mucho más avanzados que los programas de nivel CINE 3, su contenido se caracteriza por ser más especializado o detallado que los impartidos a nivel de educación secundaria alta. Claramente, estos programas son menos avanzados que los impartidos a nivel terciario en tanto que pueden impartirse en diversos entornos institucionales y, por lo tanto, no solamente en aquellas instituciones consideradas exclusivamente de educación postsecundaria no terciaria.

\section{Programas que abarcan más de un nivel CINE}

192. No se aplica.

\section{Dimensiones complementarias}

193. Dos dimensiones permiten diferenciar los programa educativos del nivel CINE 4:

- Orientación del programa (véase el párrafo 194); y

- Conclusión del nivel y acceso a un nivel CINE más avanzado (véase el párrafo 195).

\section{Orientación del programa}

194. En los párrafos 55 y 54 se definen dos categorías de orientación:

- General; y

- Vocacional.

\section{Conclusión del nivel y acceso a niveles CINE más avanzados}

195. Respecto del nivel CINE 4 se han definido tres niveles de conclusión y subcategorías de acceso:

- Nivel CINE 4 inconcluso: módulos o etapas de programas considerados demasiado cortos para conclusión del nivel. Estos no dan acceso a programas de primer título de educación terciaria de niveles CINE 5, 6 o 7. La conclusión exitosa de dichos módulos o etapas no equivale a la conclusión del nivel CINE 4.

- Conclusión del nivel CINE 4 sin acceso directo a programas de primer título de educación terciaria de niveles CINE 5, 6 o 7 (programas esencialmente destinados a preparar al estudiante para el mercado laboral).

- Conclusión del nivel CINE 4 con acceso directo a programas de primer título de educación terciaria de nivel CINE 5, 6 o 7: programas destinados principalmente a ampliar el acceso a la educación terciaria.

\section{E. Otros programas incluidos en el nivel CINE 4}

196. Este nivel incluye programas de educación de adultos con contenidos de similar complejidad a los de programas previamente clasificados en este nivel. 


\section{F. Clasificación de programas educativos de nivel CINE 4}

197. Las dos dimensiones complementarias que permiten la clasificación y elaboración de informes son: la orientación del programa (categorías) y la conclusión del nivel y el acceso a un nivel CINE más avanzado (subcategorías). No todas las combinaciones de categorías y subcategorías son posibles ni de uso difundido en los sistemas educativos. En el Cuadro 9, se muestra la clasificación de la educación postsecundaria no terciaria.

\section{Cuadro 9. Códigos de clasificación de los programas educativos de nivel CINE 4 (CINE-P)}

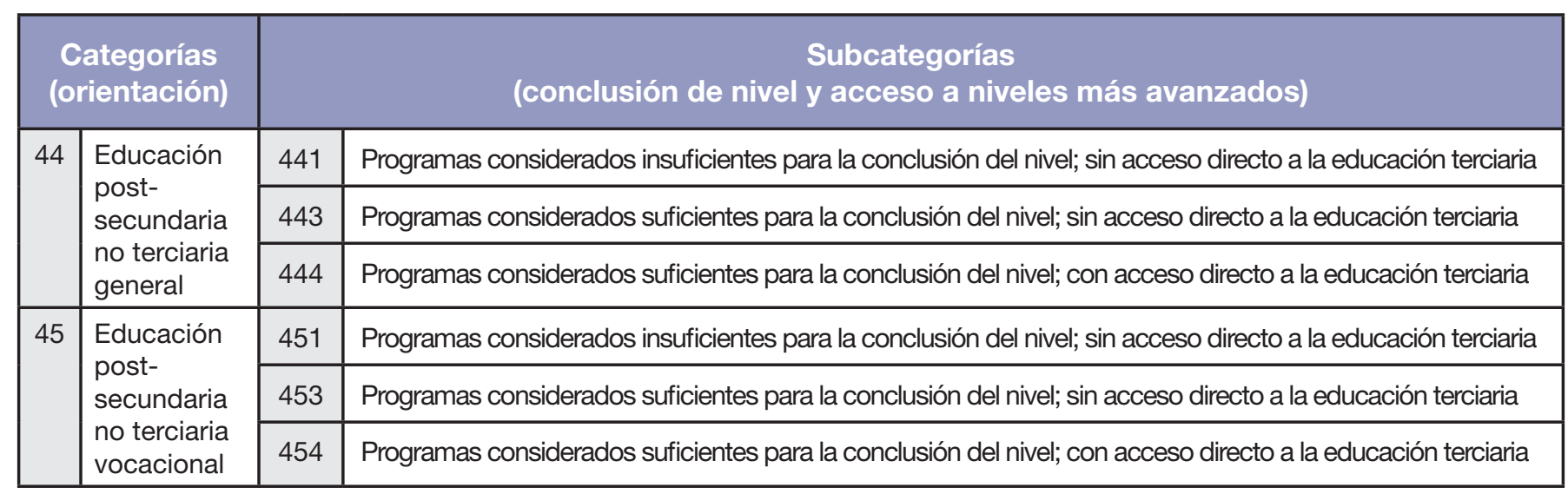

\section{G. Clasificación de logro educativo en el nivel CINE 4}

198. En términos de logro educativo, las certificaciones intermedias otorgadas por la conclusión de una etapa de un programa de nivel CINE 5 que no se consideran suficientes para la conclusión de la educación terciaria se clasifican en el nivel CINE 4.

199. En el Cuadro 10 se presentan los códigos de clasificación de logro educativo relacionados con las certificaciones de educación postsecundaria no terciaria.

\section{Cuadro 10. Códigos de clasificación de logro educativo en el nivel CINE 4 (CINE-A)}

\begin{tabular}{|c|l|c|l|}
\hline \multicolumn{2}{|c|}{$\begin{array}{c}\text { Categorias } \\
\text { (orientación) }\end{array}$} & \multicolumn{2}{c|}{$\begin{array}{c}\text { Subcategorias } \\
\text { (conclusión de nivel y acceso a niveles más avanzados) }\end{array}$} \\
\hline 34 & $\begin{array}{l}\text { Educación secundaria } \\
\text { alta general }\end{array}$ & 344 & $\begin{array}{l}\text { Conclusión exitosa reconocida de una etapa de un programa general de educación } \\
\text { postsecundaria no terciaria considerado insuficiente para la conclusión del nivel }\end{array}$ \\
\hline 35 & $\begin{array}{l}\text { Educación secundaria } \\
\text { alta vocacional }\end{array}$ & 354 & $\begin{array}{l}\text { Conclusión exitosa reconocida de una etapa de un programa vocacional de educación } \\
\text { postsecundaria no terciaria considerado insuficiente para la conclusión del nivel }\end{array}$ \\
\hline 44 & $\begin{array}{l}\text { Educación } \\
\text { Postsecundaria no } \\
\text { terciaria general }\end{array}$ & 443 & Conclusión de nivel; sin acceso directo a la educación terciaria \\
\cline { 2 - 4 } 45 & $\begin{array}{l}\text { Educación } \\
\text { postsecundaria no } \\
\text { terciaria vocacional }\end{array}$ & 453 & Conclusión de nivel; con acceso directo a la educación terciaria1 \\
\cline { 2 - 4 } & 454 & \multicolumn{2}{|c|}{\begin{tabular}{l} 
Conclusión de nivel; con acceso directo a la educación terciaria ${ }^{1}$ \\
\hline \multirow{2}{*}{ 1. Incluye la conclusión exitosa reconocida de un programa o una etapa de un programa de educación terciaria de ciclo corto considerado } \\
insuficiente para la conclusión del nivel.
\end{tabular}} \\
\hline
\end{tabular}




\section{EDUCACIÓN TERCIARIA}

200. La educación terciaria se basa o parte de los conocimientos adquiridos en la educación secundaria, proporcionando actividades de aprendizaje en campos especializados de estudio. Está destinada a impartir aprendizaje a un alto nivel de complejidad y especialización. La educación terciaria comprende lo que se conoce como "educación académica", pero también incluye la educación profesional o vocacional avanzada. Consta de los niveles CINE 5, 6, 7 y 8, denominados educación terciaria de ciclo corto, grado en educación terciaria o equivalente, nivel de maestría, especialización o equivalente y nivel de doctorado o equivalente, respectivamente. El contenido de los programas de este nivel es más complejo y avanzado que los programas de niveles inferiores.

201. Los programas de primer título de nivel CINE 5, 6 o 7 requieren la conclusión exitosa de programas de nivel CINE 3 que den acceso directo a programas de primer título de educación terciaria. A su vez, este acceso también es posible desde el nivel CINE 4. Además de los requisitos de certificación, el ingreso a programas impartidos en estos niveles puede depender de la selección de materias de estudio y/o las calificaciones obtenidas en los niveles CINE 3 o 4. Asimismo, podría ser necesario aprobar un examen de admisión.

202. Los programas de educación terciaria siempre se clasifican en el mismo nivel que el nivel de certificación que otorga su culminación exitosa (excepto si un programa ha sido clasificado parcialmente en el nivel CINE 3 - véase el párrafo 173). Por lo tanto, en contraste con los niveles CINE 0, 1, 2, 3 y 4, el concepto de programas que abarcan más de un nivel no se aplica a la educación terciaria.

203. Generalmente, se aprecia una clara jerarquía entre las certificaciones otorgadas por los programas de educación terciaria. Sin embargo, a diferencia de los programas que corresponden a los niveles CINE 1, 2, 3 y 4, los programas nacionales de nivel CINE 5, 6 y 7 pueden existir en forma paralela, en lugar que un nivel siga en forma secuencial a otro. La conclusión de un programa de nivel CINE 3 o 4 puede dar acceso a una gama de programas de primer título de educación terciaria ofrecidos en los niveles CINE 5, 6 o 7, de acuerdo a la disponibilidad de programas de cada sistema educativo y/o requisitos adicionales de ingreso. Estos programas se enumeran a continuación:

- programas de educación terciaria de ciclo corto de nivel CINE 5 (duración mínima de 2 años);

- programas de primer título del grado en educación terciaria o equivalente de nivel CINE 6 (de 3 a 4 años de duración);

- programas largos de primer título del grado en educación terciaria o equivalente de nivel CINE 6 (más de 4 años de duración); o

- programas largos de primer título de nivel de maestría, especialización o equivalente de nivel CINE 7 (duración mínima de 5 años).

204. En términos de educación terciaria, la transición entre programas no siempre es clara y podría darse la posibilidad de combinar programas y transferir créditos de un programa a otro. En ciertos casos, los créditos otorgados por programas previamente cursados se pueden transferir a un programa de nivel CINE superior. Por ejemplo, los créditos obtenidos en un programa de nivel CINE 5 pueden reducir el número de créditos o el tiempo de estudio requerido para finalizar un programa de nivel CINE 6. Algunos sistemas educativos permiten que el estudiante se traslade 
- cambie a un programa de nivel CINE 6 después de la conclusión de un programa de nivel CINE 5, hecho que puede reducir el tiempo que este requeriría para finalizar dicho programa. Otros estudiantes pueden ingresar directamente a un programa de nivel CINE 6 o 7 desde el nivel CINE 3. En muchos sistemas educativos, la mayoría de los estudiantes deben finalizar el nivel CINE 6 antes de ingresar al nivel CINE 7.

205. El ingreso al nivel CINE 8 normalmente requiere la conclusión exitosa del nivel CINE 7.

206. El Gráfico 1 ilustra las categorías de programas de educación terciaria y las trayectorias entre ellos.

\section{Gráfico 1. Trayectorias de educación terciaria de acuerdo a la CINE}
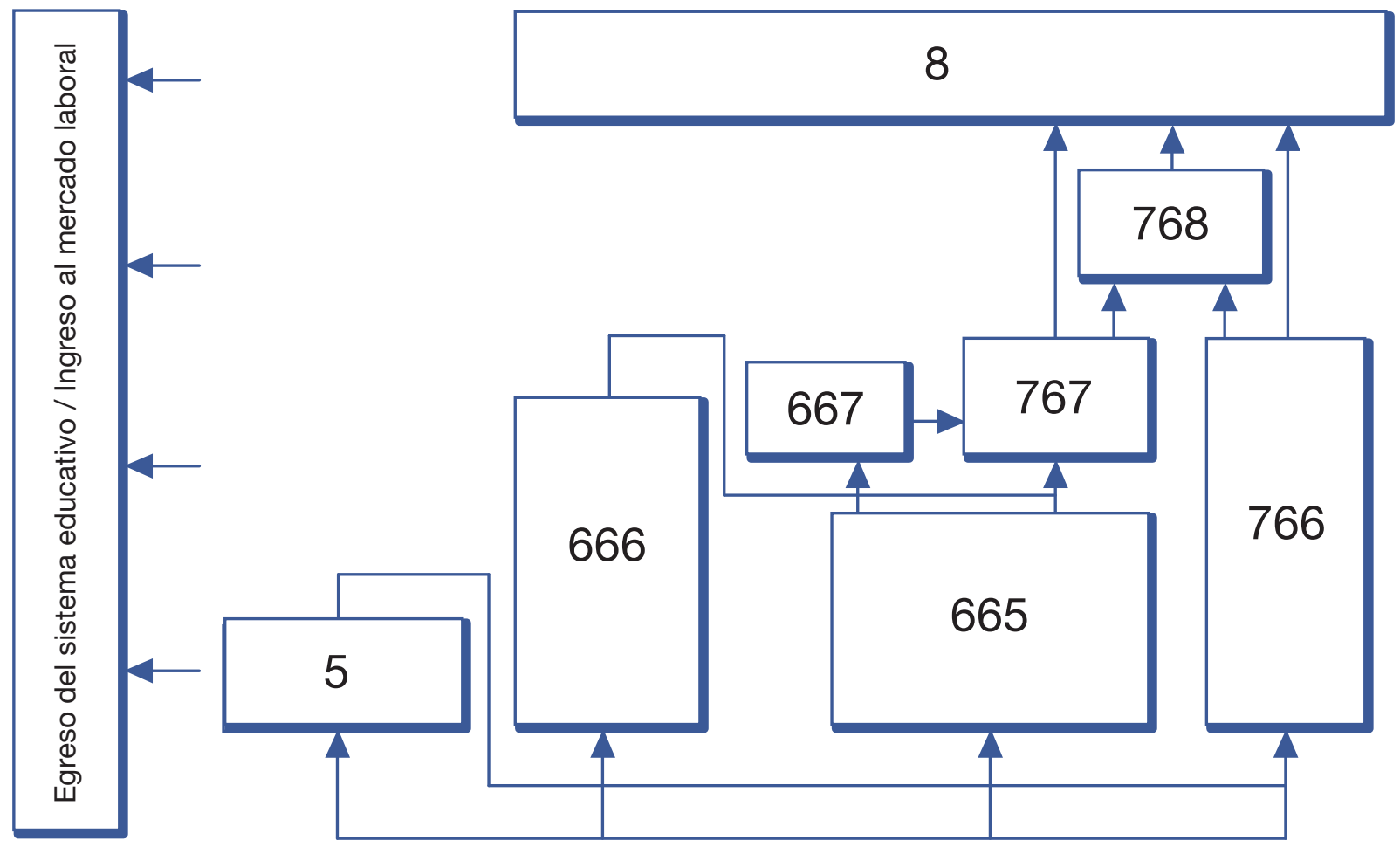

Conclusión del nivel CINE 3 o 4 con acceso directo a programas de primer título de educación terciaria de nivel CINE 5, 6 o 7 


\section{NIVEL CINE 5 EDUCACIÓN TERCIARIA DE CICLO CORTO}

\section{A. Características principales}

207. Los programas de nivel CINE 5, o educación terciaria de ciclo corto, suelen estar destinados a impartir al participante conocimientos, habilidades y competencias profesionales. Estos programas se caracterizan por estar basados en un componente práctico, estar orientados a ocupaciones específicas y preparar al estudiante para el mercado laboral. Sin embargo, también pueden facilitar el ingreso a otros programas de educación terciaria. Los programas académicos de un nivel inferior al grado en educación terciaria o nivel equivalente también se clasifican en el nivel CINE 5.

208. El ingreso a programas de nivel CINE 5 requiere la conclusión exitosa de programas de nivel CINE 3 o 4 que den acceso a la educación terciaria. En este nivel CINE, los programas suelen tener un contenido más complejo que el de los niveles CINE 3 y 4, si bien son más cortos y generalmente menos teóricos que los programas de nivel CINE 6.

209. A pesar de que los programas de nivel CINE 5 están destinados principalmente a preparar para el empleo, también pueden otorgar créditos transferibles a programas de nivel CINE 6 o 7 . En algunos sistemas educativos, el estudiante puede continuar su educación en programas de nivel CINE 6 (grado en educación terciaria o nivel equivalente) o en programas largos de primer título de nivel CINE 7 (nivel de maestría, especialización o equivalente) tras la conclusión exitosa de programas de nivel CINE 5.

210. Los programas clasificados en el nivel CINE 5 pueden recibir distintas denominaciones, por ejemplo: educación técnica (superior), (higher)technical education, junior college education, technician o advanced/higher vocational training, associate degree o bac +2 . Para propósitos de comparación a nivel internacional, se usa el término "terciaria de ciclo corto" para denominar al nivel CINE 5.

\section{B. Criterios de clasificación}

211. Para definir la educación terciaria de ciclo corto, los siguientes criterios son pertinentes:

\section{Criterios principales}

a) Contenido de los programas de educación terciaria de ciclo corto (véase el párrafo 212);

b) Requisitos de ingreso (véase el párrafo 208); y

c) Duración mínima del nivel (véase el párrafo 213).

\section{Criterios subsidiarios}
a) Punto de transición entre instituciones (véase el párrafo 214); y
b) Duración típica del nivel (véase el párrafo 213).

212. El nivel CINE 5 comprende o capta el nivel más bajo de la educación terciaria. En este nivel, el contenido de los programas es más complejo que el de los programas de educación secundaria (nivel CINE 3) o postsecundaria no terciaria (nivel CINE 4), pero menos complejo que el de los programas de nivel CINE 6 (grado en educación terciaria o nivel equivalente).

213. El nivel CINE 5 tiene una duración mínima de dos años y suele tener (aunque no siempre) una duración inferior a tres años. En el caso de los sistemas educativos que tienen programas con organización modular donde las certificaciones se otorgan en base a la acumulación de créditos, se requerirá un período comparable de tiempo y similar grado de intensidad. 
214. El punto de transición entre instituciones educativas no terciarias y terciarias puede ayudar a identificar la línea divisoria entre la educación secundaria alta (nivel CINE 3), la educación postsecundaria no terciaria (nivel CINE 4) y la educación terciaria. Con frecuencia, los programas de nivel CINE 5 se imparten en instituciones educativas distintas a las instituciones que ofrecen programas de nivel CINE 6, 7 y 8.

\section{Programas que abarcan más de un nivel CINE}

215. Los programas educativos que abarcan los niveles CINE 3 y 5 requieren especial atención para su clasificación. Solo los grados (años), etapas o ciclos que reflejen los criterios descritos en el párrafo 211 se deben clasificar en el nivel CINE 5. Los grados, etapas o ciclos que cumplan con los criterios presentados en el párrafo 166 se deben clasificar en el nivel CINE 3. Si la utilización de los criterios de clasificación no proporcionara una clara línea divisoria entre los niveles CINE 3 y 5 , se recomienda utilizar los criterios descritos en el párrafo 173 para determinar el final del nivel CINE 3 y el comienzo del nivel CINE 5.

\section{Dimensiones complementarias}

216. Dos dimensiones permiten diferenciar los programas educativos del nivel CINE 5:

- Orientación del programa (véase el párrafo 217); y

- Conclusión del nivel (véase el párrafo 218).

\section{Orientación del programa}

217. En los párrafos 55 y 54 se definen dos categorías de orientación:

- General; y

- Vocacional.

Una vez que se cuente con definiciones de programas académicos y profesionales, estas serán utilizadas como las categorías de orientación en el nivel CINE 5 reemplazando así a las categorías de general y vocacional.

\section{Conclusión de nivel}

218. Para el nivel CINE 5, se han definido dos categorías de conclusión de nivel:

- Nivel CINE 5 inconcluso: etapas (o programas) de nivel 5 de menos de dos años de duración, por lo tanto, considerados insuficientes para la conclusión de este nivel;

- Conclusión del nivel CINE 5: programas de nivel 5 de dos o más años de duración, es decir, considerados suficientes para la conclusión de este nivel.

\section{E. Otros programas incluidos en el nivel CINE 5}

219. Este nivel también incluye programas de educación continua o educación de adultos con contenidos de similar complejidad a los de programas previamente clasificados en este nivel.

\section{F. Clasificación de programas educativos de nivel CINE 5}

220. Las dos dimensiones complementarias que permiten la clasificación y elaboración de informes son: la orientación del programa (categorías) y la conclusión del nivel (subcategorías). El

Cuadro 11 presenta los códigos de clasificación que deben utilizarse en el nivel CINE 5. 


\section{Cuadro 11. Códigos de clasificación de los programas educativos de nivel CINE 5 (CINE-P)}

\begin{tabular}{|c|l|c|l|}
\hline \multicolumn{2}{|c|}{ Categorias (orientación) } & \multicolumn{2}{c|}{ Subcategorías (conclusión del nivel) } \\
\hline 54 & $\begin{array}{l}\text { Educación terciaria de } \\
\text { ciclo corto general }{ }^{1}\end{array}$ & 541 & Insuficientes para la conclusión del nivel \\
\cline { 3 - 4 } & 544 & Suficientes para la conclusión del nivel \\
\hline 55 & $\begin{array}{l}\text { Educación terciaria de } \\
\text { ciclo corto vocacional }\end{array}$ & 551 & Insuficientes para la conclusión del nivel \\
\cline { 2 - 4 } & 554 & Suficientes para la conclusión del nivel \\
\hline $\begin{array}{l}\text { 1. A utilizarse en el nivel CINE } 5 \text { dado que no se cuenta con una definición internacionalmente consensuada de las orientaciones académicas y } \\
\text { profesionales a nivel terciario. }\end{array}$
\end{tabular}

\section{G. Clasificación de logro educativo en el nivel CINE 5}

221. En términos de logro educativo, las certificaciones intermedias otorgadas tras la conclusión de una etapa (o programa) de nivel CINE 5 considerados insuficientes para concluir este nivel se clasifican en el nivel CINE 4. Por otra parte, el solo hecho de participar en un programa de nivel CINE 5 sin haberlo concluido exitosamente no se tendrá en cuenta al momento de determinar el nivel de logro educativo del estudiante.

222. Asimismo, las certificaciones intermedias otorgadas tras la conclusión exitosa de una etapa de un programa de nivel CINE 6 (anterior a un primer título) que a su vez son consideradas insuficientes para la conclusión de este nivel se clasifican en el nivel CINE 5 para los efectos de logro educativo.

223. En el Cuadro 12 se presentan los códigos de clasificación asociados con el logro educativo en programas de nivel CINE 5.

\section{Cuadro 12. Códigos de clasificación de logro educativo - Nivel CINE 5 (CINE-A)}

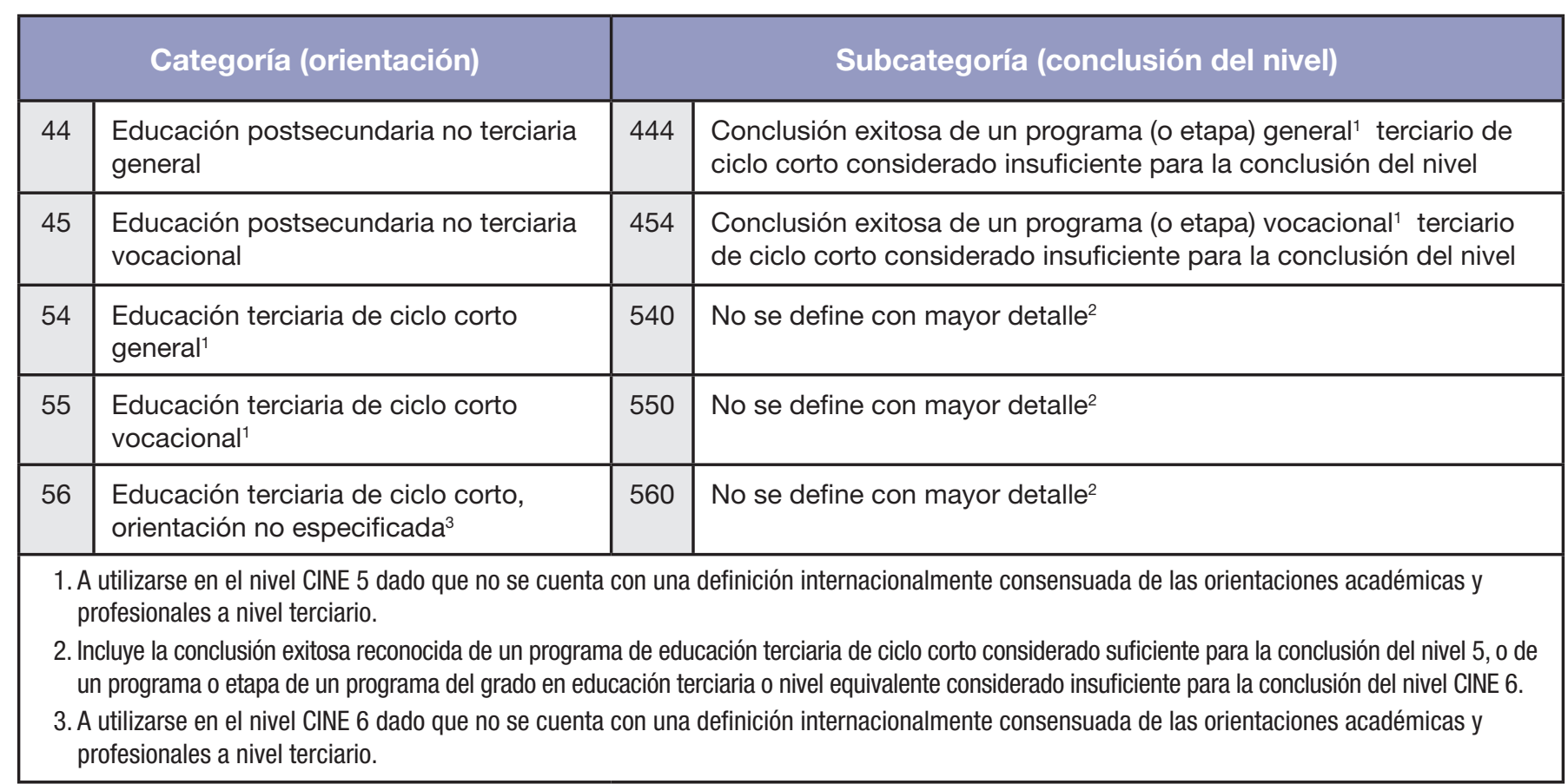




\section{NIVEL CINE 6 GRADO EN EDUCACIÓN TERCIARIA O NIVEL EQUIVALENTE}

\section{A. Características principales}

224. Con frecuencia, los programas de nivel CINE 6, o grado en educación terciaria o nivel equivalente, están destinados a impartir conocimientos, destrezas y competencias académicas o profesionales intermedias (nivel medio de complejidad o intensidad de los contenidos académicos) que conducen a un primer título o a una certificación equivalente. Los programas de este nivel son esencialmente teóricos, si bien pueden incluir un componente práctico, y están basados en investigación que refleja los últimos avances en el campo o las mejores prácticas profesionales. Tradicionalmente, los programas de este nivel son ofrecidos por universidades y otras instituciones de educación superior.

225. En este nivel, la instrucción suele ser impartida bajo la modalidad de exposiciones orales por un personal docente que normalmente ha concluido un programa de nivel CINE $7 \mathrm{u} 8$ o ha adquirido vasta experiencia profesional. Los programas de este nivel no requieren necesariamente desarrollar una tesis o proyecto de investigación, aunque de darse el caso esta no sería tan avanzada como una del nivel CINE 7 u 8, y el estudiante recibiría más orientación o tendría un menor grado de independencia que aquellos en programas de nivel CINE 7 u 8.

226. Habitualmente, el ingreso a estos programas requiere la conclusión exitosa de un programa de nivel CINE 3 o 4 que otorgue acceso a la educación terciaria. El ingreso puede depender de la selección de materias de estudio y/o las calificaciones obtenidas en los niveles CINE 3 y/o 4. Asimismo, podría ser necesario aprobar un examen de admisión. En ocasiones es factible ingresar o realizar una transferencia de créditos a un programa de nivel CINE 6 tras la conclusión exitosa del nivel CINE 5. Una vez cursados los programas de nivel CINE 6, el estudiante puede continuar su educación en el nivel CINE 7 (nivel de maestría, especialización o equivalente), si bien no todos los programas de nivel CINE 6 dan acceso al nivel CINE 7. Normalmente, los programas de nivel CINE 6 no dan acceso directo al nivel CINE 8 (nivel de doctorado o equivalente).

227. Los programas clasificados en el nivel CINE 6 pueden recibir distintas denominaciones, por ejemplo: Bachelor, licence o primer ciclo universitario. Cabe destacar, sin embargo, que los programas con nombres similares a "licenciatura" deben incluirse en el nivel CINE 6 solo si cumplen los criterios reseñados en el párrafo 228. Para propósitos de comparación a nivel internacional, se usa el término "grado en educación terciaria o nivel equivalente" para denominar al nivel CINE 6.

\section{B. Criterios de clasificación}

228. Para definir el grado en educación terciaria o nivel equivalente, los siguientes criterios son pertinentes:

\section{Criterios principales}

a) Contenido esencialmente teórico y/o profesional (véase el párrafo 224);

b) Requisitos de ingreso (véase el párrafo 226);

c) Duración acumulada mínima del programa (primer título) (véase el párrafo 229); y

d) Posición en la estructura nacional de títulos y certificaciones (véase el párrafo 230). 


\section{Criterios subsidiarios}

a) Certificaciones del personal docente (véase el párrafo 231); y

b) No da acceso directo a programas de nivel CINE 8 (véase el párrafo 226).

229. Normalmente, los programas de primer título del nivel CINE 6 requieren de tres a cuatro años de estudio a tiempo completo. En el caso de los sistemas educativos que otorgan títulos en base a la acumulación de créditos, se requerirá un período comparable de duración y similar grado de intensidad.

230. Usualmente, los programas de este nivel conducen a un primer título académico y a certificaciones equivalentes de educación terciaria (aunque la persona puede haber obtenido una certificación de nivel CINE 5 con anterioridad a la matrícula en un programa de nivel CINE 6). Pueden incluir un componente práctico y/o requerir, además de estudios teóricos, un período de experiencia laboral. En este nivel se deben incluir programas (largos) de primer título de más de 4 años de duración siempre que la complejidad de sus contenidos sea equivalente a programas del grado en educación terciaria. Asimismo, los programas que conduzcan a un segundo o siguiente título pueden incluirse en el nivel CINE 6 siempre que la complejidad de sus contenidos sea equivalente a programas ya clasificados en este nivel dentro del mismo sistema educativo y que estos cumplan los demás criterios principales. Estos programas se caracterizan por tener una duración de 1 a 2 años, suelen tener una orientación profesional y ofrecen un grado de especialización superior a los programas de primer título, aunque su contenido no es significativamente más complejo. Los programas de nivel CINE 6 no requieren, necesariamente, la preparación de una tesis o disertación.

231. En aquellos sistemas educativos donde se requiere que parte del personal docente haya obtenido cualificaciones de nivel CINE 8, esta exigencia puede ser un buen criterio de aproximación para clasificar los programas educativos de este nivel. Lo anterior permite establecer una distinción entre los programas de nivel CINE 5 y de nivel CINE 6.

\section{Programas que abarcan más de un nivel CINE}

232. No se aplica.

\section{Dimensiones complementarias}

233. Dos dimensiones permiten diferenciar los programas educativos de nivel CINE 6:

- Orientación del programa (véase el párrafo 234); y

- Duración del programa y posición en la estructura nacional de títulos y cualificaciones (véase el párrafo 235).

\section{Orientación del programa}

234. Para este nivel se han definido dos categorías de orientación:

- Académica; y

- Profesional.

\section{Duración del programa y posición en la estructura nacional de títulos y certificaciones}

235. Respecto del nivel CINE 6, se han definido cuatro subcategorías de duración del programa y posición en la estructura nacional de títulos y certificaciones: 
- Etapa (o programa) dentro del primer título del grado en educación terciaria o nivel equivalente con una duración teórica acumulada (en el nivel terciario) inferior a tres años; por lo tanto, considerada insuficiente para la conclusión del nivel CINE 6;

- Programa de primer título del grado en educación terciaria o nivel equivalente con una duración teórica acumulada (en el nivel terciario) de tres a cuatro años;

- Programa largo de primer título del grado en educación terciaria o nivel equivalente con una duración teórica acumulada (en el nivel terciario) de más de cuatro años; y

- Programa de segundo o siguiente título del grado en educación terciaria nivel o equivalente (tras la conclusión exitosa de un programa del grado en educación terciaria o programa equivalente).

\section{E. Otros programas incluidos en el nivel CINE 6}

236. Este nivel incluye programas de educación continua y educación de adultos con contenidos de similar complejidad a los de programas previamente clasificados en este nivel.

\section{F. Clasificación de programas educativos de nivel CINE 6}

237. Las dos dimensiones complementarias que permiten la clasificación y elaboración de informes son: la orientación del programa (categorías) y la combinación de la duración del programa y su posición en la estructura nacional de títulos y certificaciones (subcategorías). En el Cuadro 13 se presentan los códigos de clasificación que deben ser utilizados en el nivel CINE 6.

\section{Cuadro 13. Códigos de clasificación de los programas educativos de nivel CINE 6 (CINE-P)}

\begin{tabular}{|c|c|c|c|}
\hline \multicolumn{2}{|c|}{$\begin{array}{l}\text { Categoría } \\
\text { (orientación) }\end{array}$} & $\begin{array}{l}\text { Subcategoría } \\
\text { (duración y posición) }\end{array}$ & Descripción \\
\hline \multirow[t]{4}{*}{64} & \multirow{4}{*}{$\begin{array}{l}\text { Grado en } \\
\text { educación } \\
\text { terciaria } \\
\text { o nivel } \\
\text { equivalente, } \\
\text { académico }\end{array}$} & 641 & Insuficientes para la conclusión del nivel \\
\hline & & 645 & Primer título (3 a 4 años de duración) \\
\hline & & 646 & Programas largos de primer título (más de 4 años de duración) \\
\hline & & 647 & $\begin{array}{l}\text { Segundo o siguiente título (tras la conclusión exitosa de un programa del } \\
\text { grado en educación terciaria o programa equivalente) }\end{array}$ \\
\hline \multirow[t]{4}{*}{65} & \multirow{4}{*}{$\begin{array}{l}\text { Grado en } \\
\text { educación } \\
\text { terciaria } \\
\text { o nivel } \\
\text { equivalente, } \\
\text { profesional }\end{array}$} & 651 & Insuficientes para la conclusión del nivel \\
\hline & & 655 & Primer título (3 a 4 años de duración) \\
\hline & & 656 & Programas largos de primer título (más de 4 años de duración) \\
\hline & & 657 & $\begin{array}{l}\text { Segundo o siguiente título (tras la conclusión exitosa de un programa del } \\
\text { grado en educación terciaria o programa equivalente) }\end{array}$ \\
\hline \multirow[t]{4}{*}{66} & \multirow{4}{*}{$\begin{array}{l}\text { Grado en } \\
\text { educación } \\
\text { terciaria } \\
\text { o nivel } \\
\text { equivalente, } \\
\text { orientación no } \\
\text { especificada }{ }^{1}\end{array}$} & 661 & Insuficientes para la conclusión del nivel \\
\hline & & 665 & Primer título (3 a 4 años de duración) \\
\hline & & 666 & Programas largos de primer título (más de 4 años de duración) \\
\hline & & 667 & $\begin{array}{l}\text { Segundo o siguiente título (tras la conclusión exitosa de un programa del } \\
\text { grado en educación terciaria o programa equivalente) }\end{array}$ \\
\hline
\end{tabular}




\section{G. Clasificación de logro educativo en el nivel CINE 6}

238. En términos de logro educativo, las certificaciones intermedias otorgadas tras la conclusión exitosa de etapas de programas de nivel CINE 6 (previo a la obtención del primer título) que son consideradas insuficientes para concluir este nivel se clasifican en el nivel CINE 5. Por otra parte, el solo hecho de participar en un primer programa de nivel CINE 6 sin haberlo concluido no se tendrá en cuenta al momento de determinar el nivel de logro educativo.

239. Asimismo, para efectos del logro educativo, las certificaciones intermedias otorgadas tras la conclusión exitosa de las etapas de un primer programa de nivel CINE 7 (de nivel de Maestría, especialización o equivalente - ya sea un programa largo de primer título o un programa de segundo título) que son consideradas insuficientes para la conclusión del nivel CINE 7 se clasifican en el nivel CINE 6.

240. En el Cuadro 14 se presentan los códigos de clasificación de logro educativo para programas de nivel CINE 6.

\section{Cuadro 14. Códigos de clasificación de los programas educativos de nivel CINE 6 (CINE-A)}

\begin{tabular}{|c|c|c|c|}
\hline \multicolumn{2}{|r|}{ Categoría (orientación) } & Subcategoría & Descripción \\
\hline 54 & Educación terciaria de ciclo corto, general & 540 & No se define con mayor detalle ${ }^{1}$ \\
\hline 55 & Educación terciaria de ciclo corto, vocacional & 550 & No se define con mayor detalle ${ }^{1}$ \\
\hline 56 & Educación terciaria de ciclo corto, orientación no especificada² & 560 & No se define con mayor detalle ${ }^{1}$ \\
\hline 64 & Grado en educación terciaria o nivel equivalente, académico & 640 & No se define con mayor detalle ${ }^{3}$ \\
\hline 65 & Grado en educación terciaria o nivel equivalente, profesional & 650 & No se define con mayor detalle ${ }^{3}$ \\
\hline 66 & $\begin{array}{l}\text { Grado en educación terciaria o nivel equivalente, orientación } \\
\text { no especificada }{ }^{2}\end{array}$ & 660 & No se define con mayor detalle ${ }^{3}$ \\
\hline \multicolumn{4}{|c|}{$\begin{array}{l}\text { 1. Conclusión exitosa reconocida de un programa o etapa de un programa del grado en educación terciaria o nivel equivalente considerado } \\
\text { insuficiente para la conclusión del nivel CINE } 6 \text {. }\end{array}$} \\
\hline \multicolumn{4}{|c|}{$\begin{array}{l}\text { 2. A utilizarse en los niveles CINE } 6 \text { y } 7 \text { dado que no se cuenta con una definición internacionalmente consensuada de las orientaciones académicas } \\
\text { y profesionales a nivel terciario. }\end{array}$} \\
\hline \multicolumn{4}{|c|}{$\begin{array}{l}\text { 3. Incluye la conclusión exitosa reconocida de un programa del grado en educación terciaria o nivel equivalente considerado suficiente para la } \\
\text { conclusión del nivel CINE } 6 \text { o un programa o etapa de un programa de nivel de maestría, especialización o equivalente considerado insuficiente } \\
\text { para la conclusión del nivel CINE } 7 \text {. }\end{array}$} \\
\hline
\end{tabular}




\section{NIVEL CINE 7 NIVEL DE MAESTRÍA, ESPECIALIZACIÓN 0 EQUIVALENTE}

\section{A. Características principales}

241. Los programas de nivel CINE 7, o nivel de maestría, especialización o equivalente, suelen tener como principal objetivo impartir al participante competencias académicas y/o profesionales avanzadas que conduzcan a un segundo título o a una certificación equivalente. Los programas de este nivel pueden incluir un importante componente de investigación, aunque no otorgan las certificaciones relacionadas al nivel de doctorado. Se caracterizan por ser esencialmente teóricos - si bien pueden incluir un componente práctico - y por estar basados en investigaciones que reflejan los últimos avances del campo o en las mejores prácticas profesionales.

Tradicionalmente, este nivel lo ofrecen universidades y otras instituciones de educación superior.

242. En este nivel, la instrucción suele ser impartida bajo la modalidad de exposiciones orales por un personal docente que normalmente debe cumplir con la exigencia de haber concluido el nivel CINE 7 u 8. Los programas de este nivel pueden requerir la finalización de tesis o proyectos de investigación más avanzados que los de nivel CINE 6 pero menos avanzados que los de nivel CINE 8.

243. Habitualmente, el ingreso a programas de nivel CINE 7 que preparan para un segundo o siguiente título requiere la conclusión de un programa de nivel CINE 6 o 7. En el caso de programas largos que preparan para un primer título equivalente a un nivel de maestría/especialización, se exige como requisito de ingreso la conclusión exitosa de un programa de nivel CINE 3 o 4 que de acceso a la educación terciaria. El ingreso a programas impartidos en estos niveles puede depender de la selección de materias de estudio y/o las calificaciones obtenidas en los niveles CINE 3 y/o 4. Adicionalmente, podría ser necesario aprobar un examen de admisión. Asimismo, el contenido de los programas de nivel CINE 7 es significativamente más complejo que el contenido de los programas de nivel CINE 6 y suele ser más especializado. Una vez concluidos estos programas, la persona puede continuar sus estudios en el nivel CINE 8 (nivel de doctorado). Sin embargo, no todos los programas de nivel CINE 7 dan acceso directo al nivel CINE 8.

244. Los programas clasificados en el nivel CINE 7 pueden recibir distintas denominaciones, por ejemplo: maestrías, o magister. Cabe señalar, no obstante, que los programas con nombres similares a "maestría" deben ser incluidos en el nivel CINE 7 solo si cumplen los criterios descritos en el párrafo 245. Para propósitos de comparación a nivel internacional, se usa el término "nivel de maestría, especialización o equivalente" para denominar a nivel CINE 7.

\section{B. Criterios de clasificación}

245. Para definir el nivel de maestría, especialización o equivalente, los siguientes criterios son pertinentes:

\section{Criterios principales}

a) Contenido teórico y/o profesional (véase el párrafo 241);

b) Posición en la estructura nacional de títulos y certificaciones (véanse los párrafos 246 y 247); y

c) Requisitos de ingreso (véase el párrafo 243).

\section{Criterios subsidiarios}

a) Duración acumulada mínima de programas largos de primer título (véase el párrafo 247); y

b) Acceso directo a programas de nivel CINE 8 (véase el párrafo 249). 
246. Habitualmente, los programas de este nivel preparan para un segundo o siguiente título luego de haber obtenido un primer título de nivel CINE 6 o 7. Las certificaciones equivalentes, por ejemplo, certificaciones profesionales de post-grado, también se clasifican en el nivel CINE 7, salvo si ya han sido clasificadas en el nivel CINE 6 (véase el párrafo 230).

247. Los programas con una duración mínima de cinco años destinados a preparar al estudiante para un primer título se incluirán en este nivel si en términos de complejidad del contenido son equivalentes a una maestría/especialización. Estos programas normalmente requieren la preparación de una tesis o disertación. En este caso, el título otorgado da acceso directo al nivel CINE 8, o bien, el programa es equivalente a un programa de segundo o siguiente título ya clasificado en el nivel CINE 7. También se incluyen en este nivel estudios profesionales altamente especializados de una duración acumulada similar o superior a los anteriormente mencionados (por ejemplo, medicina, odontología, ciencias veterinarias y, en algunos casos, derecho o ingeniería) que cubren, tanto en amplitud como profundidad, una cantidad equivalente de contenido, si bien habitualmente no exigen la preparación de una tesis o disertación.

248. En este nivel, los programas de segundo o siguiente título suelen tener una duración que puede variar entre uno a cuatro años de estudio a tiempo completo. En los sistemas educativos que otorgan títulos en base a la acumulación de créditos, se requerirá un período comparable de tiempo y similar grado de intensidad. Por consiguiente, la duración acumulada de estudios de nivel terciario suele prolongarse entre cinco y ocho años, e incluso más.

249. Frecuentemente, los programas de educación terciaria que dan acceso directo al nivel CINE 8 se clasifican en el nivel CINE 7. Sin embargo, no todos los programas de nivel CINE 7 cumplen esta condición.

\section{Consideraciones relativas a programas que abarcan más de un nivel CINE}

250. No se aplica.

\section{Dimensiones complementarias}

251. Dos dimensiones permiten diferenciar los programas educativos de nivel CINE 7:

- Orientación del programa (véase el párrafo 252); y

- Posición en la estructura nacional de títulos y certificaciones (véase el párrafo 253).

\section{Orientación del programa}

252. Para este nivel se dispone de dos categorías:

- Académica; y

- Profesional.

\section{Posición en la estructura nacional de títulos y certificaciones}

253. Respecto del nivel CINE 7, se han definido cuatro categorías respecto de la posición de un programa en la estructura nacional de títulos y certificaciones: 
- Etapa (o programa) dentro del primer título de nivel maestría, especialización o equivalente con una duración teórica acumulada (en el nivel terciario) inferior a cinco años que, por lo tanto, no se considera suficiente para la conclusión del nivel CINE 7;

- Programa largo de primer título de nivel maestría, especialización o equivalente con una duración teórica acumulada (en el nivel terciario) de al menos cinco años (que no requiere estudios previos de educación terciaria);

- Programa de segundo o siguiente título de nivel maestría, especialización o equivalente (tras la conclusión exitosa de un programa del grado en educación terciaria o equivalente); y

- Programa de segundo o siguiente título de nivel maestría, especialización o equivalente (tras la conclusión exitosa de otro programa de maestría, especialización o equivalente).

\section{E. Otros programas incluidos en el nivel CINE 7}

254. El nivel CINE 7 incluye programas que conducen a la obtención de un título de investigación que han sido concebidos explícitamente para capacitar a los participantes en la conducción de investigación original, pero que se consideran de un nivel inferior al doctorado. Con frecuencia, estos programas cumplen muchos de los criterios aplicables a los programas de nivel CINE 8, aunque suelen ser de menor duración (duración acumulada entre 5 y 6 años a partir del comienzo de la educación terciaria), carecen usualmente del nivel de independencia exigido a los estudiantes que aspiran a una certificación de investigación avanzada y preparan para ingresar a programas de nivel CINE 8. La conclusión de programas de nivel CINE 7 puede reducir a menos de tres años el período de estudio de un programa posterior de doctorado. En este nivel, los programas se clasifican de acuerdo a su posición en la estructura nacional de títulos y certificaciones.

\section{F. Clasificación de programas educativos de nivel CINE 7}

255. Las dos dimensiones complementarias que permiten la clasificación y elaboración de informes son: la orientación del programa (categorías), y la combinación de la duración del programa y su posición en la estructura nacional de títulos y certificaciones (subcategorías). En el Cuadro 15 se presentan los códigos de clasificación que deben ser utilizados en el nivel CINE 7.

\section{G. Clasificación de logro educativo en el nivel CINE 7}

256. En términos de logro educativo, las certificaciones intermedias otorgadas tras la conclusión de etapas (o programas) de un primer título del nivel de maestría, especialización o equivalente consideradas insuficientes para concluir el nivel CINE 7 se clasifican en el nivel CINE 6. Por otra parte, la participación sin la conclusión exitosa en cualquier programa de primer, segundo o siguiente título de nivel CINE 7 que continua la conclusión exitosa de un programa del grado en educación terciaria o equivalente no se tendrá en cuenta al momento de determinar el nivel de logro educativo.

257. Asimismo, las certificaciones intermedias otorgadas tras la conclusión exitosa de etapas (o programas) de nivel de doctorado o equivalente consideradas insuficientes para la conclusión del nivel CINE 8 se clasifican en el nivel CINE 7 para los efectos de logro educativo.

258. En el Cuadro 16 se presentan los códigos de clasificación de logro educativo para programas de nivel CINE 7. 


\section{Cuadro 15. Códigos de clasificación de los programas educativos de nivel CINE 7 (CINE-P)}

\begin{tabular}{|c|c|c|c|}
\hline \multirow{2}{*}{74} & \multirow{2}{*}{$\begin{array}{l}\text { Nivel de } \\
\text { maestría, } \\
\text { especialización } \\
\text { o equivalente, } \\
\text { académica }\end{array}$} & 746 & Programas largos de primer título (con una duración mínima de 5 años) \\
\hline & & 748 & $\begin{array}{l}\text { Segundo o siguiente título (tras la conclusión exitosa de un programa de nivel } \\
\text { de maestría, especialización o programa equivalente) }\end{array}$ \\
\hline \multirow[t]{3}{*}{75} & \multirow{3}{*}{$\begin{array}{l}\text { Nivel de } \\
\text { maestría, } \\
\text { especialización } \\
\text { o equivalente, } \\
\text { profesional }\end{array}$} & 751 & Insuficientes para la conclusión del nivel \\
\hline & & 756 & Programas largos de primer título (con una duración mínima de 5 años) \\
\hline & & 758 & $\begin{array}{l}\text { Segundo o siguiente título (tras la conclusión exitosa de un programa de nivel } \\
\text { de maestría, especialización o programa equivalente) }\end{array}$ \\
\hline \multirow[t]{4}{*}{76} & \multirow{4}{*}{$\begin{array}{l}\text { Nivel de } \\
\text { maestría, } \\
\text { especialización } \\
\text { o equivalente, } \\
\text { orientación no } \\
\text { especificada }^{1}\end{array}$} & 761 & Insuficientes para la conclusión del nivel \\
\hline & & 766 & Programas largos de primer título (con una duración mínima de 5 años) \\
\hline & & 767 & $\begin{array}{l}\text { Segundo o siguiente título (tras la conclusión exitosa de un programa del grado } \\
\text { en educación terciaria o programa equivalente) }\end{array}$ \\
\hline & & 768 & $\begin{array}{l}\text { Segundo o siguiente título (tras la conclusión exitosa de un programa de nivel } \\
\text { de maestría, especialización o programa equivalente) }\end{array}$ \\
\hline
\end{tabular}

\section{Cuadro 16. Códigos de clasificación de logro educativo en el nivel CINE 7 (CINE-A)}

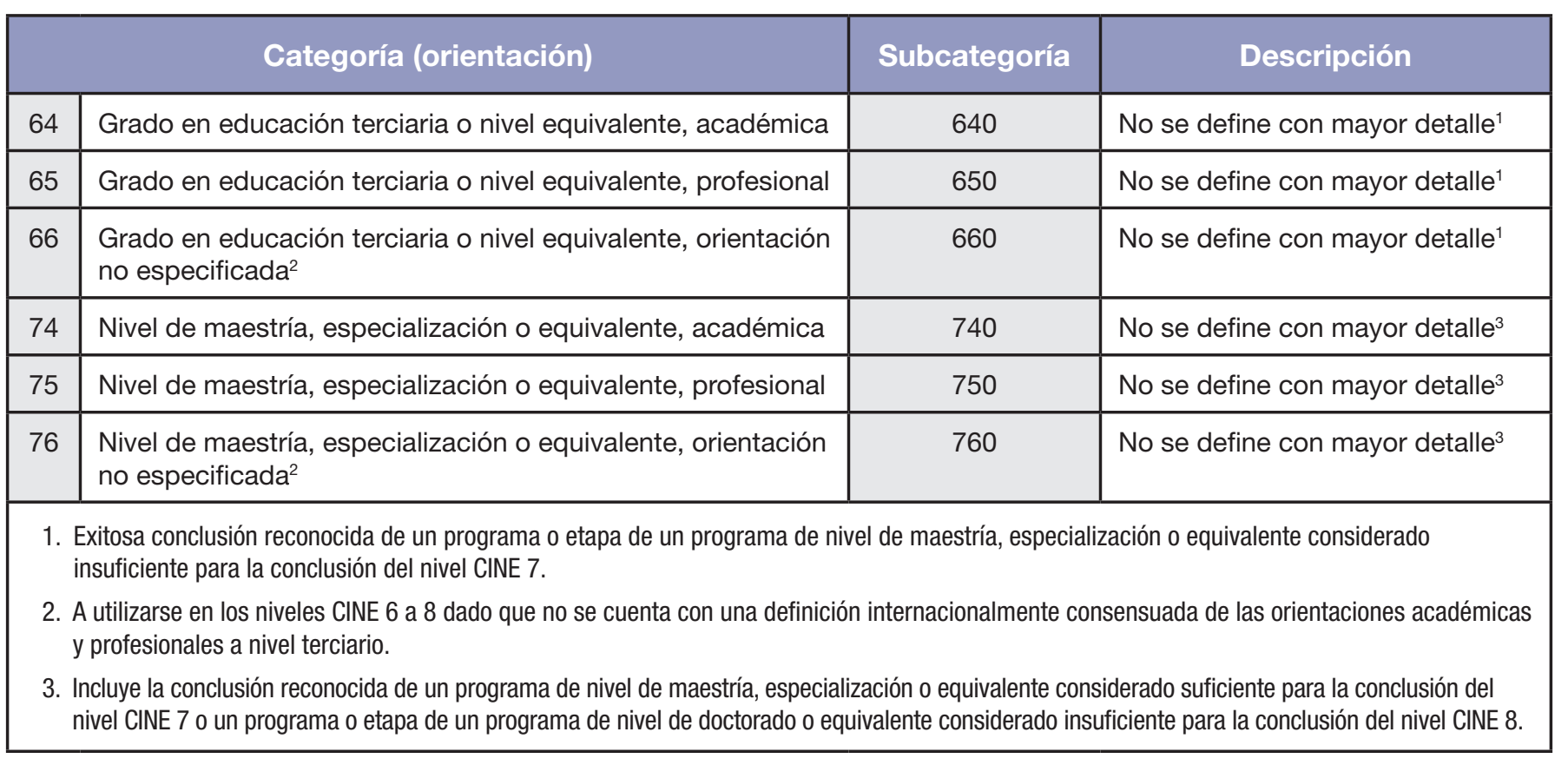




\section{NIVEL CINE 8 NIVEL DE DOCTORADO 0 EQUIVALENTE}

\section{A. Características principales}

259. Los programas de nivel CINE 8, o nivel de doctorado o equivalente, suelen tener como principal objetivo conducir a un título de investigación avanzada. Los programas de este nivel están dedicados a estudios avanzados e investigaciones originales, en tanto que suelen ser ofrecidos exclusivamente por instituciones de educación superior (universidades) dedicadas a la investigación. Se imparten programas de doctorado tanto en el campo académico como en el profesional.

260. Por lo general, el nivel CINE 8 concluye con la presentación y defensa de una tesis o disertación (o trabajo escrito equivalente en importancia y con calidad de publicación) que representa una contribución significativa al conocimiento en los respectivos campos de estudio. En consecuencia, estos programas se caracterizan por estar basados en investigación y no únicamente en cursos. Efectivamente, en algunos sistemas educativos, los programas de nivel CINE 8 ofrecen muy pocos cursos, o ninguno, y las personas que aspiran a un doctorado acostumbran a realizar trabajos de investigación en forma independiente o como parte de grupos reducidos con distintos grados de supervisión. En otros, la investigación doctoral es responsabilidad de personas contratadas por la universidad como investigadores junior o asistentes de investigación al mismo tiempo de estar matriculadas en cursos doctorales.

261. Normalmente, el ingreso a programas de nivel CINE 8 o al cargo de investigador junior requiere la conclusión exitosa de un programa de nivel CINE 7. Las calificaciones otorgadas por el nivel CINE 8 dan acceso a profesiones que exigen un alto nivel de competencias académicas, a cargos de investigación en la administración pública y la industria, así como a cargos de docencia e investigación en instituciones que imparten educación en los niveles CINE 6, 7 y 8.

262. Los programas clasificados en el nivel CINE 8 pueden recibir distintas denominaciones, por ejemplo: PhD, DPhil, D.Lit, D.Sc, LL.D, Doctorado y otros términos similares. Sin embargo, cabe destacar que los programas que otorgan un título similar al de "doctor" deben ser incluidos en el nivel CINE 8 solo si cumplen los criterios establecidos en el párrafo 263. Para propósitos de comparación a nivel internacional, se usa el término "nivel de doctorado o equivalente" para denominar al nivel CINE 8.

\section{B. Criterios de clasificación}

263. Para definir el nivel de doctorado o equivalente, los siguientes criterios son pertinentes:

\section{Criterios principales}
a) Requisitos de trabajo escrito (véase el párrafo 264);
b) Requisitos de ingreso (véase el párrafo 261); y
c) Duración mínima del nivel (véase el párrafo 265).

\section{Criterios subsidiarios}

a) Título de doctor requerido para ocupaciones específicas (véase el párrafo 266). 
264. La conclusión exitosa de un programa de nivel CINE 8 requiere la presentación de una tesis, una disertación o un trabajo escrito equivalente con calidad de publicación que sea el producto de una investigación original y que represente una contribución significativa al conocimiento en campo de estudio respectivo.

265. El nivel CINE 8 requiere como mínimo el equivalente a tres años de estudio a tiempo completo. Por consiguiente, esto representa una duración acumulada total de por lo menos siete años de estudio a tiempo completo en el nivel terciario.

266. A menudo, la obtención de una certificación de nivel CINE 8 representa un requisito para desempeñar cargos en las facultades de las instituciones educativas que ofrecen programas de niveles CINE 6, 7 y 8 o para asumir funciones de investigación en la administración pública y la industria.

\section{Programas que abarcan más de un nivel CINE}

267. No se aplica.

\section{Dimensiones complementarias}

268. Una dimensión podría ser usada para diferenciar los programas educativos de nivel CINE 8:

- Orientación del programa (véase el párrafo 269).

\section{Orientación del programa}

269. Para este nivel se dispone de dos categorías de orientación:

- Académica; y

- Profesional.

\section{E. Otros programas incluidos en el nivel CINE 8}

270. El nivel CINE 8 también incluye los segundos títulos de investigación avanzada, o los doctorados de nivel avanzado, los cuales requieren la presentación de un segundo trabajo significativo de investigación (adicional a la primera tesis doctoral) habitualmente desarrollado durante una etapa avanzada de una carrera académica y generalmente no supervisado formalmente. Algunos ejemplos de designaciones del segundo título de investigación avanzada son: habilitation o doktor nauk. No obstante, la mayoría de los sistemas educativos solo tienen una titulación de investigación avanzada que otorga títulos doctorales o certificaciones equivalentes. Normalmente, no están vinculados a un programa educativo, por ejemplo: los candidatos normalmente no están matriculados en un programa que conlleva a este título. Los segundos títulos de investigación no están codificados de manera separada dentro de la CINE. El nivel CINE 8 no contempla los títulos honorarios de doctor otorgados por universidades por motivos no relacionados con el trabajo de investigación.

\section{F. Clasificación de programas educativos de nivel CINE 8}

271. La oferta educativa de este nivel consiste en programas de nivel de doctorado o etapas (o programas) de nivel CINE 8 considerados insuficientes para la conclusión de este nivel. La existencia de una dimensión complementaria permite elaborar informes utilizando la "orientación" como categoría. En el Cuadro 17 se presentan los códigos de clasificación que deben ser utilizados en el nivel CINE 8. 


\section{Cuadro 17. Códigos de clasificación de programas educativos de nivel CINE 8 (CINE-P)}

\begin{tabular}{|c|c|c|c|}
\hline 84 & $\begin{array}{l}\text { Nivel de doctorado o equivalente, } \\
\text { académica }\end{array}$ & 844 & Suficientes para la conclusión del nivel \\
\hline \multirow[t]{2}{*}{85} & \multirow{2}{*}{$\begin{array}{l}\text { Nivel de doctorado o equivalente, } \\
\text { profesional }\end{array}$} & 851 & Insuficientes para la conclusión del nivel \\
\hline & & 854 & Suficientes para la conclusión del nivel \\
\hline \multirow[t]{2}{*}{86} & \multirow{2}{*}{$\begin{array}{l}\text { Nivel de doctorado o equivalente, } \\
\text { orientación no especificada }{ }^{1}\end{array}$} & 861 & Insuficientes para la conclusión del nivel \\
\hline & & 864 & Suficientes para la conclusión del nivel \\
\hline
\end{tabular}

\section{G. Clasificación de logro educativo en el nivel CINE 8}

272. En términos de logro educativo, las certificaciones intermedias otorgadas por la conclusión de etapas (o programas) de un primer título del nivel de doctorado o equivalente consideradas insuficientes para concluir este nivel se clasifican en el nivel CINE 7. Por otra parte, el solo hecho de participar en cualquier primer programa de nivel CINE 8 sin haberlo concluido exitosamente no se tendrá en cuenta al momento de determinar el nivel educativo concluido.

273. En el Cuadro 18 se presentan los códigos de clasificación de logro educativo para programas de nivel CINE 8.

\section{Cuadro 18. Códigos de clasificación de logro educativo de nivel CINE 8 (CINE-A)}

\begin{tabular}{|c|c|c|c|}
\hline \multicolumn{2}{|r|}{ Categoría (orientación) } & Subcategorías & Descripción \\
\hline 74 & Nivel de maestría, especialización o equivalente, académica & 740 & No se define con mayor detalle ${ }^{1}$ \\
\hline 75 & Nivel de maestría, especialización o equivalente, profesional & 750 & No se define con mayor detalle ${ }^{1}$ \\
\hline 76 & $\begin{array}{l}\text { Nivel de maestría, especialización o equivalente, orientación } \\
\text { no especificada² }\end{array}$ & 760 & No se define con mayor detalle ${ }^{1}$ \\
\hline 84 & Nivel de doctorado o equivalente, académica & 840 & No se define con mayor detalle \\
\hline 85 & Nivel de doctorado o equivalente, profesional & 850 & No se define con mayor detalle \\
\hline 86 & $\begin{array}{l}\text { Nivel de doctorado o equivalente, orientación no } \\
\text { especificada }{ }^{2}\end{array}$ & 860 & No se define con mayor detalle \\
\hline \multicolumn{4}{|c|}{$\begin{array}{l}\text { 1. Exitosa conclusión reconocida de un programa o etapa de un programa de nivel de doctorado o equivalente considerado insuficiente para la } \\
\text { conclusión del nivel CINE } 8 \text {. }\end{array}$} \\
\hline \multicolumn{4}{|c|}{$\begin{array}{l}\text { 2. A utilizarse en los niveles CINE } 7 \text { y } 8 \text { dado que no se cuenta con una definición internacionalmente consensuada de las orientaciones académicas } \\
\text { y profesionales a nivel terciario. }\end{array}$} \\
\hline
\end{tabular}




\section{SECCIÓN 10 CORRESPONDENCIA ENTRE LOS NIVELES CINE 2011 Y CINE 1997}

274. En esta sección se describe la correspondencia (o concordancia) entre los niveles CINE previstos en la CINE 2011 y el marco anterior, CINE 1997.

275. En la CINE 2011, el nivel 0 cubre la educación de la primera infancia para todos los grupos de edad, incluso los niños de muy corta edad. Según el nivel de complejidad de su contenido educativo, los programas se clasifican en dos categorías: desarrollo educacional de la primera infancia (código 010) y educación preprimaria (código 020). Los programas de desarrollo educacional de la primera infancia (código 010) están destinados a niños menores de tres años. Esta clasificación ha sido incorporada por primera vez en la CINE 2011 y no está considerada en la CINE 1997. La educación preprimaria (código 020) corresponde exactamente al nivel 0 de la CINE 1997.

276. En la CINE 2011, el nivel 1 (educación primaria) corresponde al nivel 1 de la CINE 1997.

277. Los niveles 2 y 3 (educación secundaria baja y alta) de la CINE 2011 corresponden esencialmente a los niveles 2 y 3 de la CINE 1997. Sin embargo, debido a la clarificación de los criterios principales y subsidiarios, es posible que la CINE 2011 y la CINE 1997 difieran respecto a sus implementaciones (es decir, algunos programas podría quedar clasificados en niveles distintos que en el pasado). En el caso de algunos países, estas diferencias podrían afectar los datos de series de tiempo.

278. En comparación con la CINE 1997, la CINE 2011 simplifica las dimensiones complementarias de los niveles CINE 2 y 3 :

- En la CINE 2011 la orientación de los programas solo establece una distinción entre los programas vocacionales y generales. En la CINE 1997, la educación pretécnica se clasifica en forma separada. Estos programas no otorgan certificaciones pertinentes al mercado laboral y en la actualidad se clasifican esencialmente bajo la denominación "educación general";

- La CINE 2011 identifica un solo grupo de programas que da acceso a estudios más avanzados. En comparación, en la CINE 1997 se distinguen dos subcategorías ( $\mathrm{A}$ y B) de acceso a estudios más avanzados, según el tipo de educación subsecuente. La categoría "nivel de conclusión que da acceso a estudios más avanzados" de la CINE 2011 corresponde a la combinación de las categorías A y B de la CINE 1997;

- La CINE 2011 clasifica los programas que no dan acceso a estudios más avanzados en las subcategorías: "nivel inconcluso", "conclusión parcial de nivel" y "conclusión de nivel". Estas tres subcategorías en la CINE 2011 corresponden a la categoría "C" y a las categorías "programas C cortos" y "programas C largos" del nivel 3 de la CINE 1997.

279. El nivel 4 de la CINE 2011, educación postsecundaria no terciaria, corresponde mayormente al nivel 4 de la CINE 1997. Sin embargo, en la CINE 2011 los programas que otorgan una certificación equivalente a la educación secundaria alta general se clasifican en el nivel 3 en circunstancias que en la CINE 1997 con frecuencia se clasificaban en el nivel 4. Asimismo, debido a la clarificación de los criterios principales y subsidiarios, es posible que la CINE 2011 y la CINE 1997 difieran respecto de sus implementaciones. En el caso de algunos países, estas diferencias podrían afectar los datos de series de tiempo.

280. La CINE 2011 simplifica las dimensiones de orientación del nivel CINE 4 respecto de los niveles 2 y 3 (véanse los párrafos 194, 153 y 175). Las subcategorías "con acceso a un nivel más 
avanzado" y "sin acceso a un nivel avanzado" de la CINE 2011 corresponden a los destinos A y B, respectivamente, de la CINE 1997.

281. La CINE 2011 considera cuatro niveles de educación terciaria, en comparación con los dos niveles que figuran en la CINE 1997. Los niveles 5, 6 y 7 de la CINE 2011 corresponden, en conjunto, al nivel 5 de la CINE 1997. El nivel 8 de la CINE 2011 corresponde al nivel 6 de la CINE 1997.

282. En comparación con la CINE 1997, la CINE 2011 simplifica las dimensiones complementarias de los niveles CINE terciarios:

- Respecto del nivel 5 de la CINE 2011, el segundo dígito del código permite distinguir entre los programas de orientación vocacional y general, distinción que no era posible en la CINE 1997. Adicionalmente, una vez que se cuente con definiciones internacionalmente consensuadas también será posible distinguir entre programas de orientación académica y profesional en los niveles 6, 7 y 8 de la CINE 2011.

- En los niveles 6 y 7 de la CINE 2011, el tercer dígito de clasificación establece una distinción entre los programas en función de su duración y posición en la estructura nacional de títulos y certificaciones, facilitando de esta forma el cálculo de estadísticas tales como tasas de ingreso y graduación. En la CINE 1997 se utilizó la orientación o "tipo de programa" con el fin de subclasificar el nivel CINE 5A en programas de primer título y programas de segundo y siguiente título (lo que en la CINE 2011 corresponde a los niveles 6 y 7 combinados). El tercer dígito de clasificación permite distinguir entre programas de primer título y programas de segundo y siguiente título en ambos niveles.

283. El Cuadro 19 muestra la correspondencia (o concordancia) entre los niveles CINE de las versiones 2011 y 1997.

Cuadro 19. Correspondencia entre los niveles CINE 2011 y CINE 1997

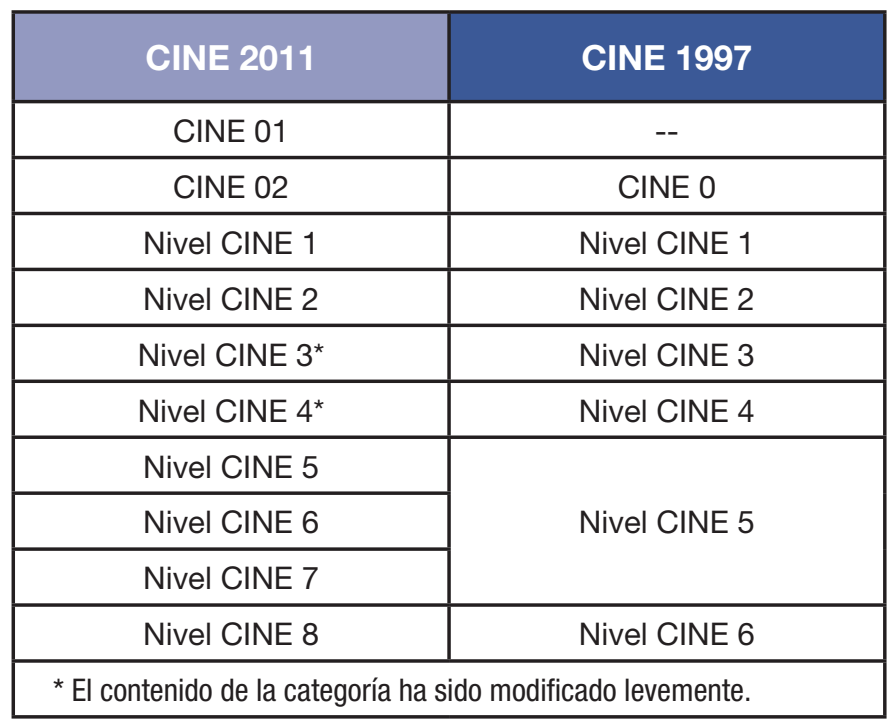

284. Los Cuadros 20 y 21 muestran en detalle la correspondencia (o concordancia) entre la CINE 2011 y la CINE 1997, incluyendo las respectivas dimensiones complementarias, categorías y subcategorías. 


\section{Cuadro 20. Detalles de la correspondencia entre la CINE 2011 y la CINE 1997 para los niveles 0 al 4}

\begin{tabular}{|c|c|c|c|c|}
\hline & & & & CINE 2011 \\
\hline $\begin{array}{l}\text { Denominación } \\
\text { del nivel }\end{array}$ & Nivel & Categoría & $\begin{array}{l}\text { Sub- } \\
\text { categoría }\end{array}$ & Notas sobre subcategorias \\
\hline $\begin{array}{l}\text { Desarrollo educacional } \\
\text { de la primera infancia }\end{array}$ & 0 & 01 & 010 & Programas educativos destinados a menores de 3 años de edad \\
\hline Educación preprimaria & & 02 & 020 & \\
\hline Educación primaria & 1 & 10 & 100 & \\
\hline \multirow{8}{*}{$\begin{array}{l}\text { Educación secundaria } \\
\text { baja }\end{array}$} & \multirow{8}{*}{2} & \multirow{4}{*}{$\begin{array}{l}24 \\
\text { General }\end{array}$} & 241 & $\begin{array}{l}\text { Insuficientes para la conclusión, o la conclusión parcial, del nivel; sin acceso directo a la } \\
\text { educación secundaria alta }\end{array}$ \\
\hline & & & 242 & Conclusión parcial del nivel; sin acceso directo a la educación secundaria alta \\
\hline & & & 243 & Conclusión del nivel; sin acceso directo a la educación secundaria alta \\
\hline & & & 244 & Conclusión del nivel; con acceso directo a la educación secundaria alta \\
\hline & & \multirow{4}{*}{$\begin{array}{l}25 \\
\text { Vocacional }\end{array}$} & 251 & $\begin{array}{l}\text { Insuficientes para la conclusión, o la conclusión parcial, del nivel; sin acceso directo a la } \\
\text { educación secundaria alta }\end{array}$ \\
\hline & & & 252 & Conclusión parcial del nivel; sin acceso directo a la educación secundaria alta \\
\hline & & & 253 & Conclusión del nivel; sin acceso directo a la educación secundaria alta \\
\hline & & & 254 & Conclusión del nivel; con acceso directo a la educación secundaria alta \\
\hline \multirow{8}{*}{$\begin{array}{l}\text { Educación } \\
\text { secundaria alta }\end{array}$} & \multirow{8}{*}{3} & \multirow{4}{*}{$\begin{array}{c}34 \\
\text { General }\end{array}$} & 341 & $\begin{array}{l}\text { Insuficientes para la conclusión, o la conclusión parcial, del nivel; sin acceso directo a la } \\
\text { educación terciaria }\end{array}$ \\
\hline & & & 342 & Conclusión parcial del nivel; sin acceso directo a la educación terciaria \\
\hline & & & 343 & $\begin{array}{l}\text { Conclusión del nivel; sin acceso directo a programas de primer título de educación terciaria } \\
\text { [aunque puede dar acceso directo a programas de educación postsecundaria no terciaria] }\end{array}$ \\
\hline & & & 344 & $\begin{array}{l}\text { Conclusión del nivel; con acceso directo a programas de primer título de educación terciaria } \\
\text { [también puede dar acceso directo a programas de educación postsecundaria no terciaria] }{ }^{1}\end{array}$ \\
\hline & & \multirow{4}{*}{$\begin{array}{l}35 \\
\text { Vocacional }\end{array}$} & 351 & $\begin{array}{l}\text { Insuficientes para la conclusión, o la conclusión parcial, del nivel; sin acceso directo a la } \\
\text { educación terciaria }\end{array}$ \\
\hline & & & 352 & Conclusión parcial del nivel; sin acceso directo a la educación terciaria \\
\hline & & & 353 & $\begin{array}{l}\text { Conclusión del nivel; sin acceso directo a programas de primer título de educación terciaria } \\
\text { [aunque puede dar acceso directo a programas de educación postsecundaria no terciaria] }{ }^{1}\end{array}$ \\
\hline & & & 354 & 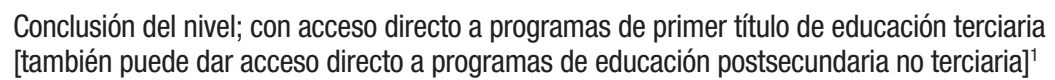 \\
\hline \multirow{6}{*}{$\begin{array}{l}\text { Educación } \\
\text { postsecundaria no } \\
\text { terciaria }\end{array}$} & \multirow{6}{*}{4} & \multirow{3}{*}{$\begin{array}{c}44 \\
\text { General }\end{array}$} & 441 & Insuficientes para la conclusión del nivel; sin acceso directo a la educación terciaria² \\
\hline & & & 443 & Conclusión del nivel; sin acceso directo a programas de primer título de educación terciaria ${ }^{2}$ \\
\hline & & & 444 & Conclusión del nivel; con acceso directo a programas de primer título de educación terciaria² \\
\hline & & \multirow{3}{*}{$\begin{array}{c}45 \\
\text { Vocacional }\end{array}$} & 451 & Insuficientes para la conclusión del nivel; sin acceso directo a la educación terciaria² \\
\hline & & & 453 & Conclusión del nivel; sin acceso directo a programas de primer título de educación terciaria² \\
\hline & & & 454 & Conclusión del nivel; con acceso directo a programas de primer título de educación terciaria² \\
\hline
\end{tabular}

1. Puede incluir programas previamente clasificados como de nivel CINE 4 siempre que sean equivalentes a programas de nivel CINE 3.

2. Con la excepción de programas previamente clasificados como de nivel CINE 4 siempre que sean equivalentes a programas de nivel CINE 3. 


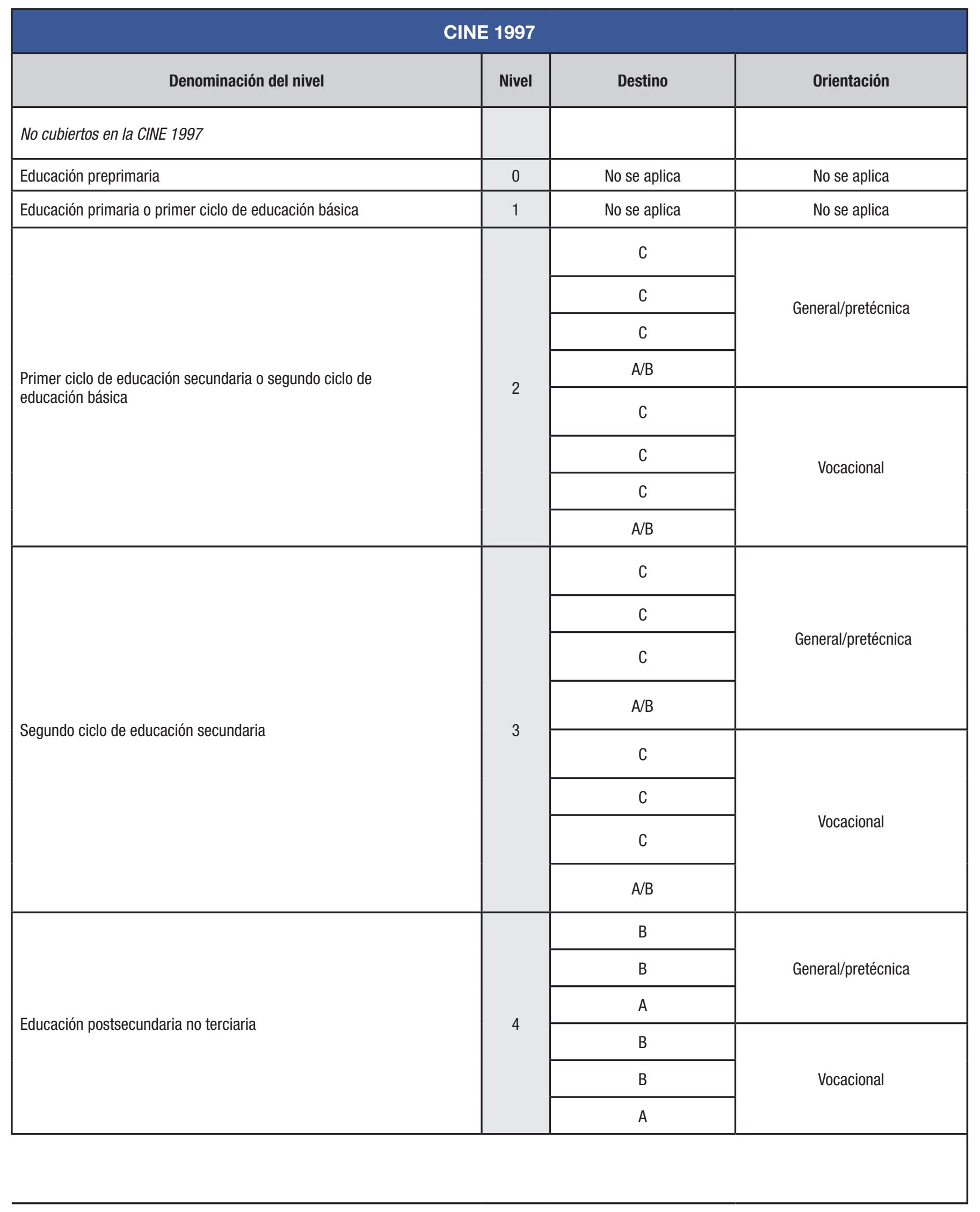




\section{Cuadro 21. Detalles de la correspondencia entre la CINE 2011 y la CINE 1997 para los niveles terciarios}

\begin{tabular}{|c|c|c|c|c|c|}
\hline $\begin{array}{l}\text { Denominación } \\
\text { del nivel }\end{array}$ & Nivel & Categoría & $\begin{array}{l}\text { Sub- } \\
\text { categoría }\end{array}$ & Notas sobre subcategorias & Notas \\
\hline \multirow{3}{*}{$\begin{array}{l}\text { Educación } \\
\text { terciaria de } \\
\text { ciclo corto }\end{array}$} & \multirow{3}{*}{5} & \multirow{2}{*}{$\begin{array}{c}54 \\
\text { General }\end{array}$} & 541 & Insuficientes para la conclusión del nivel & \\
\hline & & & 544 & Suficientes para la conclusión del nivel & \\
\hline & & & 551 & Insuficientes para la conclusión del nivel & \\
\hline \multirow{3}{*}{$\begin{array}{l}\text { Grado en } \\
\text { educación } \\
\text { terciaria o nivel } \\
\text { equivalente }\end{array}$} & \multirow{3}{*}{6} & \multirow{3}{*}{$\begin{array}{c}66^{1} \\
\text { Orientación } \\
\text { no } \\
\text { especificada }\end{array}$} & 661 & Insuficientes para la conclusión del nivel & \\
\hline & & & 665 & Primer título (3 a 4 años) & \\
\hline & & & 666 & $\begin{array}{l}\text { Programas largos de primer título (de más de } 4 \\
\text { años) (Programa del grado en educación terciaria o } \\
\text { equivalente) }\end{array}$ & \\
\hline \multirow{3}{*}{$\begin{array}{l}\text { Nivel de } \\
\text { maestría, } \\
\text { especialización } \\
\text { o equivalente }\end{array}$} & \multirow{3}{*}{7} & \multirow{3}{*}{$\begin{array}{c}76^{1} \\
\text { Orientación } \\
\text { no } \\
\text { especificada }\end{array}$} & 766 & $\begin{array}{l}\text { Programas largos de primer título (de al menos } 5 \\
\text { años) (Programa de maestría, especialización } 0 \\
\text { equivalente) }\end{array}$ & $\begin{array}{l}\text { Salvo si son equivalentes a programas ya } \\
\text { clasificados en el nivel 6; en ese caso } 666 \text {. }\end{array}$ \\
\hline & & & 767 & $\begin{array}{l}\text { Segundo o siguiente título (tras cursar un programa } \\
\text { del grado en educación terciaria o equivalente) }\end{array}$ & \\
\hline & & & 768 & $\begin{array}{l}\text { Segundo o siguiente título (tras cursar un programa } \\
\text { de maestría, especialización o equivalente) }\end{array}$ & \\
\hline \multirow{2}{*}{$\begin{array}{l}\text { Nivel de } \\
\text { doctorado } 0 \\
\text { equivalente }\end{array}$} & \multirow{2}{*}{8} & \multirow{2}{*}{$\begin{array}{c}86^{1} \\
\text { Orientación } \\
\text { no } \\
\text { especificada }\end{array}$} & 861 & Insuficientes para la conclusión del nivel & \\
\hline & & & 864 & Suficientes para la conclusión del nivel & $\begin{array}{l}\text { Programas que solo conducen } \\
\text { directamente a un grado/título de } \\
\text { doctorado. }\end{array}$ \\
\hline
\end{tabular}

1. Las correspondencias (o concordancias) entre los programas académicos y profesionales en los niveles CINE 6,7 y 8 son idénticas a aquellas relacionadas a los programas de orientación no especificada de estos mismo niveles. 


\begin{tabular}{|c|c|c|c|c|}
\hline Denominación del nivel & Nivel & Tipo & Posición & $\begin{array}{c}\text { Duración acumulada en } \\
\text { educación terciaria }\end{array}$ \\
\hline \multirow{12}{*}{$\begin{array}{l}\text { Primer ciclo de la } \\
\text { educación terciaria }\end{array}$} & 5 & B & No se aplica & $<2$ años \\
\hline & 5 & B & No se aplica & $\geq 2$ años \\
\hline & 5 & B & No se aplica & $<2$ años \\
\hline & 5 & B & No se aplica & $\geq 2$ años \\
\hline & 5 & $A$ & Intermedia & $<3$ años \\
\hline & 5 & $A$ & $1^{\mathrm{er}}$ & 3-4 años \\
\hline & 5 & $A$ & $1^{\mathrm{er}}$ & >4 años \\
\hline & 5 & $A$ & $2^{\mathrm{do}} /$ siguiente & $\geq 4$ años \\
\hline & 5 & $A$ & Intermedia & $<4$ años \\
\hline & 5 & $A$ & $1^{\mathrm{er}}$ & $\geq 5$ años \\
\hline & 5 & $A$ & $2^{\mathrm{do}} /$ siguiente & $\geq 4-5$ años \\
\hline & 5 & A & $2^{\mathrm{do}} /$ siguiente & $\geq 6$ años \\
\hline \multirow{2}{*}{$\begin{array}{l}\text { Segundo ciclo de la } \\
\text { educación terciaria }\end{array}$} & 6 & No se aplica & No se aplica & No se aplica \\
\hline & 6 & No se aplica & No se aplica & No se aplica \\
\hline
\end{tabular}




\section{ANEXO I TRAYECTORIAS EDUCATIVAS POTENCIALES EN LA CINE 2011}

Gráfico 2. Trayectorias educativas potenciales en la CINE 2011

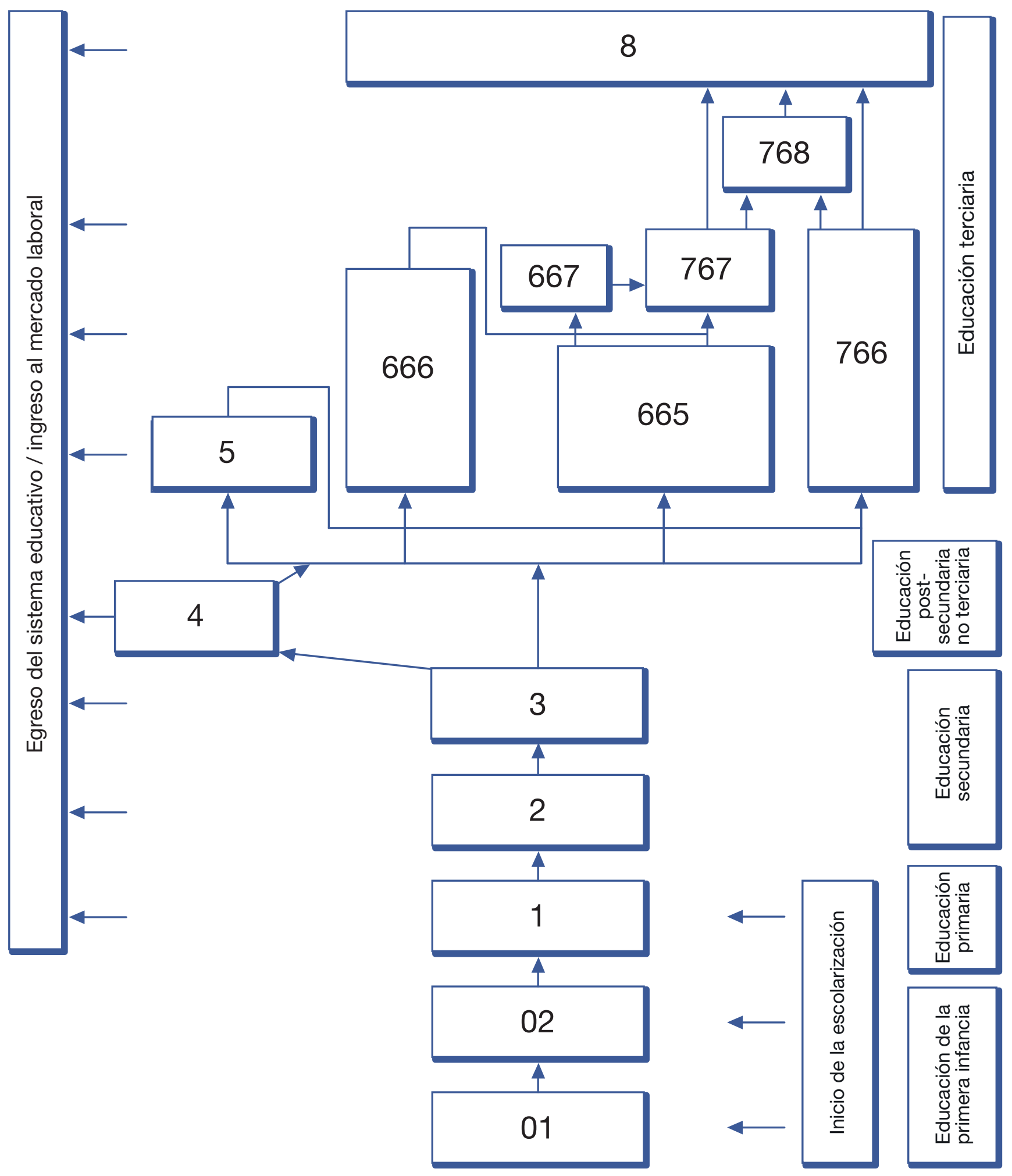




\section{ANEXO ॥| CODIFICACIÓN DE LOS PROGRAMAS EDUCATIVOS}

\section{Educación de la primera infancia}

01 Desarrollo educacional de la primera infancia

010 Desarrollo educacional de la primera infancia

02 Educación preprimaria

020 Educación preprimaria

\section{Educación primaria}

10 Educación primaria

100 Educación primaria

\section{Educación secundaria baja}

24 General

241 Insuficientes para la conclusión, o la conclusión parcial, del nivel; sin acceso directo a la educación secundaria alta

242 Suficientes para la conclusión parcial del nivel; sin acceso directo a la educación secundaria alta

243 Suficientes para la conclusión del nivel; sin acceso directo a la educación secundaria alta

244 Suficientes para la conclusión del nivel; con acceso directo a la educación secundaria alta 25 Vocacional

251 Insuficientes para la conclusión, o la conclusión parcial, del nivel; sin acceso directo a la educación secundaria alta

252 Suficientes para la conclusión parcial del nivel; sin acceso directo a la educación secundaria alta 253 Suficientes para la conclusión del nivel; sin acceso directo a la educación secundaria alta

254 Suficientes para la conclusión del nivel; con acceso directo a la educación secundaria alta

\section{Educación secundaria alta}

34 General

341 Insuficientes para la conclusión, o la conclusión parcial, del nivel; sin acceso directo a la educación terciaria

342 Suficientes para la conclusión parcial del nivel; sin acceso directo a la educación terciaria 343 Suficientes para la conclusión del nivel; sin acceso directo a la educación terciaria

344 Suficientes para la conclusión del nivel; con acceso directo a la educación terciaria 35 Vocacional

351 Insuficientes para la conclusión, o la conclusión parcial, del nivel; sin acceso directo a la educación terciaria

352 Suficientes para la conclusión parcial del nivel; sin acceso directo a la educación terciaria

353 Suficientes para la conclusión del nivel; sin acceso directo a la educación terciaria

354 Suficientes para la conclusión del nivel; con acceso directo a la educación terciaria

\section{Educación postsecundaria no terciaria}

44 General

441 Insuficientes para la conclusión del nivel; sin acceso directo a la educación terciaria 443 Suficientes para la conclusión del nivel; sin acceso directo a la educación terciaria 444 Suficientes para la conclusión del nivel; con acceso directo a la educación terciaria 45 Vocacional

451 Insuficientes para la conclusión del nivel; sin acceso directo a la educación terciaria 453 Suficientes para la conclusión del nivel; sin acceso directo a la educación terciaria 454 Suficientes para la conclusión del nivel; con acceso directo a la educación terciaria 


\section{Educación terciaria de ciclo corto}

54 General $^{1}$

541 Insuficientes para la conclusión del nivel

544 Suficientes para la conclusión del nivel

55 Vocacional $^{1}$

551 Insuficientes para la conclusión del nivel

554 Suficientes para la conclusión del nivel

\section{Grado en educación terciaria o nivel equivalente}

64 Académica

641 Insuficientes para la conclusión del nivel

645 Primer título (3 a 4 años)

646 Programas largos de primer título (más de 4 años)

647 Segundo o siguiente título (tras cursar un programa del grado en educación terciaria o equivalente)

65 Profesional

651 Insuficientes para la conclusión del nivel

655 Primer título (3 a 4 años)

656 Programas largos de primer título (más de 4 años)

657 Segundo o siguiente título (tras cursar un programa del grado en educación terciaria o equivalente)

66 Orientación no especificada ${ }^{1}$

661 Insuficientes para la conclusión del nivel

665 Primer título (3 a 4 años)

666 Programas largos de primer título (más de 4 años)

667 Segundo o siguiente título (tras cursar un programa del grado en educación terciaria o equivalente)

\section{Nivel de maestría, especialización o equivalente}

\section{Académica}

741 Insuficientes para la conclusión del nivel

746 Programas largos de primer título (duración mínima de 5 años)

747 Segundo o siguiente título (tras cursar un programa del grado en educación terciaria o equivalente)

748 Segundo o siguiente título (tras cursar un programa de nivel de maestría, especialización o equivalente) 75 Profesional

751 Programas considerados insuficientes para la conclusión del nivel

756 Programa largo de primer título (duración mínima de 5 años)

757 Segundo o siguiente título (tras cursar un programa del grado en educación terciaria o equivalente)

758 Segundo o siguiente título (tras cursar un programa de nivel de maestría, especialización o equivalente)

76 Orientación no especificada ${ }^{1}$

761 Programas considerados insuficientes para la conclusión del nivel

766 Programa largo de primer título (duración mínima de 5 años)

767 Segundo o siguiente título (tras cursar un programa del grado en educación terciaria o equivalente)

768 Segundo o siguiente título (tras cursar un programa de nivel de maestría, especialización o equivalente)

\section{Nivel de doctorado o equivalente}

84 Académica

841 Insuficientes para la conclusión del nivel

844 Suficientes para la conclusión del nivel

85 Profesional

851 Insuficientes para la conclusión del nivel

854 Suficientes para la conclusión del nivel 
86 Orientación no especificada ${ }^{1}$

861 Insuficientes para la conclusión del nivel

864 Suficientes para la conclusión del nivel

9 No clasificado en otra parte

99 No clasificado en otra parte

999 No clasificado en otra parte

1. A utilizarse si no se cuenta con una definición internacionalmente consensuada de las orientaciones académicas y profesionales a nivel terciario. 


\section{ANEXO III CODIFICACIÓN DE LOGRO EDUCATIVO}

\section{Menos que educación primaria}

01 Nunca cursó un programa educativo

010 Nunca cursó un programa educativo

02 Educación de la primera infancia en forma parcial

020 Educación de la primera infancia en forma parcial

03 Primaria en forma parcial (sin conclusión del nivel)

030 Primaria en forma parcial (sin conclusión del nivel)

\section{Educación primaria}

10 Primaria

100 Incluye la conclusión exitosa de un programa de educación secundaria baja considerado insuficiente para la conclusión, o conclusión parcial, del nivel

\section{Educación secundaria baja ${ }^{1}$}

24 General $^{1}$

242 Conclusión parcial del nivel; sin acceso directo a educación secundaria alta

243 Conclusión del nivel; sin acceso directo a educación secundaria alta

244 Conclusión del nivel; con acceso directo a educación secundaria alta ${ }^{1}$

25 Vocacional $^{1}$

252 Conclusión parcial del nivel; sin acceso directo a educación secundaria alta

253 Conclusión del nivel; sin acceso directo a educación secundaria alta

254 Conclusión del nivel; con acceso directo a educación secundaria alta ${ }^{1}$

\section{Educación secundaria alta ${ }^{1}$}

34 General $^{1}$

342 Conclusión parcial del nivel; sin acceso directo a educación terciaria

343 Conclusión del nivel; sin acceso directo a educación terciaria

344 Conclusión del nivel; con acceso directo a educación terciaria ${ }^{1}$

35 Vocacional $^{1}$

352 Conclusión parcial del nivel; sin acceso directo a educación terciaria

353 Conclusión del nivel; sin acceso directo a educación terciaria

354 Conclusión del nivel; con acceso directo a educación terciaria ${ }^{1}$

\section{Educación postsecundaria no terciaria ${ }^{1}$}

44 General $^{1}$

443 Conclusión del nivel; sin acceso directo a educación terciaria

444 Conclusión del nivel; con acceso directo a educación terciaria ${ }^{1}$

45 Vocacional $^{1}$

453 Conclusión del nivel; sin acceso directo a educación terciaria

454 Conclusión del nivel; con acceso directo a educación terciaria ${ }^{1}$

\section{Educación terciaria de ciclo corto ${ }^{1}$}

54 General $^{1,2}$

540 No se define con mayor detalle ${ }^{1}$

55 Vocacional $^{1,2}$

550 No se define con mayor detalle ${ }^{1}$

56 Orientación no especificada ${ }^{1,2}$

560 No se define con mayor detalle ${ }^{1}$ 


\section{Grado en educación terciaria o nivel equivalente ${ }^{1}$}

64 Académica $^{1}$

640 No se define con mayor detalle ${ }^{1}$

65 Profesional $^{1}$

650 No se define con mayor detalle ${ }^{1}$

66 Orientación no especificada ${ }^{1,2}$

660 No se define con mayor detalle ${ }^{1}$

\section{Nivel de maestría, especialización o equivalente ${ }^{1}$}

74 Académica $^{1}$

740 No se define con mayor detalle ${ }^{1}$

75 Profesional $^{1}$

750 No se define con mayor detalle ${ }^{1}$

76 Orientación no especificada ${ }^{1,2}$

760 No se define con mayor detalle ${ }^{1}$

\section{Nivel de doctorado o equivalente ${ }^{1}$}

84 Académica $^{1}$

840 No se define con mayor detalle

85 Profesional $^{1}$

850 No se define con mayor detalle

86 Orientación no especificada ${ }^{1,2}$

860 No se define con mayor detalle

\section{No clasificado en otra parte}

99 No clasificado en otra parte

999 No clasificado en otra parte

1. Incluye la conclusión de un programa de este nivel considerado suficiente para la conclusión del nivel o la conclusión de un programa o etapa de un programa de un nivel CINE superior considerado insuficiente para la conclusión, o la conclusión parcial, de dicho nivel superior.

2. A utilizarse si no se cuenta con una definición internacionalmente consensuada de las orientaciones académicas y profesionales a nivel terciario. 


\section{ANEXO IV GRUPOS AMPLIOS Y CAMPOS DE EDUCACIÓN}

285. Los campos de educación no han sufrido modificación alguna respecto de los descritos en la CINE1997. EI UIS planea desarrollar una clasificación jerárquica de tres dígitos asociada con los campos de educación y capacitación, perfeccionando la codificación preliminar elaborada por la UNESCO el año 1999. Si bien dicha codificación ha sido utilizada por la Eurostat y la OCDE por más de una década, esta requiere una revisión y subsecuente actualización. Una vez que la nueva clasificación de los campos de educación y capacitación haya sido formalmente adoptada por la Conferencia General de la UNESCO, esta adquirirá el carácter de clasificación separada e independiente, y la presente sección será eliminada de la actual versión de los niveles de la CINE.

286. En la actualidad hay 25 campos de educación estructurados en torno a 9 grupos amplios. Al momento de clasificar los programas interdisciplinarios o multidisciplinarios, se recomienda aplicar la regla de la "mayoría", es decir, asignarlos al campo de educación al que los estudiantes le dedican la mayor parte de su tiempo.

Campos de Educación de la CINE:

\section{Programas generales}

\section{Programas básicos}

Programas básicos de educación preescolar, elemental, primaria, secundaria, etc.

\section{Programas de alfabetización y de aritmética}

Alfabetización simple y funcional; aritmética elemental.

\section{Desarrollo personal}

Desarrollo de destrezas personales, por ejemplo, capacidad de comportamiento, aptitudes intelectuales, capacidad organizativa, programas de orientación.

\section{Educación}

\section{Formación de personal docente y ciencias de la educación}

Formación de personal docente para: educación preescolar, jardines de infancia, escuelas elementales, asignaturas profesionales, prácticas y no profesionales, educación de adultos, formación de personal docente, formación de maestros de niños minusválidos. Programas generales y especializados de formación de personal docente.

Ciencias de la educación: elaboración de programas de estudio de materias no profesionales y profesionales. Evaluación de conocimientos, pruebas y mediciones, investigaciones sobre educación; otros programas relacionados con las ciencias de la educación.

\section{Humanidades y artes}

\section{Artes}

Bellas artes: dibujo, pintura y escultura;

Artes del espectáculo: música, arte dramático, danza, circo;

Artes gráficas y audiovisuales: fotografía, cinematografía, producción musical, producción de radio y televisión, impresión y publicación;

Diseño; artesanía.

\section{Humanidades}

Religión y teología;

Lenguas y culturas extranjeras: lenguas vivas o muertas y sus respectivas literaturas, estudios regionales interdisciplinarios;

Lenguas autóctonas: lenguas corrientes o vernáculas y su literatura; 
Otros programas de humanidades: interpretación y traducción, lingüística, literatura comparada, historia, arqueología, filosofía, ética.

\section{Ciencias sociales, educación comercial y derecho}

\section{Ciencias sociales y del comportamiento}

Economía, historia de la economía, ciencias políticas, sociología, demografía, antropología (excepto antropología física), etnología, futurología, psicología, geografía (excepto geografía física), estudios sobre paz y conflictos, derechos humanos.

\section{Periodismo e información}

Periodismo, bibliotecología y personal técnico de bibliotecas, personal técnico de museos y establecimientos similares;

Técnicas de documentación;

Archivología.

\section{Educación comercial y administración}

Comercio al por menor, comercialización, ventas, relaciones públicas, asuntos inmobiliarios;

Gestión financiera, administración bancaria, seguros, análisis de inversiones;

Contabilidad, auditoría, teneduría de libros;

Gestión, administración pública, administración institucional, administración de personal;

Secretariado y trabajo de oficina.

\section{Derecho}

Magistrados locales, notarios, derecho (general, internacional, laboral, marítimo, etc.), jurisprudencia, historia del derecho.

\section{Ciencias}

\section{Ciencias de la vida}

Biología, botánica, bacteriología, toxicología, microbiología, zoología, entomología, ornitología, genética, bioquímica, biofísica, otras ciencias afines, excepto medicina y veterinaria.

\section{Ciencias físicas}

Astronomía y ciencias espaciales, física y asignaturas afines, química y asignaturas afines, geología, geofísica, mineralogía, antropología física, geografía física y demás ciencias de la tierra, meteorología y demás ciencias de la atmósfera, comprendida la investigación sobre el clima, las ciencias marinas, vulcanología, paleoecología.

\section{Matemáticas y estadística}

Matemáticas, investigación de operaciones, análisis numérico, ciencias actuariales, estadística y otros sectores afines.

\section{Informática}

Informática: Concepción de sistemas, programación informática, procesamiento de datos, redes, sistemas operativos - elaboración de programas informáticos solamente (el material y equipo se deben clasificar en el sector de la ingeniería).

\section{Ingeniería, industria y construcción}

\section{Ingeniería y profesiones afines}

Dibujo técnico, mecánica, metalistería, electricidad, electrónica, telecomunicaciones, ingeniería energética y química, mantenimiento de vehículos, topografía.

\section{Industria y producción}

Alimentación y bebidas, textiles, confección, calzado, cuero, materiales (madera, papel, 
plástico, vidrio, etc.), minería e industrias extractivas.

\section{Arquitectura y construcción}

Arquitectura y urbanismo: arquitectura estructural, arquitectura paisajística, planificación comunitaria, cartografía;

Edificación, construcción;

Ingeniería civil.

\section{Agricultura}

\section{Agricultura, silvicultura y pesca}

Agricultura, producción agropecuaria, agronomía, ganadería, horticultura y jardinería, silvicultura y técnicas forestales, parques naturales, flora y fauna, pesca, ciencia y tecnología pesqueras.

\section{Veterinaria}

Veterinaria, auxiliar de veterinaria.

\section{Salud y servicios sociales}

\section{Medicina}

Medicina: anatomía, epidemiología, citología, fisiología, inmunología e inmunohematología, patología, anestesiología, pediatría, obstetricia y ginecología, medicina interna, cirugía, neurología, psiquiatría, radiología, oftalmología;

Servicios médicos: servicios de salud pública, higiene, farmacia, farmacología, terapéutica, rehabilitación, prótesis, optometría, nutrición;

Enfermería: enfermería básica, partería;

Servicios dentales: auxiliar de odontología, higienista dental, técnico de laboratorio dental, odontología.

\section{Servicios sociales}

Asistencia social: asistencia a minusválidos, asistencia a la infancia, servicios para jóvenes, servicios de gerontología;

Trabajo social: orientación, asistencia social no clasificados en otra parte

\section{Servicios}

\section{Servicios personales}

Hotelería y restaurantes, viajes y turismo, deportes y actividades recreativas, peluquería, tratamientos de belleza y otros servicios personales: lavandería y tintorería, servicios cosméticos, ciencias del hogar.

\section{Servicios de transporte}

Formación de marinos, oficiales de marina, náutica, tripulación de aviones, control del tráfico aéreo, transporte ferroviario, transporte por carretera, servicios postales.

\section{Protección del medio ambiente}

Conservación, vigilancia y protección del medio ambiente, control de la contaminación atmosférica y del agua, ergonomía y seguridad.

\section{Servicios de seguridad}

Protección de personas y bienes: servicios de policía y orden público, criminología, prevención y extinción de incendios, seguridad civil;

Educación militar.

\section{Sectores desconocidos o no especificados}

(Esta categoría no forma parte de la clasificación en sí, pero en la recopilación de datos "99" se necesita para "los sectores de educación desconocidos o no especificados".) 


\section{ANEXO V EDUCACIÓN NO FORMAL DE ACUERDO A LA CINE: OTROS TEMAS DE INTERÉS}

287. La CINE 2011 define la educación no formal (párrafo 39) y describe los distintos tipos de educación no formal (párrafo 40). Destaca que, habitualmente, la educación no formal no da acceso a un nivel de educación más avanzado a no ser que se encuentre debidamente validada por el sistema educativo formal (párrafo 41). Asimismo, al momento de clasificar los programas de educación no formal (párrafo 42), se recomienda utilizar el criterio de equivalencia del contenido y/o las certificaciones otorgadas por estos.

288. En este anexo se presentan características adicionales de los programas ofrecidos por la educación no formal. El concepto de programas no formales requeriría de un mayor desarrollo que permita medirlos adecuadamente para propósitos de las estadísticas internacionales. Se puede obtener información más específica consultando algunos ejemplos de iniciativas internacionales de acopio de datos.

289. El párrafo 40 de la CINE 2011 establece que, dependiendo del contexto nacional, la formación y capacitación no formal podrían incluir programas:

i) capaces de contribuir a la alfabetización de jóvenes y adultos y a la educación de niños no escolarizados (programas alternativos a la primera educación); y

ii) destinados a impartir habilidades básicas para la vida, destrezas ocupacionales u orientados al desarrollo social y cultural.

Estos último pueden incluir:

- la capacitación en el lugar de trabajo destinada a reforzar o adaptar certificaciones y destrezas ya existentes, y la capacitación para el empleo a personas sin empleo o económicamente inactivas; $y$

- actividades de aprendizaje con fines de desarrollo personal (emprendidas por las personas durante su tiempo libre).

290. La heterogeneidad de los programas de educación no formal conlleva la dificultad de proporcionar pautas generales sobre cómo aplicarlos en instrumentos estadísticos para propósitos de comparabilidad internacional. Al momento de clasificar los programas no formales de educación, la CINE 2011 recomienda utilizar el criterio de equivalencia del contenido dado que este establece una relación entre programas no formales y programas formales de contenido similar. En principio, esto permitiría la clasificación de los primeros por nivel. Por ejemplo, si un programa de educación de adultos cumple los criterios de contenido establecidos para el nivel CINE 1, dicho programa podría clasificarse en este nivel.

291. Las certificaciones otorgadas tras la conclusión exitosa de un programa no formal pueden facilitar la clasificación de un programa educativo. Por ejemplo, la capacitación vocacional no formal podría clasificarse en base a la equivalencia - comparada con un programa de educación formal - del nivel y tipo de certificación (si la hubiere) que se otorga tras su conclusión exitosa. Con el fin de determinar la equivalencia de contenido entre programas y certificaciones dentro del mismo sistema educativo, los marcos nacionales y regionales de certificación (donde existan) pueden ser de gran utilidad. La CINE 2011 recomienda identificar claramente los programas formales y no formales de educación. 
292. La educación no formal es una modalidad que puede ser ofrecida por diversas entidades entre las que se incluyen establecimientos de educación, empresas privadas, organizaciones no gubernamentales e instituciones públicas. En ciertos casos, las mismas instituciones que imparten educación formal también pueden ofrecer educación y capacitación no formal. Sin embargo, así como ocurre con los programas de educación formal, el tipo de proveedor no debe utilizarse como criterio principal para establecer distinciones entre la educación y capacitación no formales, ni entre la educación formal y no formal.

293. La duración de un programa no formal puede ser muy breve. En particular, las actividades de capacitación para el trabajo o las desarrolladas durante el tiempo libre de las personas pueden servir para propósitos prácticos particulares relacionados con el contexto laboral o la vida privada de éstas. En consecuencia, con frecuencia un programa no formal puede ser descrito como un curso de capacitación.

294. Los programas no formales suelen privilegiar la adquisición de conocimientos, destrezas o competencias prácticas dentro de un contexto concreto y, por lo tanto, no enfatizan el aprendizaje teórico. Por ejemplo, un programa formal puede enseñar ciencias de la informática (con miras a otorgar una certificación reconocida de ingeniero informático) en circunstancias que un programa no formal puede cubrir programas específicos de informática destinados a impartir conocimientos prácticos sobre el uso de computadores en el lugar de trabajo.

295. En países donde el sistema educativo formal se encuentra menos desarrollado o tiene un alcance limitado. Estos programas no son reconocidos como formales por las autoridades competentes; suelen estar cubiertos bajo los niveles CINE 0 a 3 y pueden ser proporcionados por entidades privadas entre las que se incluyen las organizaciones no gubernamentales (ONG).

296. Si bien la educación no formal es una modalidad reconocida por la CINE, es muy probable que, con el objetivo permanente de la comparabilidad internacional y la viabilidad en los procesos de producción de estadísticas educativas, las iniciativas internacionales de acopio de datos (elaboración de mapas, encuestas, censos, etc.) limiten su cobertura exclusivamente a programas de educación formal. Por consiguiente, la línea divisoria entre los programas formales y no formales adquiere particular relevancia y debe recibir especial atención. Sin embargo, en la presente etapa, la CINE 2011 no ofrece recomendaciones específicas sobre la elaboración de mapas asociados con programas no formales o cualquier certificación educativa no formal relacionada. 


\section{ANEXO VI GLOSARIO}

Actividad de aprendizaje. Toda actividad deliberada en la que una persona participa con la intención de aprender.

Actividad educativa. Toda actividad deliberada que conlleve alguna modalidad de comunicación destinada a producir aprendizaje.

Año académico. Período anual de enseñanza y evaluación durante el cual los estudiantes asisten a clases o rinden exámenes en forma continua, sin considerar interrupciones breves. Su duración puede ser inferior a 12 meses, aunque habitualmente no menor a 9 meses. Dentro de un país, el año académico puede tener distinta duración según el nivel de educación o el tipo de establecimiento. También se conoce como ‘año escolar' o 'año lectivo', principalmente en los niveles inferiores al nivel terciario.

Aprendizaje. La adquisición de conocimientos, actitudes, valores o competencias por parte de una persona, y la generación de cambios en sus niveles de comprensión y comportamiento a través de la experiencia, la práctica, el estudio o la instrucción.

Aprendizaje aleatorio. Véase Aprendizaje imprevisto o aleatorio.

Aprendizaje imprevisto o aleatorio. Las diversas formas de aprendizaje no organizado, incluyendo las que comprenden actividades de comunicación que no han sido diseñadas con el fin de producir un aprendizaje. El aprendizaje imprevisto o aleatorio se puede producir como consecuencia del quehacer diario, de eventos, o de actividades de comunicación no concebidas como actividades intencionadas de educación o aprendizaje. Entre los ejemplos de aprendizaje aleatorio se pueden mencionar las actividades que tienen lugar durante una reunión o las asociadas con una transmisión de radio o televisión que no han sido diseñadas como un programa educativo.

Aprendizaje informal. Modalidades de aprendizaje intencionadas, aunque no institucionalizadas. De esta manera, se caracterizan por ser menos estructuradas y organizadas que la educación formal o no formal. El aprendizaje informal puede incluir actividades de aprendizaje realizadas en el hogar, el lugar de trabajo, la comunidad o como parte del vivir diario. Asimismo, puede tener carácter individual, familiar o social.

Campo de educación. Dominio amplio, rama o área de contenido cubierto por un programa, curso o módulo educativo. Con frecuencia, se denomina "asignatura" o "disciplina". También se conoce como "campo de estudio".

Capacitación/formación. Educación destinada a impartir objetivos de aprendizaje predeterminados, particularmente en el ámbito de la educación vocacional. La definición de educación de la CINE comprende la capacitación o formación.

Certificación. Confirmación oficial de la conclusión exitosa de un programa o etapa de un programa. Generalmente, esta confirmación se oficializa mediante un documento. Las certificaciones se obtienen mediante: i) la conclusión exitosa de un programa educativo; ii) la conclusión exitosa de una etapa del programa educativo (certificaciones intermedias); o iii) la validación de destrezas, conocimientos y competencias, independientemente de la participación de la persona en un programa educativo. También se conoce como, "título", "diploma" o "credencial". 
Certificación (de educación) no formal. Acreditación otorgada tras el logro de los objetivos de aprendizaje de un programa educativo no formal que ante las autoridades nacionales competentes no es equivalente a una certificación de educación formal.

Certificación intermedia. Confirmación oficial de la conclusión de una etapa educativa de un programa. Generalmente, esta confirmación se oficializa a través de un documento.

Certificación reconocida. Ratificación oficial por parte de las autoridades nacionales competentes de una certificación otorgada tras el logro de los objetivos de aprendizaje de un programa educativo.

Conclusión de un nivel CINE. Conclusión exitosa de un programa educativo considerado suficiente para la conclusión del nivel. En los niveles CINE 1 y CINE 4 al 8, la conclusión exitosa de un programa que cumple los criterios de contenido y duración mínima establecidos para el nivel se considera equivalente a la conclusión del nivel. En los niveles CINE 2 y 3, la conclusión de cualquier programa que dé acceso a programas de un nivel CINE más avanzado (por ejemplo, al nivel CINE 3 en el caso de programas de nivel CINE 2, y al nivel CINE 5, 6 o 7 en el caso de programas de nivel CINE 3) se considera equivalente a la conclusión del nivel, como lo es también la conclusión de cualquier programa terminal que cumpla los criterios de contenido, duración mínima (dos años) y duración acumulada para el nivel respectivo (es decir, 8 años a partir del inicio del nivel CINE 1 en el caso de programas de nivel CINE 2 y 11 años en el caso de programas de nivel CINE 3).

Conclusión de un programa educativo. Participación en todos los componentes de un programa educativo (incluyendo exámenes finales, en caso de que sean requeridos), independientemente del resultado de cualquier evaluación del logro de objetivos de aprendizaje.

Conclusión exitosa de un programa educativo. Se refiere al logro de objetivos predeterminados de aprendizaje de un programa educativo validado, habitualmente, a través de una evaluación de las destrezas, competencias y conocimientos adquiridos. En general, la conclusión exitosa se documenta mediante el otorgamiento de una certificación educativa.

Conclusión no exitosa de un programa educativo. Intento fallido de lograr los objetivos predeterminados de aprendizaje de un programa educativo, a pesar de haber asistido o cursado todos sus componentes (incluyendo exámenes finales, de haberlos). La conclusión no exitosa supone que alguna evaluación del logro de los objetivos de aprendizaje se ha realizado, pero las destrezas, competencias o conocimientos adquiridos por la persona evaluada se han considerado insuficientes.

Conclusión parcial del nivel CINE 2. La conclusión exitosa de un programa que representa al menos dos años en el nivel CINE 2, con una duración acumulada de al menos ocho años desde el comienzo del nivel CINE 1, y que forma parte de una secuencia de programas dentro del nivel CINE 2 sin constituir el último programa de la secuencia. Estos programas no dan acceso directo al nivel CINE 3.

Conclusión parcial del nivel CINE 3. La conclusión exitosa de un programa que representa al menos dos años en el nivel CINE 3, con una duración acumulada de al menos 11 años desde el comienzo del nivel CINE 1, y que forma parte de una secuencia de programas dentro del nivel CINE 3 sin constituir el último programa de la secuencia. Estos programas no dan acceso directo a ningún nivel CINE más avanzado.

Crédito. Unidad relacionada a la conclusión exitosa de cursos o módulos y que es obtenida y documentada durante y al final de un programa educativo. Los créditos expresan el volumen de aprendizaje basado en la carga de trabajo típica necesaria para lograr los objetivos de aprendizaje esperados. 
Curso. Unidad de instrucción organizada como una secuencia de actividades educativas en torno a un campo específico de educación o a una serie de campos relacionados. También se conoce como "módulo", "unidad" o "asignatura".

Duración acumulada. Se define como la duración teórica total de una secuencia de programas educativos. En la CINE, la duración acumulada - contada a partir del inicio de los niveles CINE 1 o 3 o desde el inicio de la educación terciaria - se requiere frecuentemente con el propósito de clasificar un programa educativo.

Duración mínima. Se define como la duración teórica mínima de un programa educativo para propósitos de clasificar un programa en un nivel CINE específico o establecer la conclusión o conclusión parcial de un nivel CINE determinado.

Duración teórica. El período, expresado en años académicos, que toma impartir un programa educativo asumiendo una participación continua a tiempo completo.

Duración típica. El período, expresado en años académicos, que normalmente toma a los estudiantes finalizar exitosamente un programa educativo asumiendo una participación continua a tiempo completo.

Educación. Proceso mediante el cual las sociedades transmiten en forma intencionada el acervo de información, comprensión, conocimientos, actitudes, valores, habilidades, competencias y comportamientos de una generación a otra. Comprende el uso de actividades de comunicación destinadas a producir aprendizaje.

Educación basada en el trabajo. Actividades educativas desarrolladas en el entorno laboral, generalmente en el contexto de programas de educación vocacional. Su propósito es de alcanzar objetivos de aprendizaje predeterminados a través de una instrucción de carácter práctico y la participación en actividades laborales realizadas bajo la orientación de trabajadores o capacitadores experimentados.

Educación basada en escuelas o en centros educativos postsecundarios no terciarios. Actividades educativas desarrolladas en instituciones establecidas con el fin de formar a niños y adolescentes durante el período de la educación formal previa al ingreso al mercado laboral. Estos programas están destinados a impartir objetivos de aprendizaje predeterminados a través de instrucción en el aula y puede incluir cursos realizados en entornos especializados (por ejemplo, laboratorios de ciencia, salas de música o informática, gimnasios, etc.) y trabajo en grupos bajo la supervisión de uno o más profesores. Los estudiantes suelen agruparse por grado, edad o nivel de habilidad.

Educación de adultos. Educación orientada específicamente a las personas definidas como "adulto" por la sociedad, que persigue mejorar sus certificaciones técnicas o profesionales, perfeccionar sus destrezas y enriquecer sus conocimientos, preparándolas para finalizar un nivel de educación formal, adquirir o actualizar conocimientos, habilidades y competencias en un campo particular. Esta modalidad de educación también incluye lo que se conoce como educación "continua" o "de segunda oportunidad".

Educación de la primera infancia (nivel CINE-P 0). La Educación de la primera infancia provee actividades educativas y de aprendizaje con un enfoque integral con el objetivo de apoyar el desarrollo temprano cognitivo, físico, social y emocional de los niños, e iniciar a los niños muy pequeños a una instrucción organizada fuera del contexto familiar para desarrollar algunas de las destrezas que los prepararán para los estudios académicos y el ingreso a la educación primaria. 
Educación de segunda oportunidad. Educación destinada a personas que, por diversos motivos, nunca asistieron a la escuela o la abandonaran antes de finalizar el nivel de educación en el que estaban matriculados, o completaron el nivel pero desean postular a un programa educativo u ocupación para el cual no se encuentran cualificados. Los participantes suelen ser mayores que el grupo de edad que característicamente cursa programas en los distintos niveles de la CINE (aunque no necesariamente adultos).

Educación formal. Educación institucionalizada, intencionada y planificada por organizaciones públicas y organismos privados acreditados. En su conjunto, esta constituye el sistema educativo formal del país. Por consiguiente, los programas de educación formal son reconocidos por las autoridades nacionales pertinentes o instancias equivalentes, por ejemplo, cualquier otra institución que colabore con las autoridades nacionales o subnacionales de educación. La educación formal comprende esencialmente la educación previa al ingreso al mercado laboral. Con frecuencia, la educación vocacional, la educación para necesidades especiales y parte de la educación de adultos se reconocen como parte integral del sistema nacional de educación formal.

Educación formal previa al ingreso al mercado laboral. Educación formal impartida a las personas antes de ingresar al mercado laboral, es decir, durante el período que normalmente estarían estudiando a tiempo completo. Está orientada a personas definidas como niños, adolescentes y adultos jóvenes por la sociedad. Típicamente, se imparte en instituciones educativas en un sistema diseñado como una trayectoria educativa continua.

Educación general. Programas educativos destinados a desarrollar conocimientos, capacidades y competencias generales, así como habilidades de lectura, escritura y la utilización de números (numeracy en inglés), a menudo con el fin de preparar al estudiante para continuar su educación ya sea en el mismo nivel CINE o en uno más avanzado o de sentar las bases para el aprendizaje a lo largo de la vida. Habitualmente, estos programas se imparten en escuelas o en centros educativos postsecundarios no terciarios. La educación general incluye programas educativos que preparan al estudiante para ingresar a la educación vocacional, aunque no así para desempeñar una ocupación u oficio determinado, o diversos tipos de ocupaciones u oficios, ni dan acceso directo a una certificación pertinente para el mercado laboral.

Educación no formal. Educación institucionalizada, intencionada y organizada por un proveedor de educación. La característica que define la educación no formal es que representa una alternativa o un complemento a la educación formal de las personas dentro del proceso de aprendizaje a lo largo de la vida. Con frecuencia, se plantea como una forma de garantizar el derecho a la educación para todos. Atiende a todos los grupos de edad aunque no está necesariamente estructurada como una trayectoria continua. La educación no formal puede ser corta en términos de duración y/o intensidad y habitualmente se imparte bajo la forma de cursos cortos, seminarios o talleres. En general, no conduce a certificaciones reconocidas por las autoridades nacionales o subnacionales competentes como equivalentes a las otorgadas por la educación formal. En ocasiones no otorga certificación alguna. La educación no formal incluye programas que pueden contribuir a la alfabetización de jóvenes y adultos, a la educación de los niños no escolarizados, así como programas destinados a impartir habilidades básicas para la vida, destrezas ocupacionales o programas orientados al desarrollo social o cultural.

Educación para necesidades especiales. Educación destinada a facilitar el aprendizaje de personas que, por diversas razones, requieren apoyo adicional y métodos pedagógicos adaptados para poder participar y cumplir los objetivos de aprendizaje de un programa educativo. Dichas razones pueden incluir (si bien pueden haber otras) una discapacidad física, conductual, intelectual, emocional o social. Los programas de educación para necesidades especiales suelen implementar un currículo similar al ofrecido en el sistema paralelo de educación convencional. Sin embargo, las necesidades 
de las personas se atienden a través de la provisión de recursos específicos (por ejemplo, personal especialmente capacitado, equipamiento o espacios) y, de ser pertinente, a través de modificaciones a los contenidos educativos u objetivos de aprendizaje. Estos programas pueden ser impartidos a estudiantes individuales como parte del programa ya existente o bajo la forma de clases separadas dentro de la misma escuela o en otras instituciones educativas.

Educación postsecundaria no terciaria (nivel CINE 4). La educación postsecundaria no terciaria proporciona a las personas experiencias de aprendizaje que refuerzan los conocimientos adquiridos en educación secundaria y las preparan para ingresar al mercado laboral, así como para continuar sus estudios de educación terciaria. Normalmente, está orientada a estudiantes que han concluido la educación secundaria alta (nivel CINE 3), pero que desean aumentar sus posibilidades de insertarse en el mercado laboral o de avanzar a la educación terciaria. Los programas de este nivel no suelen ser mucho más avanzados que los impartidos en la educación secundaria alta y se caracterizan por ampliar conocimientos, destrezas y competencias en lugar de profundizarlos. Por consiguiente, su objetivo es impartir un tipo de aprendizaje por debajo del nivel de complejidad que caracteriza a la educación terciaria.

Educación primaria (nivel CINE 1). La educación primaria consiste en aprendizaje y actividades educativas principalmente destinados a proporcionar a los estudiantes destrezas básicas en lectura, escritura y matemática (es decir, alfabetismo y utilización de números - numeracy) y sentar una sólida base para el aprendizaje y la comprensión de las áreas esenciales del conocimiento y el desarrollo personal y social como preparación a la educación secundaria baja. Se promueve el aprendizaje a un nivel básico de complejidad y con muy poca, o ninguna, especialización.

Educación regular. La educación formal previa al ingreso al mercado laboral destinada a personas sin necesidades educativas especiales.

Educación secundaria (niveles CINE 2 y 3). La educación secundaria ofrece actividades educativas y de aprendizaje sustentados en los conocimientos adquiridos en educación primaria y que preparan tanto para el mercado laboral como para continuar sus estudios a nivel de educación postsecundaria no terciaria y educación terciaria. En términos generales, la educación secundaria promueve el aprendizaje a un nivel intermedio de complejidad. La CINE establece una distinción entre educación secundaria baja y educación secundaria alta.

Educación secundaria alta (nivel CINE 3). Los programas de nivel CINE 3, o educación "secundaria alta", suelen tener como principal objetivo consolidar la educación secundaria en preparación a la educación terciaria o proporcionar destrezas laborales (o ambos). Los programas de este nivel se caracterizan por impartir a los estudiantes un tipo de instrucción más diversificada, especializada y avanzada que los programas de educación secundaria baja (nivel CINE 2). Asimismo, presentan un mayor grado de diferenciación y ofrecen un espectro más amplio de opciones y trayectorias.

Educación secundaria baja (nivel CINE 2). Los programas de nivel CINE 2, o educación "secundaria baja", suelen estar destinados a avanzar en el aprendizaje iniciado en el nivel CINE 1. En general, el objetivo que se persigue es sentar las bases del desarrollo humano y de la educación a lo largo de la vida sobre las cuales sea posible ampliar las oportunidades de educación. Los programas de este nivel suelen estar estructurados en torno a un programa de estudio más orientado a asignaturas o materias, caracterizado por presentar conceptos teóricos a través de un amplio espectro de asignaturas.

Educación terciaria (niveles CINE 5 a 8). La educación terciaria se desarrolla sobre la base de los conocimientos adquiridos en la educación secundaria, proporcionando actividades educativas y de aprendizaje en campos especializados de estudio. Se caracteriza por promover el aprendizaje a un 
nivel elevado de complejidad y especialización. Si bien la educación terciaria incluye lo que es comúnmente entendido como "educación académica", pero incluye también la educación vocacional o profesional avanzada.

Educación vocacional. Programas educativos destinados principalmente a impartir destrezas, conocimientos y competencias prácticas, así como la comprensión necesaria para ejercer una ocupación u oficio determinado, o diversos tipos de ocupaciones u oficios. La educación vocacional puede incluir un componente basado en el trabajo (por ejemplo, aprendizaje de oficios, programas de sistema dual). La conclusión exitosa de estos programas otorga certificaciones pertinentes para el mercado laboral reconocidas por la autoridad nacional competente y/o el mercado.

Etapa. Subnivel de un programa educativo definido en términos de su duración teórica, o un conjunto predeterminado de módulos que el estudiante debe completar, o bien, un número de créditos que debe obtener. Una etapa determinada tiene características únicas que la distinguen de otras etapas del mismo programa educativo y puede ser acreditada en forma individual mediante una certificación intermedia.

Evaluación de resultados de aprendizaje. Evaluación de los objetivos de aprendizaje logrados por una persona a través de diferentes métodos (pruebas o exámenes escritos, orales o prácticos, proyectos o carpetas) durante o al final del programa educativo.

Grado. Una etapa específica de instrucción de la educación formal previa al ingreso al mercado laboral normalmente cubierta durante un año académico. Los estudiantes de un mismo grado suelen tener una edad similar. También se conoce como "clase", "cohorte" o "año".

Graduación. La conclusión exitosa de un programa educativo. Es factible que un graduado tenga más de una graduación (incluso durante el mismo año académico) si el estudiante estuvo matriculado en dos o más programas simultáneamente y los terminó exitosamente.

Graduado de un programa educativo. Persona que ha finalizado exitosamente un programa educativo.

Ingreso. El acto de comenzar a participar en un nivel educativo, o conjunto de niveles, programas, etapas o módulos asociados con dicho nivel.

Ingresos. Personas matriculadas al inicio de un nivel educativo determinado, o en un conjunto de niveles, programas, etapas o módulos, independientemente de la edad.

Institución educativa. Institución establecida con el fin de proporcionar educación, tales como escuelas, centros educativos postsecundarios, universidades o centros de capacitación o formación. Normalmente, estas instituciones están acreditadas o autorizadas por las autoridades nacionales competentes o autoridades equivalentes. Su funcionamiento también puede estar a cargo de organizaciones privadas como organizaciones religiosas, grupos especiales de interés, o empresas privadas dedicadas a la educación y capacitación, tanto con o sin fines de lucro.

Logro educativo. El nivel CINE más alto que una persona ha concluido exitosamente. Normalmente, este nivel se mide respecto del programa más avanzado concluido que normalmente otorga una certificación reconocida. Las certificaciones intermedias se clasifican en un nivel inferior del correspondiente al programa.

Matrícula. Individuos registrados oficialmente en un programa educativo determinado, o en una etapa o módulo asociado con este, independientemente de la edad. 
Menos que educación primaria (nivel CINE-A 0). Un nivel amplio de logro educativo que cubre la falta o carencia de participación en educación, la participación parcial en educación de la primera infancia y/o la participación parcial en educación primaria.

Módulo. Un curso, o parte de un curso, en el contexto de un programa modular. El módulo se pude cursar en forma individual o en combinación con otros módulos disponibles.

Niveles de educación. Un set ordenado de programas educativos en relación a grados de experiencias de aprendizaje y a los conocimientos, destrezas y competencias que un programa educativo se propone impartir. La CINE refleja el grado de complejidad y especialización de los contenidos de un programa, desde lo básico hasta lo complejo.

Objetivos de aprendizaje. Descripción de los resultados de aprendizaje que el participante debe lograr tras la conclusión de una actividad educativa o de aprendizaje. Estos comprenden el mejoramiento de conocimientos, competencias y destrezas dentro de un contexto personal, cívico, social o laboral. Normalmente, los objetivos de aprendizaje están relacionados al propósito de preparar a la persona para seguir estudios más avanzados o desempeñar una ocupación u oficio específico (o un tipo de ocupaciones u oficios).

Participación. La acción de cursar o asistir a un programa educativo, etapa o módulo asociado con este.

Participante. Persona que asiste o cursa un programa educativo, etapa o módulo asociado con este.

Primer título. Diploma otorgado tras la conclusión exitosa de un programa educativo de nivel CINE 6 o 7 que no exige la conclusión previa de otro título de nivel CINE 6 para ingresar al programa.

Programa educativo. Un conjunto o secuencia de actividades educativas coherentes diseñadas y organizadas para lograr un objetivo predeterminado de aprendizaje o realizar un conjunto especifico de tareas educativas a lo largo de un periodo sostenido. Dentro de un programa educativo, las actividades pueden estar estructuradas en torno a subcomponentes que se conocen por distintos nombres en los países, tales como "cursos", "módulos", "unidades" o "asignaturas". Un programa puede estar organizado en base a componentes no habitualmente considerados cursos, unidades o módulos, por ejemplo, actividades lúdicas, prácticas o pasantías laborales, proyectos de investigación y preparación de disertaciones.

Programas de sistema dual. Programas educativos que combinan el trabajo en escuelas o en centros educativos postsecundarios no terciarios con el trabajo en empresas. Si bien ambos componentes son significativos (es decir, son bastantes más extensos que una pasantía o un curso ocasional), estos programas destinan el 50 por ciento del tiempo o más a la parte relacionada con la dimensión laboral.

Programas modulares. Programas educativos que dan al estudiante flexibilidad al momento de organizar el contenido de su educación permitiéndole combinar distintos cursos o módulos. Por consiguiente, los programas modulares no suelen tener una secuencia claramente definida.

Proveedor de educación. Organización que tiene por finalidad principal o secundaria la provisión de educación. Puede ser una institución de educación pública, una empresa privada, una organización no gubernamental o un organismo público no relacionado con la educación.

Resultados de aprendizaje. La totalidad de la información, conocimientos, comprensión, actitudes, valores, destrezas, competencias o comportamientos que se espera que una persona domine tras la conclusión exitosa de un programa educativo. 
Segundo o siguiente título. Diploma otorgado tras la conclusión exitosa de un programa educativo de nivel CINE 6 o 7 que tiene como requerimiento de ingreso la previa conclusión de un programa de nivel CINE 6 o 7.

Siguiente título. Véase la definición de Segundo o siguiente título.

Título. Certificación otorgada tras la conclusión exitosa de determinados programas de educación terciaria (tradicionalmente impartidos en universidades o instituciones equivalentes).

Validación de los resultados de aprendizaje. Evaluación de los objetivos de aprendizaje logrados por una persona a través de diferentes métodos (pruebas o exámenes escritos, orales o prácticos, proyectos o carpetas) sin asumir participación en un programa educativo. 
Dado que los sistemas educativos de los distintos países suelen presentar variaciones en términos de estructura y contenidos, la finalidad de la Clasificación Internacional Normalizada de la Educación (CINE) es proporcionar un marco de referencia que permita presentar datos en forma comparable y uniforme. Por el hecho de facilitar la transformación de datos nacionales de educación en categorías internacionalmente consensuadas, esta clasificación hace posible la realización de comparaciones internacionales.

La CINE es una clasificación de referencia que forma parte de la familia internacional de Clasificaciones Económicas y Sociales de las Naciones Unidas. Originalmente desarrollada en la década de los setenta por la UNESCO, la CINE ha sido objeto de actualizaciones periódicas orientadas a reflejar la continua evolución experimentada por los sistemas educativos del mundo. En este sentido, la nueva versión CINE 2011 (que reemplaza a la CINE 1997) ofrece definiciones más precisas y un mayor alcance que permiten un mejor monitoreo de las tendencias mundiales en educación. Las secciones sobre educación terciaria y de la primera infancia han sido extensamente revisadas con esta finalidad. Adicionalmente, la CINE 2011 presenta nuevos esquemas de codificación para programas de educación y logro educativo.

El Instituto de Estadística de la UNESCO (UIS) es el custodio de la CINE y, de esta manera, es responsable de su desarrollo, mantenimiento, actualización y revisión. Asimismo, el Instituto brinda orientación en el uso efectivo y consistente de la CINE durante la recolección y el análisis de datos internacionales.

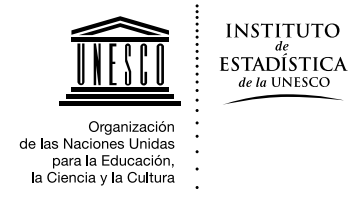

El Instituto de Estadística de la UNESCO (UIS) es la oficina de estadística de la Organización de las Naciones Unidas para la Educación, la Ciencia y la Cultura (UNESCO) y es depositario de la ONU en materia de estadísticas internacionalmente comparables en los campos de educación, la ciencia y la tecnología, la cultura y la comunicación. 